\title{
LAS ESPECIES DE SIDA SECC. MALACROIDEAE (MALVACEAE) DEL CONO SUR DE SUDAMÉRICA
}

\author{
ANTONIO KRAPOVICKAS
}

\begin{abstract}
Summary: Krapovickas, A. 2007. The species of Sida sect. Malacroideae (Malvaceae) from southern South America. Bonplandia 16 (3-4): 209-253. ISSN 0524-0476.

The 21 South American species of the section Malacroideae of the genus Sida (Malvaceae) are described, including 9 new species: Sida Bordasiana, S. castanocarpa, S. caulorrhiza, S. Cristobaliana, S. Dureana, S. Ferrucciana, S. Harleyi, S. Pedersenii and S. Simpsonii, and a new combination S. albiflora (Chodat \& Hassl.) Krapov.
\end{abstract}

Key words: Sida, Malvaceae, South America, taxonomy.

Resumen: Krapovickas, A. 2007. Las especies de Sida secc. Malacroideae (Malvaceae) del Cono Sur de Sudamérica. Bonplandia 16 (3-4): 209-253. ISSN 0524-0476.

Se describen las 21 especies sudamericanas de la sección Malacroideae del género Sida (Malvaceae), incluyendo 9 especies nuevas: Sida Bordasiana, S. castanocarpa, S. caulorrhiza, S. Cristobaliana, S. Dureana, S. Ferrucciana, S. Harleyi, S. Pedersenii y S. Simpsonii y una nueva combinación, S. albiflora (Chodat \& Hassl.) Krapov.

Palabras clave: Sida, Malváceas, Sudamérica, taxonomía.

\section{Introducción}

La sección Malacroideae G.Don del género Sida L. agrupa una serie de especies que tienen en común la flor subsésil inserta en la base del pecíolo soldado con la base de las estípulas. Este carácter también está presente en Malachra L. y Nototriche Turcz., géneros filogenéticamente no afines entre sí, ni con la secc. Malacroideae.

Las especies que integran la secc. Malocroideae son muy parecidas entre ellas, tanto que para muchas se utilizó el nombre colectivo Sida ciliaris L. Sin embargo, la presencia de diferentes niveles de ploidía, los caracteres de los mericarpos y el tomento de las hojas, no utilizados hasta ahora, permiten diferenciar taxones, varios de ellos con distribución geográfica exclusiva.

La sección presenta dos centros de variación importantes en Sudamérica: uno en la región chaqueña de Paraguay y el otro en la "caatinga" del nordeste de Brasil. En el este de África existe otro centro de variación (Vollesen, 1986) con 5 especies, todas ellas semejantes a $S$. Bordasiana Krapov. del Chaco paraguayo, lo que demuestra la uniformidad de esta sección.

En 1985, Fryxell al tratar las especies de Sida de América del Norte y Central, modificó la ortografía original de la sección

${ }^{1}$ Instituto de Botánica del Nordeste (UNNE-CONICET), Casilla de Correo 209, 3400 Corrientes, Argentina. E-mail: ibone@agr.unne.edu.ar 
Malacroideae por Malachroideae. No está claro si Don suprimió la "h" de Malachra intencionalmente o si se trata de un error tipográfico, inclinándonos por la primera posibilidad, ya que Don era muy prolijo con las etimologías.

En el art. 60 del Código Internacional de Nomenclatura Botánica (Greuter \& al., 2000) se da el ejemplo de Amaranthus L., que no debe alterarse, manteniendo el deletreo original, a pesar de que Amarantus sea filológicamente preferible.

\section{Historia}

La primera especie de este grupo, Sida ciliaris, fue descripta por Linneo (1759) sobre material de Jamaica coleccionado por Browne.

Cavanilles (1785) describió S. plumosa Cav. basado en un ejemplar coleccionado por Commerson en Brasil.

Cavanilles (1797) describió S. tridentata Cav. de Santo Domingo y en 1801 publicó S. muricata Cav. de México.

Willdenow (1801) describió Melochia truncata Willd. de India Oriental.

De Candolle (1824) describió $S$. brachystemon DC. de México y realizó la nueva combinación Riedleia truncata (Willd.) DC.

Saint-Hilaire (1827) describió S. anomala A.St.-Hil., de Uruguay y a $S$. fulva A.St.Hil.(= S.plumosa), de Brasil.

La sección Malacroideae del género Sida fue creada por G. Don en 1831, incluyendo las especies conocidas hasta entonces: $S$. fulva, $S$. anomala y $S$. plumosa, excepto $S$. ciliaris, $S$. brachystemon y $S$. muricata que las ubicó en la secc. Malvinda.

Roxburgh (1832) describió S. cuneifolia Roxb., de la India.

En 1837, Wight crea el género Dictyocarpus Wight, con una especie, D. truncatus (Willd.) Wight, basada en Melochia truncata.

Richard (1845) describió Sida involucrata de Cuba.

En 1847 Richard describió Sida Schimperiana, de Etiopía.

En 1890, K. Schumann creó dentro de Sida la sección Pseudomalachra con una especie, $S$. ciliaris y una variedad, S. ciliaris var. anomala (A.St.-Hil.) K. Schum.

En 1891, K. Schumann trató la sección Pseudomalachra, para Brasil, en la que ubicó a Sida ciliaris, con las variedades typica, guianensis K.Schum. y fulva (A.St.-Hil.) K.Schum., y a S. anomala.

En 1924, Gandoger publicó un estudio sobre Sida, en el que subdivide a Sida ciliaris de América Central en varias entidades infraespecíficas que denominó "Sida avicularioides Gand.", "Sida bellidifolia Gand." , "Sida jaliscensis Gand.", "Sida microtricha Gand.", "Sida minutifolia Gand." y "Sida ononidifolia Gand.", diferenciándolas solamente por los caracteres de la clave en latín. Utilizó nomenclatura binaria y creó confusión sobre estas entidades infraespecíficas. Según el Código de Nomenclatura el uso de nomenclatura binaria para subdivisiones de especies no es admisible. Stafleu \& Cowan (1976:910-911) refiriéndose a la Flora Europaea de Gandoger denominan a sus subdivisiones de especies "microespecies", no incluidas en el rango de categorías taxonómicas, por lo cual se deben considerar como no válidamente publicadas y por ello no figuran en el Index Kewensis.

En 1926, Fawcett \& Rendle observaron que el material de Sida ciliaris de Jamaica tenía el epifilo glabro y que material de Sudamérica tenía el epifilo con pelos simples.

En 1937 Rodrigo publicó la nueva especie S. paradoxa Rodrigo, que crece en Mercedes, en la provincia argentina de Corrientes.

Más adelante, en 1944, Rodrigo publicó las especies argentinas y uruguayas del género Sida, y en la sección Pseudomalachra ubicó a S. anomala, S. ciliaris y S. paradoxa, ilustrándolas con muy buenos dibujos comparativos.

Kearney (1954) presentó una clave para las especies norteamericanas de Sida. Reconoció S. Brittonii León de Cuba y a S. ciliaris y $S$. anomala, de Texas a Sudamérica.

En 1957 Clement publicó "Studies in Sida" en los que revisó varias secciones, entre las cuales se encuentra Malacroideae G. Don. El autor designó como tipo a Sida ciliaris , especie que no figura en la descripción de G. Don. Aceptó S. Brittonii, S. centuriata Clement, S. 
surumuensis Ulbr., S. paradoxa y S. ciliaris; esta última con 5 variedades. Analizó el protólogo de la descripción original de $S$. ciliaris y eligió como lectotipo el ejemplar del herbario linneano coleccionado por $\mathrm{Br}$ [owne] en Jamaica.

En 1958 Kearney publicó una clave tentativa de las especies sudamericanas de Sida. Reconoció la sección Pseudomalachra, en la que ubicó a $S$. paradoxa, S. anomala, $S$. surumuensis y $S$. ciliaris.

En 1966 J. van Borssum Waalkes en su estudio sobre las Malváceas malesianas, trató a Sida ciliaris. Aceptó la opinión de Clement sobre la designación del tipo.

En 1966 Monteiro presentó en el XVII Congresso da Sociedade Botânica do Brasil, Brasilia, "Pseudomalachra (K. Schum.) H. Monteiro n.g.". Los Anais de este congreso nunca se publicaron $\mathrm{y}$ en el resumen mimeografiado no se cumple con las condiciones requeridas por el art. 32.3 del Código Internacional de Nomenclatura Botánica (Greuter \& al., 2000) al no indicar claramente el basónimo. Incluyó en Pseudomalachra a Sida ciliaris, S. anomala, S. plumosa, S. paradoxa Rodrigo y una nueva especie que nunca llegó a publicar.

En 1974, Monteiro en sus "Comentarios sobre algunas especies de Cavanilles", trató a S. ciliaris, S. plumosa y S. tridentata como pertenecientes al género Pseudomalachra, pero como éste no fue formalmente publicado, las combinaciones no son legítimas.

En 1975, Fryxell eligió como tipo de la sección Malacroideae a S. anomala y describió la nueva especie Sida meridiana, del estado de Minas Gerais, Brasil.

En 1985, Fryxell al tratar las especies de Sida de América del Norte y Central modificó la ortografía original de la sección Malacroideae por Malachroideae. Enumeró las especies pertenecientes a esta sección: $S$. brachystemon, S. Brittonii, S. ciliaris de América del Norte, las especies sudamericanas $S$. centuriata, S. paradoxa, S. plumosa y $S$. surumuensis y S. cuneifolia del Viejo Mundo. Fue el primer autor en ubicar a esta última especie en la sección Malacroideae.

En 1986, Vollesen estudió el complejo Sida cuneifolia en África. Este complejo con- siderado usualmente como constituido por una sola especie extendida desde Etiopía a Tanzania en África y de India en Asia. Encontró que $S$. cuneifolia es endémica de India y que en África viven cinco especies. $S$. Schimperiana A. Rich. y cuatro especies nuevas: S. massaica Vollesen, S. shinyangensis Vollesen, S. tanaensis Vollesen y $S$. tenuicarpa Vollesen, que describió e ilustró.

En 1995, Fuertes Aguilar en su tratamiento del género Sida para la flora de Colombia, reconoció dos especies de la sección Malacroideae: S. ciliaris y S. brachystemon. En esta última incluyó todos los ejemplares que Clement (1957) citó para Colombia de $S$. ciliaris var. anomala.

\section{Morfología}

\section{Tallo}

El tallo puede ser erecto o postrado. En este caso en algunas especies se presentan raíces adventicias filiformes. Las especies con esta característica son: S. albiflora (Chodat. \& Hassl.) Krapov., S. brachystemon, $S$. caulorrhiza Krapov., S. Cristobaliana Krapov., S. Dureana Krapov., S. meridiana, S. plumosa, S. Simpsonii Krapov. y S. surumuensis.

Los pelos pueden ser mayores de $0,5 \mathrm{~mm}$ y en este caso tenemos:

Pelos de 4 ramas adpresos y pocos estrellados: S. albiflora, S. anomala (Fig. 1 A), S. caulorrhiza, S. Dureana, S. Ferrucciana Krapov. y S. plumosa.

Pelos estrellados multiradiados adpresos: S. Bordasiana Krapov., S. castanocarpa Krapov., S. centuriata, S. ciliaris, S. Cristobaliana, S. Monteiroi Krapov. (Fig. 1 B) y S. Simpsonii.

Pelos estrellados no adpresos: $S$. Brittonii, $S$. meridiana (Fig. 1 C) y S. Harleyi Krapov.

En el grupo con pelos menores de 0, $5 \mathrm{~mm}$ tenemos:

Pelos estrellados menores de 0,5 mm, 

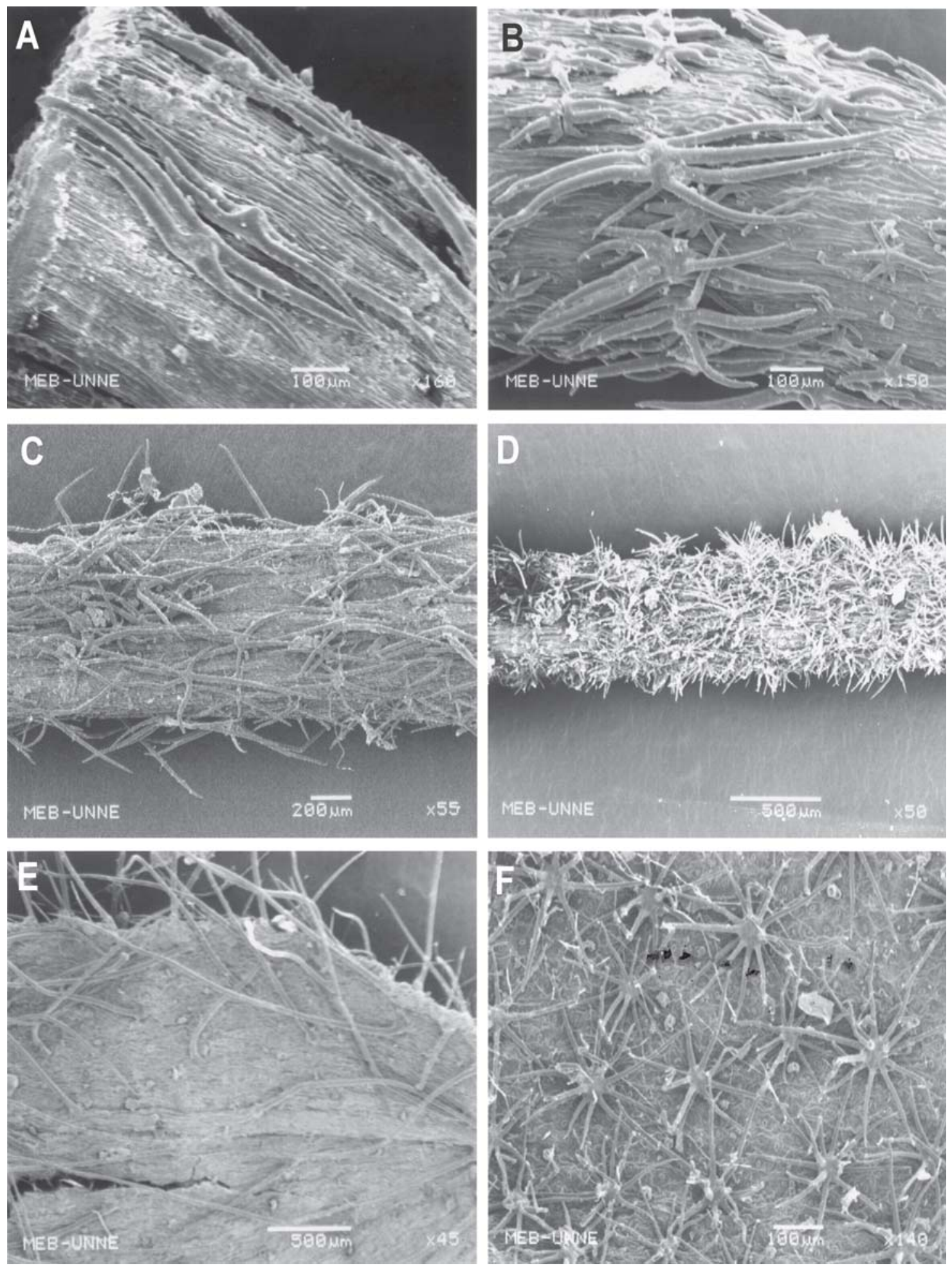

Fig. 1. Tricomas del tallo: A, Sida anomala (Lavia 7); B, S. Monteiroi (Schinini 36278); C, S. meridiana (Krapovickas 37933); D, S. Pedersenii (Pedersen 4109). Tricomas del epifilo: E, S. Brittonii (Fernández 2854). F: S. Pedersenii (Pedersen 4109). 
adpresos: S. brachystemon, S. cuneifolia, $S$. paradoxa y $S$. surumuensis.

Pelos estrellados menores de 0,5 mm, no adpresos: S. Pedersenii Krapov. (Fig. 1 D).

\section{Hoja}

Menos de $5 \mathrm{~mm}$ lat.: $S$. anomala, $S$. Bordasiana, S. brachystemon, S. ciliaris (=S.muricata), S. Dureana, S. Ferrucciana, S. Monteiroi, S. paradoxa, S. Pedersenii, S. Simpsonii y $S$. surumuensis.

Más de 5 mm lat.: S. albiflora, S. Brittonii, S. castanocarpa, S. caulorrhiza, S. centuriata, S. ciliaris, S. Cristobaliana, S. Dureana, S. Harleyi, S. meridiana y S. plumosa.

\section{Epifilo}

Glabro: S. Bordasiana, S. caulorrhiza, S. ciliaris, S. cuneifolia, S. paradoxa y $S$. Monteiroi (pelos estrellados en hojas muy jóvenes).

Pelos estrellados: S. brachystemon, $S$. centuriata, S. Ferrucciana, S. meridiana, $S$. Monteiroi (en hojas muy jóvenes), $S$. Pedersenii (Fig. 1 F), S. Simpsonii y $S$. surumuensis.

Pelos simples: S. anomala, S. Brittonii (Fig. 1 E), S. Dureana y S. plumosa.

Pelos estrellados y algunos simples: S. albiflora, S. castanocarpa, S. Cristobaliana y $S$. Harleyi.

\section{Cáliz}

3 mm long.: S. Bordasiana y S. Monteiroi.

4-5 mm long.: S. albiflora, S. Brittonii, S. castanocarpa, S. ciliaris, S. Cristobaliana, S. cuneifolia, S. Ferrucciana, S. Pedersenii y S. plumosa.

5-6 mm long.: S. brachystemon, S. meridiana y $S$. surumuensis.

5-7 mm long.: S. anomala y S. centuriata.

$6 \mathrm{~mm}$ long.: S. caulorrhiza, S. ciliaris, S. Dureana y S. Harleyi.

$8 \mathrm{~mm}$ long.: S. paradoxa.

\section{Pétalos}

13-23 mm long.: S. albiflora, S. brachystemon,
S. caulorrhiza, S. centuriata, S. Dureana, S. paradoxa, S. Simpsonii y S. surumuensis.

12-13 mm long.: S. Brittonii y S. Ferrucciana.

$10 \mathrm{~mm}$ long.: S. anomala, S. Bordasiana, S. castanocarpa, S. Harleyi y S. meridiana

7-13 mm long.: S. Cristobaliana, $S$. Pedersenii y S. plumosa.

5-11 mm long.: S. ciliaris.

4-7 mm long.: S. Monteiroi.

\section{Tubo estaminal}

Glabro: S. ciliaris, S. meridiana, S. paradoxa y S. Pedersenii.

Pelos simples: S. albiflora, S. anomala, S. Bordasiana, S. Brittonii, S. castanocarpa, S. caulorrhiza, S. Cristobaliana, S. cuneifolia, S. Dureana, S. Harleyi, S. Monteiroi, S. plumosa y S. Simpsonii.

Pelos simples o de 2 ramas: $S$. brachystemon.

Pelos estrellados: $S$. centuriata, $S$. Ferrucciana y S. surumuensis.

\section{Mericarpos}

Prominencias con un pelo estrellado apical de radios retrorsos (gloquidios).

Superficie con pelos glandulares punctiformes: S. albiflora, S. anomala (Fig. 2A-B), S. brachystemon, S. ciliaris y S. Cristobaliana.

Superficie con pelos glandulares con pie pluricelular: S. caulorrhiza, S. Dureana, S. Ferrucciana, S. Harleyi, S. meridiana (Fig. 3 C-D) y S. Simpsonii.

Superficie con pelos estrellados similares al apical y pelos glandulares de pie unicelular: S. centuriata y S. surumuensis.

Prominencias sin pelo estrellado apical.

Superficie con pelos glandulares pedicelados: S. Brittonii (Fig. 2 E-F), S. Dureana y $S$. paradoxa.

Superficie con pelos estrellados: $S$. Bordasiana, S. caulorrhiza, S. cuneifolia, S. paradoxa y, S. Pedersenii (Fig. 3 A-B).

Superficie con pelos estrellados blandos y pelos glandulares con pie pluricelular: $S$. castanocarpa, S. Monteiroi (Fig.2 C-D) y S. plumosa. 

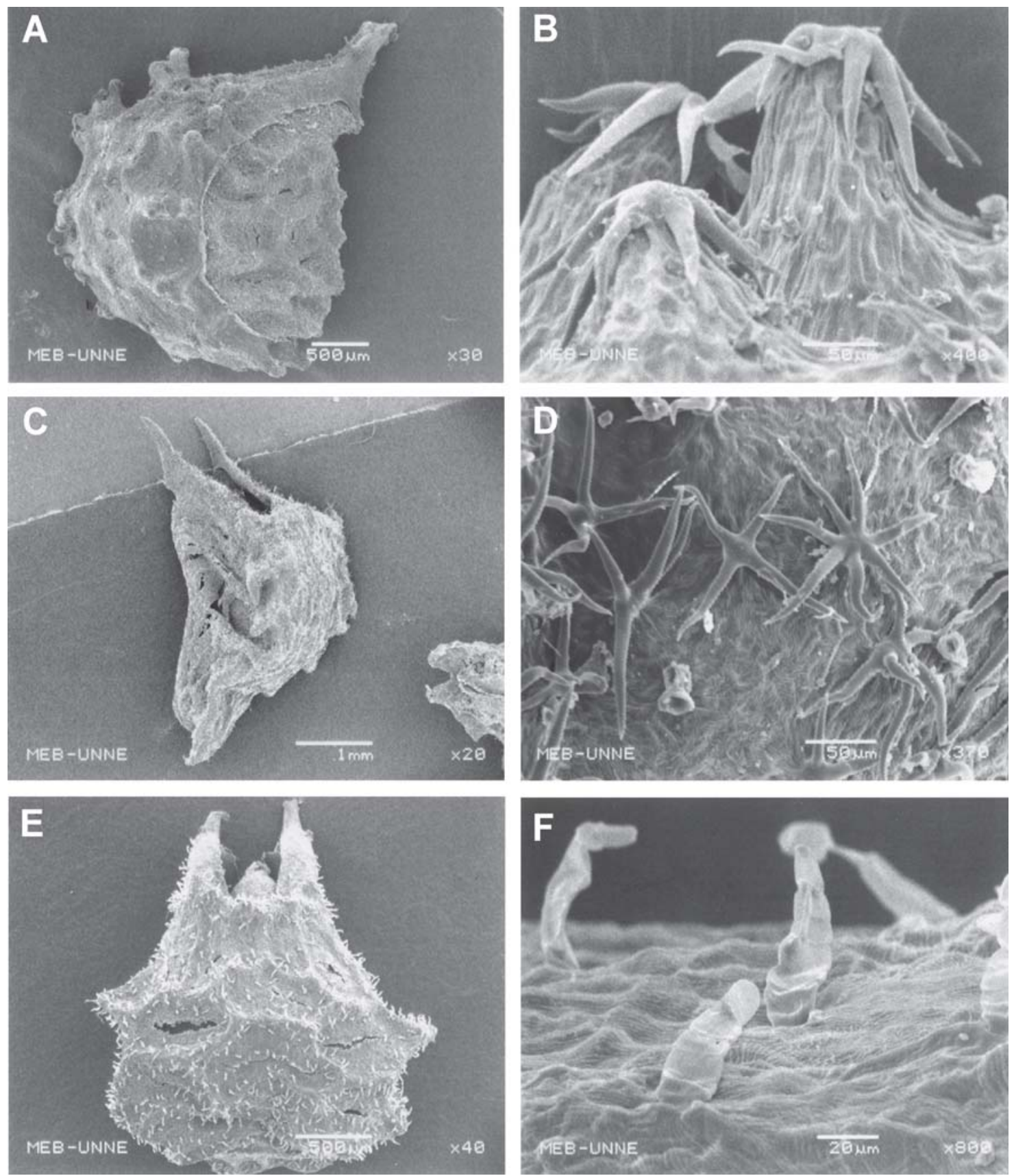

Fig. 2. Mericarpos: A y B, Sida anomala (Ahumada 1408 ); C y D, S. Monteiroi (Krapovickas 47766); E y F, S. Brittonii (Rosales 435).

\section{Semilla}

Pelos estrellados, ondulados: S. anomala (Fig. 4 A-B), S. brachystemon, S. Brittonii, S. caulorrhiza, S. ciliaris, S. Cristobaliana, S. Dureana, S. Ferrucciana, S. Harleyi, S. meridiana, S. plumosa, S. Simpsonii y S. surumuensis.

Pelos estrellados diminutos: S. albiflora, S. Bordasiana, S. centuriata, S. Monteiroi, S. paradoxa y S. Pedersenii (Fig. 4 CD). 

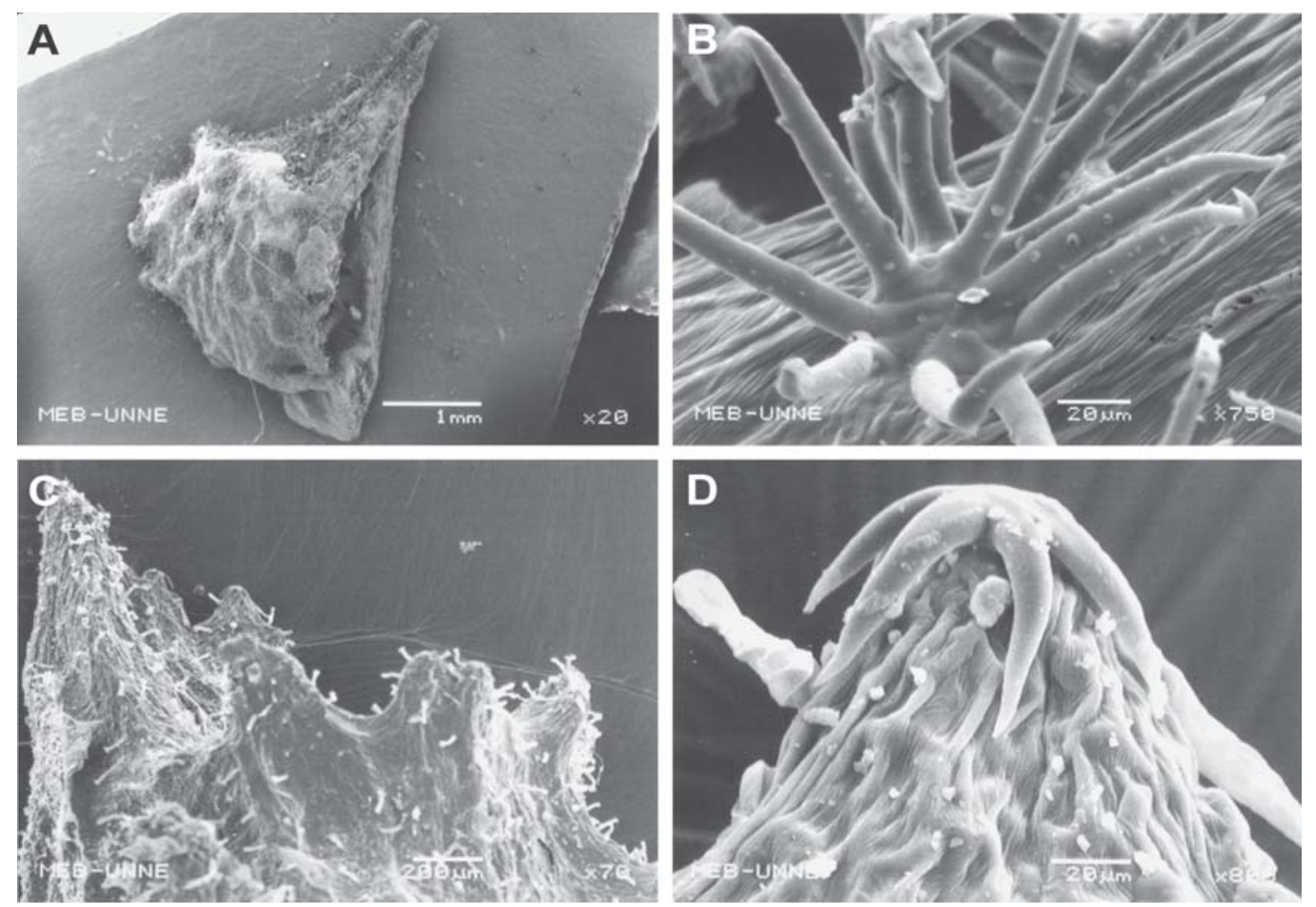

Fig. 3. Mericarpos: A y B, Sida Pedersenii (Pedersen 4109); C y D, S. meridiana (Krapovickas 37993).
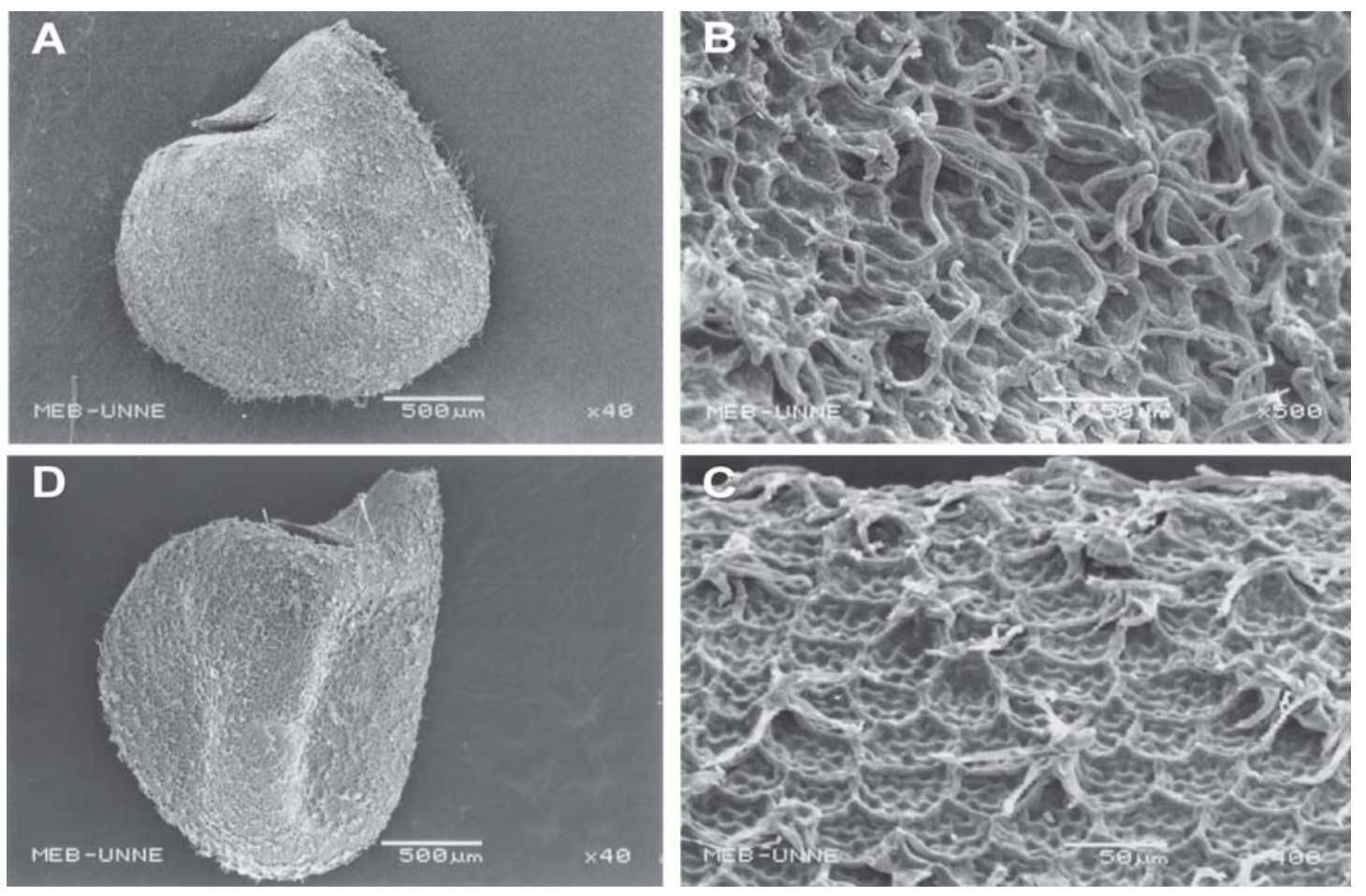

Fig. 4. Semillas: A y B, Sida anomala (Ahumada 1408); C y D, S. Pedersenii (Pedersen 4109). 


\section{Cromosomas}

\begin{tabular}{|c|c|c|c|}
\hline & Especie & $2 n$ & Procedencia \\
\hline$*$ & S. ciliaris & 16 & $\begin{array}{l}\text { K } 45283 \text { PY, Fortín Tte. } \\
\text { Ochoa }\end{array}$ \\
\hline$*$ & S. ciliaris & 16 & $\begin{array}{l}\text { SN } 1065 \text { BO, } 22 \text { km E } \\
\text { de S.Cruz }\end{array}$ \\
\hline$*$ & S. ciliaris & 16 & $\begin{array}{l}\text { SN } 1410 \text { BO, } \\
\text { Chuquisaca, Zudañez }\end{array}$ \\
\hline$*$ & S. anomala & 16 & $\begin{array}{l}\text { SN } 1336 \text { BO, SC, } 47 \text { km } \\
\text { W Samaipata }\end{array}$ \\
\hline$*$ & S. anomala & 16 & $\begin{array}{l}\text { K. } 7963 \text { RA, CTES, } \\
\text { Mercedes }\end{array}$ \\
\hline$*$ & S. Monteiroi & 16 & $\begin{array}{l}\text { K } 47907 \text { RA, Formosa, } \\
\text { E. del Campo }\end{array}$ \\
\hline$*$ & S. Monteiroi & 16 & $\begin{array}{l}\text { K } 45255 \text { PY, Pozo } \\
\text { Colorado }\end{array}$ \\
\hline$*$ & S. Monteiroi & 16 & K.10599 PY, Concepción \\
\hline$*$ & S. Monteiroi & 16 & $\begin{array}{l}\text { K.47766 RA, Salta, Los } \\
\text { Blancos }\end{array}$ \\
\hline & S. paradoxa & 32 & $\begin{array}{l}\text { K } 11858 \text { (Fernández, } \\
\text { 1974) }\end{array}$ \\
\hline & S. plumosa & 32 & $\begin{array}{l}\text { K } 33556 \text { (Fernández, } \\
\text { 1981) }\end{array}$ \\
\hline$*$ & S. Cristobaliana & 32 & $\begin{array}{l}\text { K.45401 PY, Nueva } \\
\text { Asunción }\end{array}$ \\
\hline$*$ & S. Cristobaliana & 32 & $\begin{array}{l}\text { SN 1264, BO. Sa. Cruz, } \\
\text { S. Rafael }\end{array}$ \\
\hline
\end{tabular}

Abreviaturas. F: Fernández, K: Krapovickas, SN: Solis Neffa, BO: Bolivia, BR: Brasil, PY: Paraguay, RA: República Argentina, *: novedades (Lavia \& al., 2007).

Distribución geográfica: Las especies de la sección Malacroideae viven en América entre los $30^{\circ} \mathrm{N}$ y $33^{\circ} \mathrm{S}$ de latitud.

En Sudamérica son elementos del Dominio Chaqueño (Cabrera \& Willink, 1973) especialmente de las Provincias Chaqueña y de la Caatinga y el extremo norte del Espinal.

En el Dominio Amazónico son muy escasas en la Provincia del Cerrado, salvo en sus márgenes y faltan en las otras Provincias, salvo la Provincia Atlántica, donde vive $S$. plumosa.

En la provincia fitogeográfica Chaqueña (Cabrera, 1976) las siguientes especies: $S$. anomala, S. Monteiroi, S. Pedersenii viven en el bosque chaqueño en pequeñas depresiones de pocos centímetros de profundidad con
Nostoc o Sellaginella en el SelaginelloAyenietum odonelii (Martínez-Crovetto, 1980), comunidad herbácea que habita entre los bosques de quebracho colorado y que se caracteriza por la dominancia de Selaginella Sellowii Hieron., especie que crece formando tapices densos sobre suelos arcillosos impermeables y poco profundos, que se ven expuestos periódicamente a exceso o a falta de agua en el lapso de pocos días. El pH de estos suelos oscila entre 6 y 6,5 en la provincia de Corrientes.

Sida anomala y S. Monteiroi extienden su área a la provincia del Espinal, también del Dominio Chaqueño (Cabrera, 1976) en la provincia argentina de Entre Ríos. Sida anomala además llega a la orilla oriental del río Uruguay en Uruguay y en el extremo SW de Río Grande do Sul en Brasil.

Paraguay: S. albiflora, S. anomala, S. Bordasiana, S. centuriata, S. ciliaris, S. Cristobaliana, S. Dureana, S. Ferrucciana, S. Monteiroi, S. Pedersenii.

Brasil, Bahía: S. Harleyi, S. meridiana, S. plumosa, S. castanocarpa. Fuera de este estado, viven en Goiás S. caulorrhiza, en Mato Grosso S. anomala y S. Simpsonii, en Mato Grosso do Sul, S. anomala, S. centuriata y $S$. Dureana y en Río Grande do Sul S. anomala y S. paradoxa. En el nordeste $S$. Brittonii y $S$. castanocarpa. En Roraima crece $S$. surumuensis.

\section{Tratamiento Taxonómico}

\section{Sida sect. Malacroideae G.Don}

Don, G., Gen. hist. 1: 498. 1831. Lectotypus: S. anomala A.St.-Hil.(Fryxell, 1975).

Dictyocarpus Wight, Madras J. Lit. Sci. 5:310, t. 19. 1837. Typus: D. truncatus (Willd.) Wight (Melochia truncata Willd. 1801) (= S. cuneifolia Roxb. 1832) [Non Sida truncata Cav. 1785].

Sida sect. Pseudomalachra K.Schum., in Engler \& Prantl, Nat. Pflanzenfam. 3(6):43.1890. Typus: Sida ciliaris L.

Sida sect. Ciliares Small, Man. Southeast Fl.: 849. 1933. Typus: Sida ciliaris L.

Pseudomalachra (K.Schum.) Monteiro, Portugal. 
Acta Biol. B, 12(1-4): 141. 1974. Combinación no validamente publicada (art 33.3, ICBN, 2000).

Sida sect. Malachroideae Fryxell, Sida 11(1):
62-91. 1985, orth. var., variante ortográfica que no corresponde de acuerdo al art. 60 del Código de Nomenclatura (Greuter \& al., 2000).

\section{Clave para diferenciar las especies}

A. Tallos con raíces adventicias.

B. Pétalos 10-20 mm long. Cáliz 5-7 mm long. Tubo estaminal con pelos simples o de 2 ramas.

C. Epifilo con pelos.

D. Margen de la hoja entero.

E. Tubo estaminal con pelos simples o de 2 ramas. Mericarpos 5-6, con pelos glandulares punctiformes. Pétalos 18-23 mm long. Indumento de pelos estrellados 1 mm diám.

4. S. brachystemon DC.

E'. Tubo estaminal con pelos estrellados. Mericarpos 6-8, con pelos estrellados adpresos, semejantes a los apicales de las prominencias y pelos glandulares punctiformes. Pétalos 13$16 \mathrm{~mm}$ long. Indumento de pelos estrellados muy pequeños, menores de 0,5 mm de diámetro.

21. S. surumuensis Ulbr.

D’. Margen de la hoja dentado.

F. Corola blanca. Epifilo con pelos estrellados y simples. Mericarpos con pelos glandulares punctiformes. Pétalos 15-20 mm long.

1. S. albiflora (Chodat \& Hassl.) Krapov.

F'. Corola rosada. Mericarpos con pelos glandulares con pedicelo breve. Pétalos 15 mm.

G. Epifilo con pelos estrellados.

20. S. Simpsonii Krapov.

G’. Epifilo con pelos simples.

12. S. Dureana Krapov.

C’. Epifilo glabro. Corola amarilla. Envés de la hoja subglabro, con pocos pelos estrellados sobre los nervios o algo más abundantes en hojas apicales. Mericarpos subglabros, con pelos glandulares de pie pluricelular, gloquidios pequeños.

7. S. caulorrhiza Krapov.

B’. Pétalos menos de $10 \mathrm{~mm}$ long.

H. Cabezuelas multifloras.

I. Mericarpos con pelos glandulares punctiformes y con gloquidios.

10. S. Cristobaliana Krapov.

I. Mericarpos glabro, sin gloquidios.

19. S. plumosa Cav.

H’. Cabezuelas paucifloras. Mericarpos con pelos glandulares con pie pluricelular, y con gloquidios.

15. S. meridiana Fryxell

A’. Tallos sin raíces adventicias

J. Lámina de margen entero, menores de 5 mm lat. Mericarpos 5.

K. Ápice foliar apenas escotado y con un pequeño apículo en el centro; epifilo glabro.

L. Tubo estaminal con pelos simples. Pétalos 8 a 11 mm long. 
M. Mericarpos birostrados y con protuberancias en el dorso.

\section{S. Bordasiana Krapov.}

M’ Mericarpos múticos, sin protuberancias.

11. S. cuneifolia Roxb.

L’. Tubo estaminal glabro. Pétalos 17 mm long.

17. S. paradoxa Rodrigo

K’. Ápice foliar agudo, a veces tridentado pero el diente central mayor; epifilo con pelos estrellados. Tubo estaminal glabro.

18. S. Pedersenii Krapov.

J’. Lámina con el margen diversamente dentado.

N. Epifilo glabro en todas las hojas.

O. Tubo estaminal glabro. Mericarpos 6-8, con pelos glandulares punctiformes.

9. S. ciliaris L.

O’. Tubo estaminal con pelos simples. Mericarpos 5, con pelos estrellados. Cabezuelas paucifloras.

16. S. Monteiroi Krapov.

N'. Epifilo con pelos en todas o en algunas hojas (S. anomala).

P. Epifilo con pelos simples. Tubo estaminal con pelos simples.

Q. Mericarpos 5, con pelos glandulares con pie de 4-5 células. Hoja hasta $10 \mathrm{~mm}$ lat.

5. S. Brittonii León

Q’. Mericarpos 6-8.

R. Mericarpos 7-8, con pelos glandulares punctiformes. Hoja menos de 5 mm lat., haz sólo con pelos simples o glabro en una misma planta.

2. S. anomala A.St.-Hil.

R’. Mericarpos 6-8, con pelos glandulares de pie con varias células. Hoja hasta 10 mm lat., haz con pelos simples y a veces también pelos estrellados.

14. S. Harleyi Krapov.

P'. Epifilo sólo con pelos estrellados.

S. Pétalos 18-22 mm long. Tubo estaminal con pelos estrellados.

8. S. centuriata Clement

S’. Pétalos menores de 10-13 mm.

T. Mericarpos con pelos estrellados, sin gloquidios. Tubo estaminal con pelos simples.

6. S. castanocarpa Krapov.

T'. Mericarpos con pelos glandulares pedicelados, con gloquidios. Tubo estaminal con pelos estrellados.

13. S. Ferrucciana Krapov.

\section{Sida albiflora (Chodat \& Hassl.) Krapov., comb. \& stat.. nov.}

Fig. 5
Hassl. 2: 553, 1905. Lectotypus, designado aquí: Paraguay, Paraguarí, "in glareosis pr. Chololó in valle flum. Y-aca, dec. [Hassler] n. 6615" (G!, isotypi LIL!, S!, UC!).

Sida anomala f. albiflora subf. hirsuta Chodat Sida anomala f. albiflora Chodat \& Hassl., Pl. \& \& Hassl., Pl. Hassl. 2: 553. 1905. nom. superfl. 


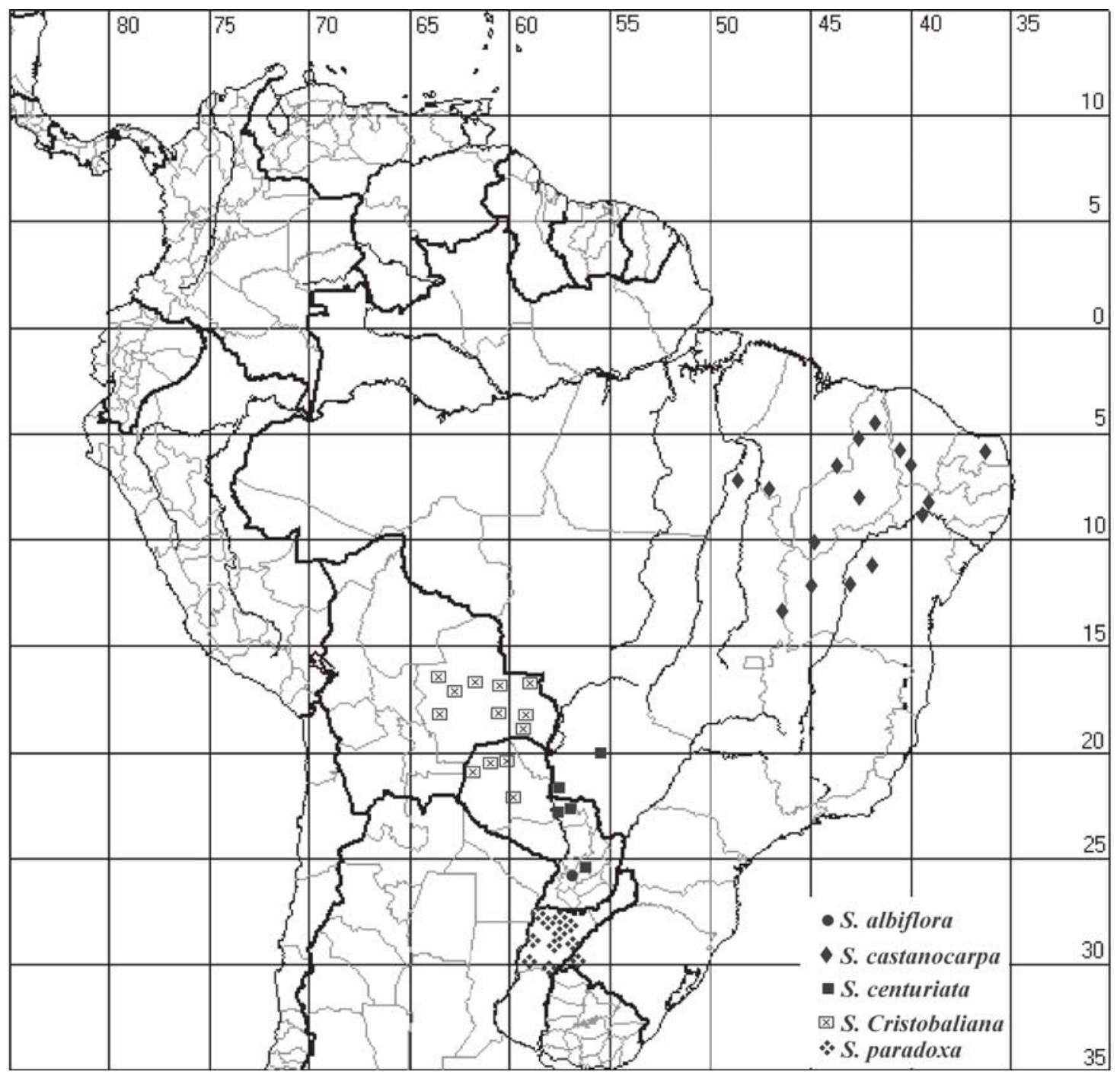

Fig. 5. Distribución geográfica de especies de Sida secc. Malacroideae.

Hierba perenne, postrada, tallos con raíces adventicias, con pelos de 4 ramas, adpresos. Estípulas $10 \mathrm{~mm}$ long., espatuladas a lineales, tomentosas y con márgenes ciliados. Pecíolo ca. $8 \mathrm{~mm}$ long., con algunos pelos estrellados adpresos y con los márgenes ciliados. Lámina elíptica, 8-16 mm long. x 4-6 mm lat. margen dentado en el tercio superior; epifilo con pelos estrellados adpresos y a veces también pelos simples, dejan ver la epidermis; hipofilo con pelos estrellados adpresos más abundantes; margen ciliado. Flores solitarias, subsésiles o con pedúnculo hasta $3 \mathrm{~mm}$ long., insertas en la unión de estípulas y pecíolo, agrupadas en cabezuelas paucifloras. Cáliz 5 $\mathrm{mm}$ long, cubierto de pelos estrellados adpresos; lóbulos con el margen ciliado. Corola blanca, pétalos 15-20 mm long. x 6-10 mm lat., blancos con la uña amarillo-crema, glabra. Tubo estaminal $2 \mathrm{~mm}$ long., piloso, pelos simples. Estilos sobresalen $5 \mathrm{~mm}$ sobre el tubo estaminal. Mericarpos 7, 3 mm long., incluidas las aristas apicales 0,5 mm long., caras reticuladas, dorso con numerosas prominencias con un pelo estrellado apical de radios retrorsos, superficie con pelos glandulares punctiformes. Semilla solitaria, péndula, con pelitos muy pequeños, esparcidos. 
Distribución geográfica: Fue coleccionada en un área muy pequeña, en las inmediaciones del límite de los departamentos de Cordillera y Paraguarí, en Piribebuy y en los saltos de Chololo, en el arroyo Y-acá, localidades distantes unos $20 \mathrm{~km}$ entre sí. Vive en suelos arenosos entre rocas aflorantes.

Material adicional estudiado: PARAGUAY. Paraguarí: Chololó, 14-XI-1969, Pedersen 9296 (C, CTES); Saltos del Chololó, 14-XI-1978, Arbo \& al. 1713 (CTES); ídem, Arbo \& al. 1766 (CTES, FCQ, G); Chololó, 16-X-1994, Krapovickas \& al. 45657 (CTES, G, LIL, MO, NY, SI). Cordillera: Piribebuy, Hassler 1876 (G); Piribebuy, 9-II1966, Krapovickas \& al. 12585 (CTES, FCQ, G, $\mathrm{MO})$.

Obs.: Las flores abren alrededor de las 14,30 horas.

\section{Sida anomala A.St.-Hil.}

Figs. 1 A, 2 A-B, 4 A-B, 6

Saint Hilaire, A., Fl. Bras. mer. 1: 177, tab. 33. 1827. Typus: Paturage près la village de Sando, prov. Cisplatine [Paysandú, Uruguay], St. Hilaire C2/2470 (holotypus P!, foto F 35529!)

Sida ciliaris var. anomala (A.St.-Hil.) K. Schum., in Engler \& Prantl, Nat. Pflanzenfam. 3(6): 43. 1890.

Iconografía adicional. Rodrigo, 1944, figs. 2 y 3.2; Krapovickas, 2005: 313, fig. 151.

Hierba perenne, de 10-20 cm alt. Tallo con pelos estrellados de 4 ramas, adpresos. Estípulas 4-7 mm long., lineales, algo ensanchadas en el ápice. Pecíolos 10-15 mm long. Lámina lineal-lanceolada, hasta $25 \mathrm{~mm}$ long. x $5 \mathrm{~mm}$ lat., con la mitad superior con el margen dentado y la mitad inferior con el margen liso, entero, epifilo con pelos simples o glabro en una misma planta, hipofilo con pelos estrellados, grandes, esparcidos. Flores reunidas (2 a 8) en el ápice de las ramas, rodeadas de estípulas ciliadas. Cáliz 5-7 mm long., con una capa de pelos estrellados muy peque- ños y largas cilias esparcidas. Pétalos rosamorados, $10 \mathrm{~mm}$ long., asimétricos, margen ciliado. Tubo estaminal con pelos simples. Fruto 7-8-carpelar. Mericarpos 3 mm long., biaristados, aristas ca. $1 \mathrm{~mm}$ long. con el dorso con prominencias con un pelo estrellado de radios retrorsos y la superficie con pelos glandulares punctiformes y muy pocos pedicelados. Cromosomas $2 n=16$.

Distribución geográfica: Bolivia, sur de Brasil, Uruguay, Paraguay y Argentina. Es una especie chaqueña y del Espinal. Florece en primavera y verano.

Material seleccionado estudiado: ARGENTINA. Chaco: Dep. $1^{\circ}$ de Mayo, Colonia Benítez, XII-1931, Schulz 552 (CTES, LP); Colonia Benítez, III-1954, Schulz 8734 (LIL); Margarita Belén, 23-XI-1945, Aguilar 480 (LIL); Dep. San Fernando, Resistencia, I-1886, Spegazzini 1293 (LP); Fontana, 15-XI-1931, Meyer 663 (LIL); Resistencia, río Negro, 19-IV-1964, Krapovickas y Cristóbal 11366 (CTES); Dep. Bermejo, Las Palmas, X-1017, Jorgensen 2315 (LIL, LP); 20 km S de Puerto Velaz, ayo. Cangui, 15-III-1967, Krapovickas 13038 (CTES). Córdoba: Dep. Río $1^{\circ}$, Obispo Trejo, 15-XII-1946, Balegno 1066 (LIL). Corrientes: Corrientes, 8-XI-1934, Burkart 6917 (LP, SI). Dep. Bella Vista, 10 km S de B. Vista, 13-IX-1072, Schinini 5221 (CTES); 3 km de ruta 27, camino a Rincón de Ambrosio, 14X-1974, Schinini y Cristóbal 9950 (CTES); Dep. Concepción, Oratorio, 17-V-1944, Ibarrola 5 (LIL); Dep. Curuzú Cuatiá, Solari, 4-XII-1941, Birabén 5001 y 5028 (LP), Curuzú Cuatiá, 2-III1945, Ibarrola 2551 (LIL); Dep. Empedrado, El Pollo, 30-VIII-1845, Ibarrola 3235; (LIL); Empedrado, 4-IV-1994, Lavia \& al. 7 (CTES); Dep. Esquina, $47 \mathrm{~km}$ W de Sauce, ruta 126, 23-X-1977, Ahumada \& al. 1408 (CTES); Dep. General Paz, Las Lomas, 8-V-1945, Huidobro 3357 (LIL); Palmar Grande, 13-II-1958, Cristóbal \& al. 105 (LIL); Dep. Goya, Ea. Peguahó, 5 km S de Goya, 19-II-1970, Carnevali 2231 (CTES); Goya, 26XI-1945, Boelcke 1377 (LIL, SI). Dep. Mburucuyá, Campo Dios Gracia, 26-X-1952, Pedersen 1869 (CTES). Dep. Mercedes, Iberá, 1910, Puyssegur 5 (SI); Pay-ubre Grande, XI1936, Rodrigo 698 (LP); ayo. Villanueva, XI-36, Rodrigo 649 (LP); entre Mercedes y Pellegrini, 


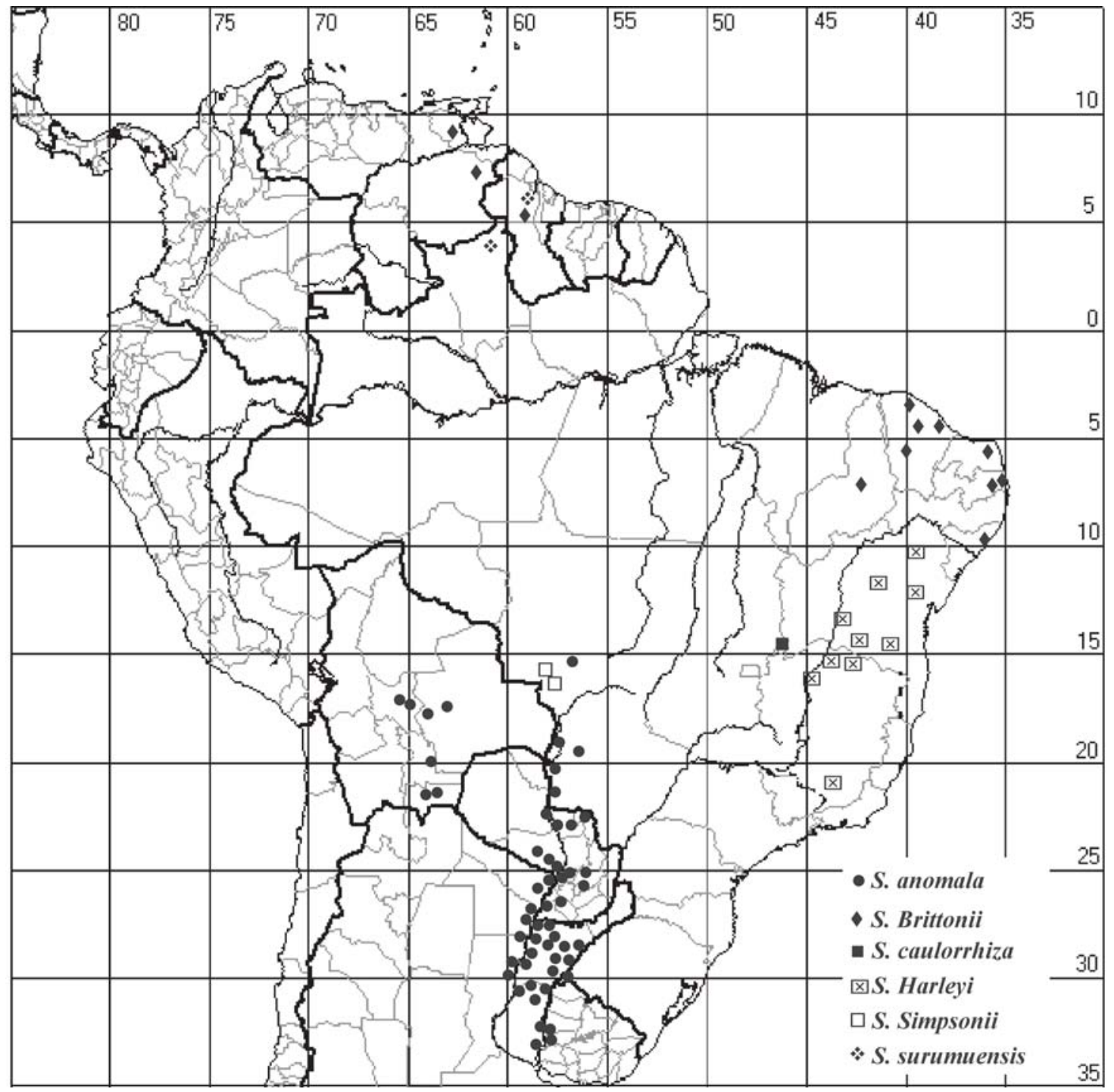

Fig. 6. Distribución geográfica de especies de Sida secc. Malacroideae.

10-III-1953, Krapovickas 7962 (LIL, SI); estancia Yacaré, 2-XII-1998, Arbo \& al. 8176 (CTES); 17 km S de Mercedes, 18-I-1973, Krapovickas \& al. 22745 (BAA, CTES); Dep. Paso de los Libres, Bonpland, 11-III-1953, Krapovickas 7968 (LIL, SI); Parada Pucheta, ruta 127, 17-II-1979, Ahumada 2552 pp (CTES); Dep. Saladas, Pago Los Deseos, 6-III-1969, Pedersen 9044 (C, CTES); Dep. San Luis del Palmar, San Luis del Palmar, 23-IX1944, Ibarrola 856 (LIL); 10 km SE de S.L. del Palmar, ruta 5, 26-IX-1973, Quarín 1376 (CTES); Dep. San Martín, Yapeyú, 28-XII-1946, Ibarrola 3751 (LIL); 5 km N de C. Pellegrini, 9-III-1953,
Krapovickas 7957, (LIL, SI); Arrocera Drews, 8 km N de C. Pellegrini, 16-II-1976, Krapovickas \& al. 29187 (BAA, CTES); C. Pellegrini, laguna Iberá, 5-XI-1073, Schinini 7812 (CTES); Dep. San Cosme, Paso de la Patria, 25-V-1945, Wirth 60 (LIL);Dep. Dep. San Luis del Palmar, Herlitzka, 18-IX-1945, Ibarrola 3357 (LIL). Entre Ríos: Dep. La Paz: La Paz, Burkart 21282 (SI). Dep. Federación, Estancia "Buena Esperanza", Pedersen 6273 (CTES, SI); Chajarí, Muñoz 1782 (CTES). Dep. Uruguay: Concepción del Uruguay, XII-1878, Lorentz 1762 (BAF, CORD); íd. XII.1877, Lorentz 1250; íd. río Gualeguaychú, X- 
1877, Lorentz 1202 (BAF, CORD); Concepción del Uruguay, ayo. Isletas, Burkart 23404 (SI); Uruguay, río Gualeguaychú, Nicora 3218 (SI); Gualeguaychú, 6-I-1932, Burkart 4236 (SI). Formosa: Laguna Los Indios, 4-IV-1947, Reales 30 (LIL); Dep. Pilcomayo, Monteagudo (km 10, ruta 11), 14-I-1947, Reales 160 (CTES, LIL); Puerto Ramos, 2-II-1949, Morel 7181 (CTES, LIL); Clorinda, 5-XI-1946, Morel 1579 (LIL); Clorinda, 13-XII-1992, Krapovickas y Cristóbal 44406 (CTES, LIL) Curicua, 25-II-1947, Reales 314 (LIL). Santa Fé: Dep. General Obligado, El Rabón, 27-XI-1939, Birabén 115 (LP); Berna, 7I-1937, Ragonese 2586 (LP); 25 km W de Reconquista, camino a Tostado, XI-1954, Sayago 1833 (LIL). BOLIVIA. Chuquisaca: prov. Belisario Boeto, 3 km SW de V. Serrano,28-II-1994, Serrano 633 (CTES). Cochabamba: Cochabamba, 2550 m, III-1039, Müsch 83 (SI); prov. Mizque, Rakaypampa, 2800 m, 1-XII-1986, Sigle 181 (CTES, LPB); Mizque, 2020 m, 24-II-1967, Steinbach 747 (CTES, LPB). Santa Cruz: Cerro de Alto, Mairana, 2300 m, 21-XII-1921, Steinbach 6042 (LIL, SI); between Hierba Buena and Mataral, 1300 m, 18-II-1995, Wood 9435 (LPB); prov. Valle Grande, Comarapa, 2200 m, 27-I-1958, Krapovickas 8891 (LIL); Comarapa, 2200 m, 27-I-1958, Krapovickas 8861 (CTES, LIL); El Trigal, 1700 m, Saravia Toledo 12379 (CTES); Valle Grande, Cochabambita, $1650 \mathrm{~m}$, 27-I-1993, Joaquín y Martínez 11301 (CTES); Florida, ca. 47 km W de Samaipata, 1408 m, 30-I2004, Solís Neffa \& al. 1336 (CTES). Tarija: de Tarija a Narváez, 2000 m, 19-III-1982, Kiesling 3687 (CTES, SI); prov. Méndez, Tomatas, 1950 m, 8-XII-1985, Bastián 66 (CTES, LPB); Padcaya, 2100 m, 11-XII-1903, Fiebrig 2551 (SI); Padcaya, 1910 m, 27-III-1996, Moraes 2384 (CTES, LPB); Colón (prov. Avilés), 31-I-1988, Beck \& Liberman 16307 (CTES, LPB). BRASIL. Mato Grosso: Cuiabá, 23-I-1989, Krapovickas \& Cristóbal 43081 (CTES). Mato Grosso do Sul: Bonito, 31-I-1998, Ribas \& Pereira 2385 (CTES, MBM); Porto Murtinho, 11-VI-1968, Krapovickas 14428 (CTES); Mun. Aquidauana, Faz. Santa Cruz, 200 m 16-VII-1969, Hatschbach 21897 (CTES, MBM); Faz. Santa Cruz, 18-VII1969, Hatschbach 21966 (CTES, MBM); Mun. Corumbá, Faz. Coqueiro, 23-X-1988, Pott \& Pott 4447 (CTES); Faz. Coqueiro, 15-II-1989, Pott \& al 759 (CTES); Mun. Miranda, Estancia Caiman,
1-IV-1998, Pott \& Pott 7899 (CTES). Rio Grande do Sul: Mun. Uruguaiana, 24-I-1948, Palacios \& Cuezzo 218 (LIL); Barra do Quaraí, 10-XII-1986, Bueno 4883 (CTES, HAS). PARAGUAY. Cerro Patony, 4-IV-1885, Kurtz 227a (CORD); Paraguay, 20/25-II-1903, Fiebrig 910 (AS, LIL). Alto Paraguay: Puerto Casado, 25-XI-1916, Rojas 1929 (AS, CTES, SI). Caaguazú: Carayao, arroyo Tobatiry, 23-IX-1988, Pedersen 15103 (CTES). Central: Asunción, 27-X-194 172, Rojas 10088 (AS, CTES, LP); Trinidad, X-1916, Rojas 91 (AS, LIL, SI); Trinidad, 10-XI-1950, Sparre \& Vervoorst 35 (CTES,LIL); esteros de Trinidad, 5I-1951, Schwarz 11486 (CTES, LIL); Lambaré, !8-XI-1950, Sparre \& Vervoost 253 (LIL); Itá, 29I-1966, Krapovickas \& al. 12144 (CTES); Areguá, Isla Valle, XI-1988, Mereles 1676 (CTES); Limpio, 15-III-1985, Bordas 3769 (CTES); Itá Enramada, 24-III-1973, Schinini 6297 (CTES); Tavarory, Acosta Ñu, 4-I-1991, Zardini \& al. 25345 (CTES, MO); Paso Ñandeyara, 2 km SE de Limpio, 9-V-1974, Schinini 8795 (CTES); Estero del Ypoá, 7-XII-1990, Zardini \& al. 24907 (CTES, MO). Concepción: 10 km N de Concepción, 17.XII-1983, Vanni \& al. 364 (CTES); estancia San Rafael, 140 km E de Concepción, 20-III1001, Eliceche 107 (CTES, FCQ); Col. San Antonio, 19 km E de Concepción, 8-XI-2001, Schinini \& al. 35556 (CTES). Cordillera: entre Ypacaraí y San Bernardino, 26-V-1964, Krapovickas y Cristóbal 11485 (CTES); río Salado, camino de Limpio a Emboscada, 13-IX-1978, Arbo \& al. 1623 (CTES). Guairá: Villa Rica, Jorgensen 4281 (SI); estancia III, Jorgensen 4287 (LP). Misiones: near Villa Florida, 21-XI-1984, Pedersen 14031 (C, CTES). Ñeembucu: Pilar. Humaitá, 13-XII-1950 Meyer 16204 (LIL). Paraguarí: Cerro Hu, 25-X, Sparre \& Vervoost 561 (LIL); río Tebicuary, frente a Florida, 4-II-1966, Krapovickas \& al. 12385 (CTES); cerro Jhú, 10-II-1966, Krapovickas \& al. 12597 (CTES); Valle Apu’a, estancia Lago Ypoa, 8-XI-2000, Mereles \& al. 8203 (CTES, FCQ). Presidente Hayes: 5 km NW de Chaco-i, 10-V1974, Schinini 9219 (CTES); ruta Transchaco, km 65, 28-XI-1988, Soria 3706 (CTES); ruta Transchaco, km 141, Ea. Santa Ana, 6-XII-1992, Krapovickas \& Cristóbal 44177 (CTES, G, PY); ruta Transchaco, km 245, 18-XII-1987, Schinini y Palacios 25809 (CTES). URUGUAY. Río Negro: Tres Bocas, Marchesi \& al. 20787 (CTES, MVFA). 
Obs.: En Corrientes, Sida anomala comienza a abrir las flores alrededor de las 11,30 hs. y a las 12 hs. está en plena floración.

\section{Sida Bordasiana Krapov., sp. nov.}

Figs. 7, 8

Fruticulus erectus. Folia oblonga retusa basi cuneata, integerrima, supra glabrata, infra stellato pubescentia. Flores ad apicem ramulorum subcongestae. Petala $10 \mathrm{~mm}$ longa $5 \mathrm{~mm}$ lata. Tubus stamineus pilosus. Styli 5. Carpidia $4 \mathrm{~mm}$ longa 3,5 $\mathrm{mm}$ lata, aristata, aristae $1 \mathrm{~mm}$, minutissime stellato tomentellae.

Holotypus: Paraguay, Alto Paraguay, Mayor Pedro Lagerenza, $60^{\circ} 45^{\prime} \mathrm{W}, 20^{\circ} \mathrm{S}$, cauce seco del río Timane, 2-IV-1978, A. Schinini \& E. Bordas 14882 (CTES).

Pequeño arbusto erecto, $30 \mathrm{~cm}$ alt., ramificado, perenne. Tallo con pelos de 4-8 ramas, adpresos, menores de 0,5 mm de diámetro, en las partes jóvenes. Pecíolo y estípulas soldados en la base. Estípulas lineales, 2-3 mm long., glabras; pecíolo $3 \mathrm{~mm}$ long. canaliculado, con los márgenes con pocos pelos simples muy breves y con un mechón de pelos estrellados en la base y otro en el ápice, lámina hasta $20 \mathrm{~mm}$ long. x $5 \mathrm{~mm}$ lat., oblonga, retusa, de base cuneada, ápice apenas escotado y con un pequeño apículo en el centro, margen entero; epifilo glabro; hipofilo con pelos estrellados multiradiados, esparcidos. Flores solitarias, subsésiles en el punto en que se separan pecíolo y estípulas, pedúnculo 1-2 mm long., agrupadas en el ápice de las ramas formando cabezuelas paucifloras. Cáliz $3 \mathrm{~mm}$ long. lóbulos con el nervio medio y los márgenes algo engrosados y cubiertos de pelos estrellados más o menos adpresos; cara interna de los lóbulos pilosa. Pétalos $10 \mathrm{~mm}$ long. x 5 $\mathrm{mm}$ lat. Tubo estaminal $3 \mathrm{~mm}$ long., con pocos pelos simples, hialinos. Estilos 5, sobresalen $3 \mathrm{~mm}$ sobre el tubo estaminal; estigmas en cabezuela. Mericarpos $4 \mathrm{~mm}$ long. x 3,5 mm lat., más aristas apicales $1 \mathrm{~mm}$ long., subglabros, con pelos estrellados muy pequeños dispersos. Semilla péndula, 2,5 mm long. x $2 \mathrm{~mm}$ lat. con pelos estrellados muy pequeños esparcidos.

Distribución geográfica: Conocida solamente de la localidad tipo, en el noroeste árido del Chaco paraguayo.

Paratypus: PARAGUAY. Alto Paraguay. Cap. Pablo Lagerenza, cauce del río Timane, $250 \mathrm{~m}$, 24-X-1987, Spichiger \& al. 2511 (G).

Obs.: Especie afín al grupo S. cuneifolia de India y NW de África (Vollesen, 1986) por su porte arbustivo y por la forma de sus hojas. Por la forma de la hoja se parece a $S$. cuneifolia y a S. Schimperiana y por los mericarpos a $S$. shinyangensis.

Etimología: Dedico esta especie a Eugenia Bordas, entusiasta botánica paraguaya, que participó en la colección del ejemplar tipo.

\section{Sida brachystemon DC.}

De Candolle, A. P., Prodr. 1: 459. 1824. Typus: Icones Florae Mexicanae s. n. (Torner Collection acc. no. 6331. 1803, Hunt Institute).

Sida Wendtii Fryxell, Phytologia 46: 393, fig. 4. 1980. Typus: México, Oaxaca: Mpio. Santo Domingo Armenta, ca. $20 \mathrm{~km}$ al oeste de Pinotepa Nacional, 8-XI-1979, Koch, Fryxell \& Wendt 79424 (holotypus ENCB, isotypus CTES!).

Hierba perenne, rastrera, con raíces adventicias en la base de las ramas. Tallo con pelos estrellados adpresos, 0,5 mm long. Estípulas lineal-lanceoladas, con pelos estrellados y margen ciliado. Pecíolo 4-7 mm long. Lámina elíptica, lineal-lanceolada, 10-22 mm long. $\mathrm{x}$ 2-4,5 mm lat., ápice agudo, margen entero, ambas caras con pelos estrellados adpresos. Flores agrupadas en cabezuelas pauciflora apicales. Pedicelos 1-4 mm long., con pelos estrellados adpresos. Cáliz 5-6 mm long., cubierto de pelos estrellados pequeños y pelos simples en los lóbulos, cara interna de los lóbulos con abundantes pelos simples ca. 2 $\mathrm{mm}$ long. Pétalos rosa-anaranjado a rosa oscuro, $16-23 \mathrm{~mm}$ long. x 6-10 mm lat. Tubo estaminal 2,5-4,5 mm long., con pelos estre- 


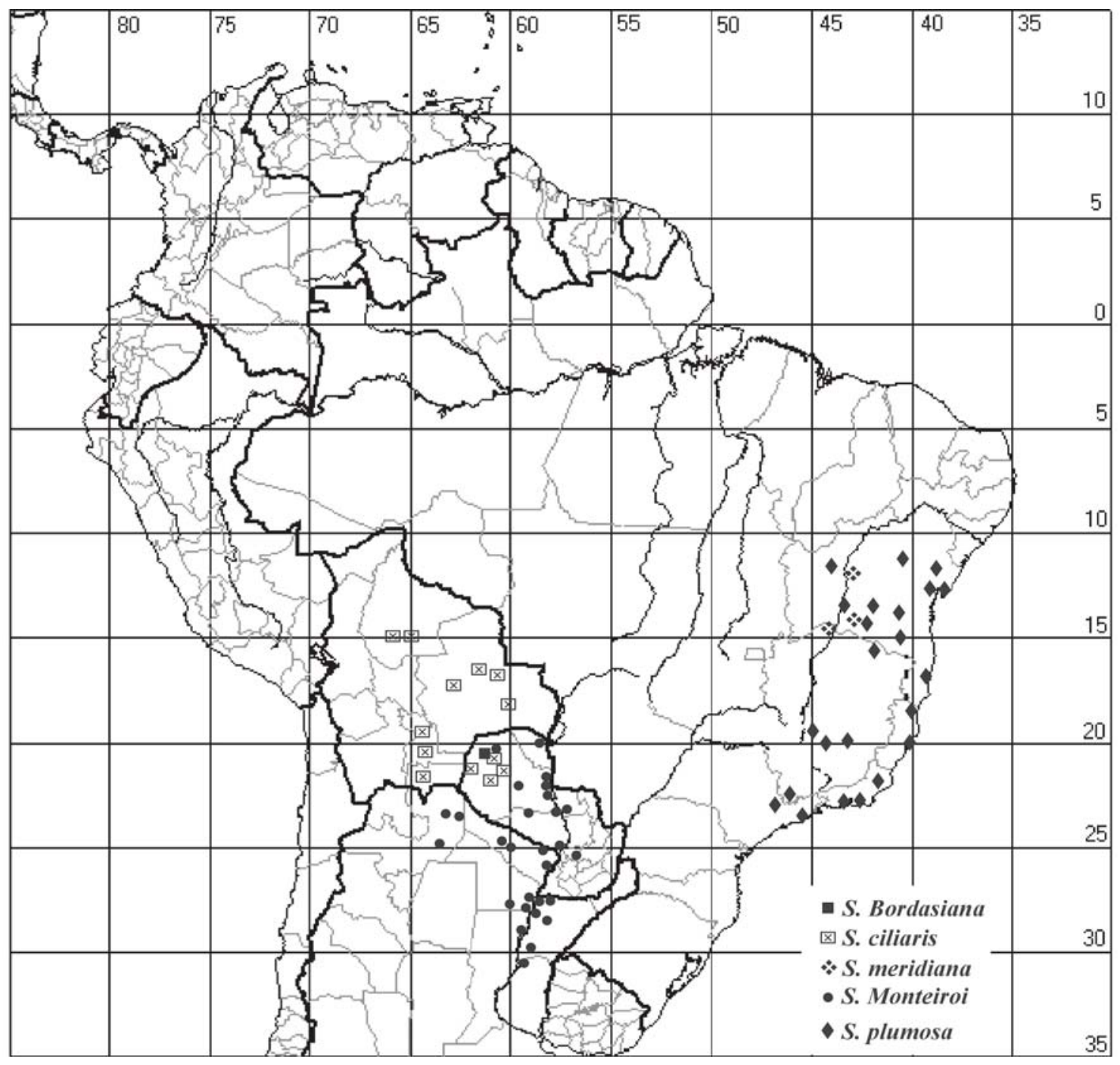

Fig. 7. Distrbución geográfica de especies de Sida secc. Malacroideae.

llados. Mericarpos 5-8, 2 mm long., brevemente apiculados, reticulados, con prominencias con un pelo de ramas retrorsas en el ápice y pelos glandulares pedicelados, esparcidos. Semilla con pelos estrellados de ramas onduladas.

\section{Sida Brittonii León}

Figs. 1 E, 2 E, 6

León, Torreya 19: 172, 1919. Lectoypus, desig- nado por Areces \& Fryxell (2007): "dry savanna, Chirigota, Pinar del Río Prov., Cuba", León \& Roca 7466 (holotypus HAC, isotypus NY!).

Sida ciliaris L. var. guianensis K. Schum., in Mart., Fl. bras. 12(3): 284. 1891. Lectotypus, designado por Clement (1957): Brit. Guiana, 1841-2, Schomburgk 405 (P!, isotypus US). Nuevo sinónimo.

Iconografía adicional: Areces \& Fryxell, 2007: 168, lam. II-3; 176, fig. 21.

Hierba perenne, postrada. Tallo con pelos de 4 y más ramas algo levantadas, no 


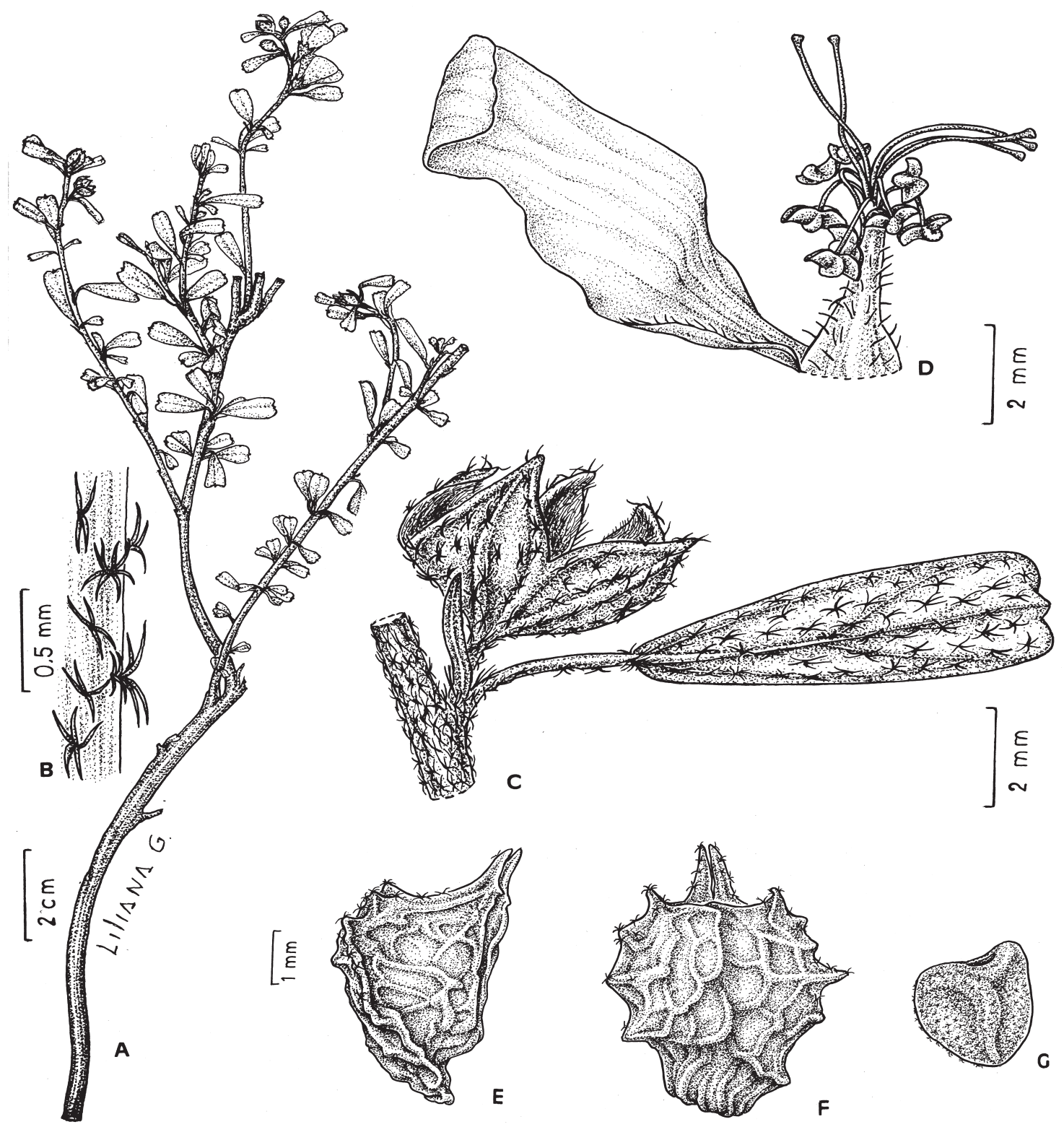

Fig. 8. Sida Bordasiana. A: rama. B: tallo. C: cáliz y hoja. D: tubo estaminal (Schinini \& Bordas 14822). E: mericarpo, vista lateral. F: mericarpo, vista dorsal. G: semilla (Spichiger 2511).

adpresos. Estípulas angosto-obovales a lineales, 6-12 mm long., pilosas, margen ciliado, en las cabezuelas soldadas a la base del pecíolo. Pecíolo 4-7 mm long. Lámina oblonga a elíptica u obovada, 10-20 mm long. x 4-10 $\mathrm{mm}$ lat., margen dentado en el tercio superior; haz con pelos simples $2 \mathrm{~mm}$ long., envés cubierto totalmente de pelos estrellados de ra- mas largas. Flores agrupadas en cabezuelas terminales. Pedicelo $2 \mathrm{~mm}$ long. Cáliz $5 \mathrm{~mm}$ long., lóbulos triangulares, con un mechón de pelos en la base y pelos simples, largos en ambas caras de los lóbulos. Pétalos amarillos, 12-13 mm long. Columna estaminal con pelos simples. Estilos 5. Carpelos 5. Mericarpos 5, reticulados, 2,5-3 mm long. $\mathrm{x}$ 1,3-1,5 mm lat. 
sin gloquidios, cubiertos de pelos glandulares de 4-5 células. Semilla pilosa.

Material adicional estudiado: CUBA. Pinar del Río: Herradura, 10-IV-1920, Ekman 10710 (G). VENEZUELA. Bolívar: Mun. Cedeño, entre kms 12-120, al Sur de Caicara del Orinoco, 100 m, 18XI-1984, Aymard \& Dtergios 3164 (CTES, PORT); Mun. Piar, Hato Morichito, 240 m, V1986, Fernández 2854 (CTES, MYF); Fundo La Trinidad, La Culebra, $300 \mathrm{~m}, 7^{\circ} 50^{\prime} \mathrm{N} 62^{\circ} 34^{\prime} \mathrm{W}$, 16-VII-1989, Rosales y Briceño 435 (CTES, MYF); Mun. Roscio, entre Hato El Manguito y el río Oronata, $200 \mathrm{~m}, 7^{\circ} 36^{\prime} \mathrm{N} 62^{\circ} 14$ ’W, V-1986, Fernández 2796 (CTES, MYF); Monaguas, Jusepin, 21-VIII-1970, Aristeguieta y Vera 83068 (VEN). BRASIL. Alagoas: Maceió, Ponta Verde, Ramalho Campêlo 990 (CTES, UFAL); Bahia, Blanchet 995 (G). Ceará: Sobral, 12-IV-1967, Krapovickas 12944 (CTES, ESA, MBM); Fortaleza, 16-IX-1988, Mata s.n. (CTES); id. 2-I-1976, Fernandes 2678 (CTES, EAC); Mun. Quixeré, Chapada do Apodi, 110 m, 14-V-1997 Melo \& al. 99 (CTES); ídem, 17-VI-1997, Barros 147 (CTES, EAC); Mun. São Gonçalo do Amarante, Estação Ecológica de Pecém, 13-IV-2000, Magalhaes 226 (CTES, EAC); 12 km de Tauá em direção a Arneiroz, Souza, Lorenzi \& Fernandes 28760 (CTES, ESA). Paraiba: Agreste, 11-XII1958, Coelho de Moraes 2005 (CTES; LIL); Cabo Branco, 16-IV-1967, Krapovickas 12904 (CTES); Mun. Pedra da Fogo, 28 km S de João Pessoa, 16IV-1967, Krapovickas 12874 (CTES, ESA, MBM, SP); Barra de Mamanguape, 27-VII-2001, Souza \& Souza 26582 (CTE\$·SW, ESA). Piauí: Gardner 2052 (NY). Rio Grande do Norte: BR226 Entroncamento 226/304 - Currais Novos, km 15, 21-VII-1980, Coradin \& al. 3212 (CEN, CTES).

Obs.: Clement (1957:18) manifiestó que $S$. Brittoni era conocida solamente de la provincia Pinar del Rio, Cuba y encontró que era superficialmente similar a ejemplares de Brasil y a los que utilizó K. Schumann para crear S. ciliaris var. guianensis K. Schum. Supuso que estos ejemplares representan no más que una tendencia en $S$. ciliaris y que no tenían relación estrecha con $S$. Brittonii. Sin embargo, éstos materiales son muy difíciles de separar de $S$. Brittonii, y si bien en Brasil viven en el nordeste, su àrea se extiende hasta la costa del Caribe, en Venezuela, lo cual apoya la sinonimia aquí propuesta.

\section{Sida castanocarpa Krapov., sp. nov.}

Figs. 5, 9

Herba erecta vel prostrata. Folia ovata usque ad $30 \mathrm{~mm}$ longa et $8 \mathrm{~mm}$ lata, margine supra 2/3 serrata, basi integerrima, supra et infra stellato tomentosa. Flores ad apicem ramulorum congestae. Petala $10 \mathrm{~mm}$ longa. Tubo stamineo piloso. Ovario 5 carpidiato. Fructus castaneo, carpidia muricata, 2 $\mathrm{mm}$ longa et aristae $1 \mathrm{~mm}$ longae, pilis castaneis.

Holotypus: Brasil, Tocantins, $40 \mathrm{~km} \mathrm{NE}$ de Wanderlandia, BR-226, km 1192, en cerrado, flor rosada, 10-III-1982, A. Krapovickas, J.F.M. Valls \& G.P. Silva 37845 (CEN, isotypi CTES, NY, SI, SP).

Hierba erecta o postrada, sin raíces adventicias. Tallo con pelos estrellados adpresos. Estípulas lineales, 5-10 mm long., margen ciliado. Pecíolo 3-5 mm long. Lámina oval, hasta $30 \mathrm{~mm}$ long. x $8 \mathrm{~mm}$ lat., margen dentado hacia el ápice, ambas caras con pelos estrellados adpresos y con frecuencia también pelos simples en el haz. Flores agrupadas en cabezuelas paucifloras, en la axila del pecíolo soldado a la base de las estípulas, ambos ciliados. Pedicelo $3 \mathrm{~mm}$ long. Cáliz $4 \mathrm{~mm}$ long., cubierto de pelos estrellados, lóbulos triangulares $2 \mathrm{~mm}$ long. x 1,5 mm lat., setosos; cara interna pilosa. Corola rosada a blanca, a veces en una misma población. Pétalos $10 \mathrm{~mm}$ long., cara externa con pelos glandulares pequeños, dispersos. Tubo estaminal con pelos simples. Carpelos 5. Fruto con tinte castaño. Mericarpos muricados, $2 \mathrm{~mm}$ long. y aristas $1 \mathrm{~mm}$ long., cubiertos de pelos estrellados castaños con tinte rosado, blandos y pelos glandulares pedicelados. Semilla péndula, pilosa, pelos ondulados.

Distribución geográfica: Vive en el Nordeste de Brasil. Habita en suelos arenosos, tanto en la caatinga como en el cerrado.

Paratypi: BRASIL. Bahia: Espigâo Mestre, ca. $25 \mathrm{~km}$ W of Barreiras, $600 \mathrm{~m}, 3-I I I-1971$, Irwin \& al. 31352 (CTES, NY); Ibotirama, 15-V-1978, 
A. Krapovickas, Sida secc. Malacroideae (Malvaceae) del Sur de Sudamérica
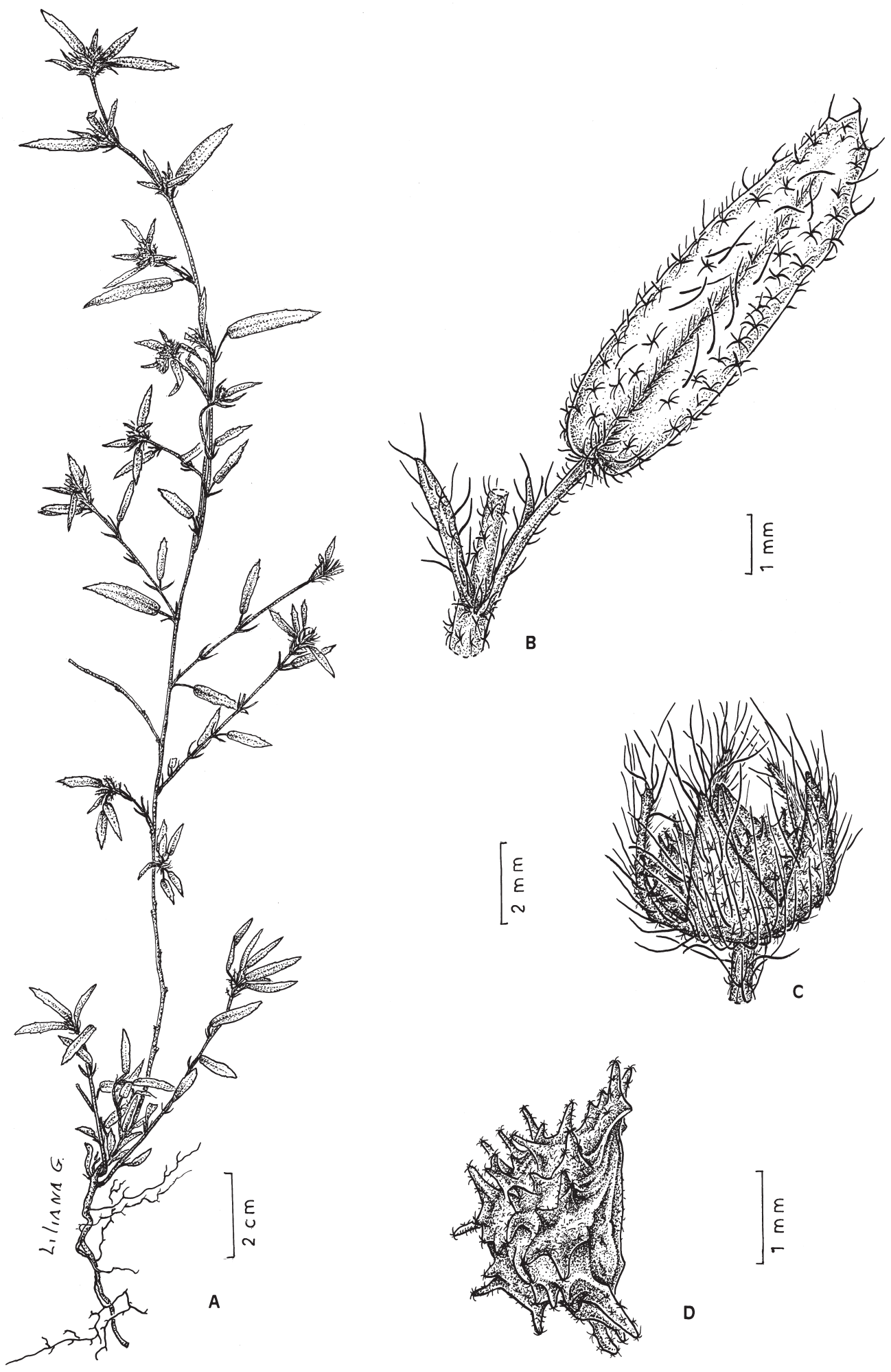

Fig. 9. Sida castanocarpa. A: planta. B: hoja. C: cáliz. D: mericarpo (Krapovickas 37845). 
Silva 517 (CTES, SP); 5 km S de Ibotirama, 19III-1982, Krapovickas \& al. 37896 (CEN, CTES); estrada Xique Xique-Santo Inacio, km 25, 30-VI1983, Coradin \& al. 6283 (CEN, CTES); Mun. Xique-Xique, Boa Vista, 14-III-1998, Hatschbach \& al. 67761 (CTES, MBM); Mun. Tucano. Distrito de Caldas do Jorro, Parque das Água, 2-III1992, Carvalho \& Hind 3870 (CEPEC, CTES) Inhambupe, 14-II-1983, Pinto 37/83 (CTES) 15 km W de Joazeiro, 8-IV-1967, Krapovickas 12930 (CTES). Ceará: Estaçâo Ecológica, Aiuaba, 30IV-1981, Martins \& Cesar 10259 (CTES, EAC); ídem, 22-III-1984, Nunes 12398 (CTES, EAC); Parambu, Faz. Pau Preto, 23-V-1982, Nunes 11495 (CTES, EAC). Goiás: Mun. Campos Belos, estrada para Pouso Alto, $18 \mathrm{~km}$ a direita da Usina Mosquito, 26-IV-2001, Fonseca \& al. 2624 (CTES, IBGE). Maranhâo: $10 \mathrm{~km}$ E de Carolina,170 m, 7²3'S 4722’W, 13-III-1982, Krapovickas \& al. 37854 (CEN, CTES); mun. Barâo do Grajaú, Barâo de Grajaú, rio Parnaiba, 645’S 43ํW, 7-IV-1983, Krapovickas \& al. 38749 (C, CEN, CTES, F, G, IPA, LIL); Pernambuco, Petrolina, margem do Rio Sâo Francisco, 26-I-1958, Heringer 5874 (CTES). Piauí: Bom Jesus, BR-135, 4-IV-1983, Krapovickas \& al. 38741 (CEN, CTES, HAS , UC); 3 km W de Oeiras, BR-230, 7²'S 428'W, 200 m, 8-IV-1093, Krapovickas \& al. 38759 (CEN, CTES, WIS); mun. Campo Maior, Fazenda Sol Posto, 4³9'40"S, W42¹0’07", 21-IV1994, M.S. Bona Nascimento 122 (CTES), mun. Castelo do Piaú, Fazenda Cipó, 5¹9'S 41³3’W, 19-IV-1994, Bona Nascimento 208 (CTES); mun. Piripiri, Parque Nacional de Sete Cidades, 30-I-1981, Krapovickas y Cristóbal 37208 (CTES); Mun. Corrente, Branquinha, 438 m, 9-III-1994, Bona Nascimento 534 (CTES); Mun. São João do Piaui, Porfirio, 222 m, 14-IV-1994, Bona Nascimmmento 461 (CTES). Rio Grande do Norte: Est.Exp. Seridó, Cruzeta 20-III-1935, Xavier 358 (CTES, RBR).

Etimología: El nombre de la especie deriva del color castaño-rosado de los frutos.

\section{Sida caulorrhiza Krapov., sp. nov.}

Figs. 6, 10

Herba perennis, caulibus prostratis, radicibus tenuibus praesertim. Folia usque $15 \mathrm{~mm}$ longa et $10 \mathrm{~mm}$ lata, in dimidio superiore serrata inferius integerrima basi angustissime cordata, supra glabra, subtus tantum pilis stellatis supra nervos. Flores ad apicem ramulorum congestae. Petala $15 \mathrm{~mm}$ longa et $6 \mathrm{~mm}$ lata, lutea. Ovario 6-7 carpidiato. Carpidia $3 \mathrm{~mm}$ longa, biaristata, muricata.

Holotypus: Brasil, Goiás, Mun. Flores de Goiás, 4 km de Flores de Goiás, caminho para Rio dos Macacos, 500 m, 16-I-1997, W.L.Werneck, C.L. Cristóbal \& A. Krapovickas 930 (CEN, isotypi: CTES, G, K, LIL, MBM, MO, NY, SI).

Hierba perenne, rastrera, con tallos ca. 60 cm long., radicantes, cubiertos de pelos de 4 ramas, más o menos adpresos, glabros hacia la base. Estípulas dimorfas, una espatulada hasta $5 \mathrm{~mm}$ long. x $1 \mathrm{~mm}$ lat. y la otra lanceolada, algo más corta y más delgada, con ambas caras glabras y margen ciliado; en las cabezuelas las estípulas son iguales y delgadas. Pecíolo 5-6 mm long. dorso por lo común glabro o con pelos estrellados adpresos y con mechón de pelos en el ápice, margen ciliado. Lámina oblonga, levemente cordada, hasta 15 mm long. x $10 \mathrm{~mm}$ lat., margen dentado en la mitad o tercio superior; epifilo glabro, hipofilo glabro, solamente pocos pelos estrellados adpresos en los nervios principales. Flores sésiles en la unión de estípulas y pecíolo, agrupadas en cabezuelas apicales, paucifloras. Cáliz $6 \mathrm{~mm}$ long. con pelos estrellados adpresos y algunos multiradiados muy pequeños, dejan ver la epidermis, margen de los lóbulos largamente ciliados y cara interna pilosa. Pétalos $15 \mathrm{~mm}$ long. x $6 \mathrm{~mm}$ lat., completamente amarillos, uña glabra. Tubo estaminal $3 \mathrm{~mm}$ long., con pelos de 1 o 2 ramas. Estilos 6-7, sobrepasan al tubo estaminal, estigmas en cabezuela. Mericarpos 6-7, $3 \mathrm{~mm}$ long., incluidas las aristas 0,5 mm; trígonos, caras reticuladas; cara dorsal subglabra, con pocos pelos glandulares pedicelados, esparcidos; márgenes con prominencias con un pelo estrellado apical con radios algo retrorsos. Semilla solitaria, péndula, pilosa.

Distribución geográfica: Especie coleccio- 


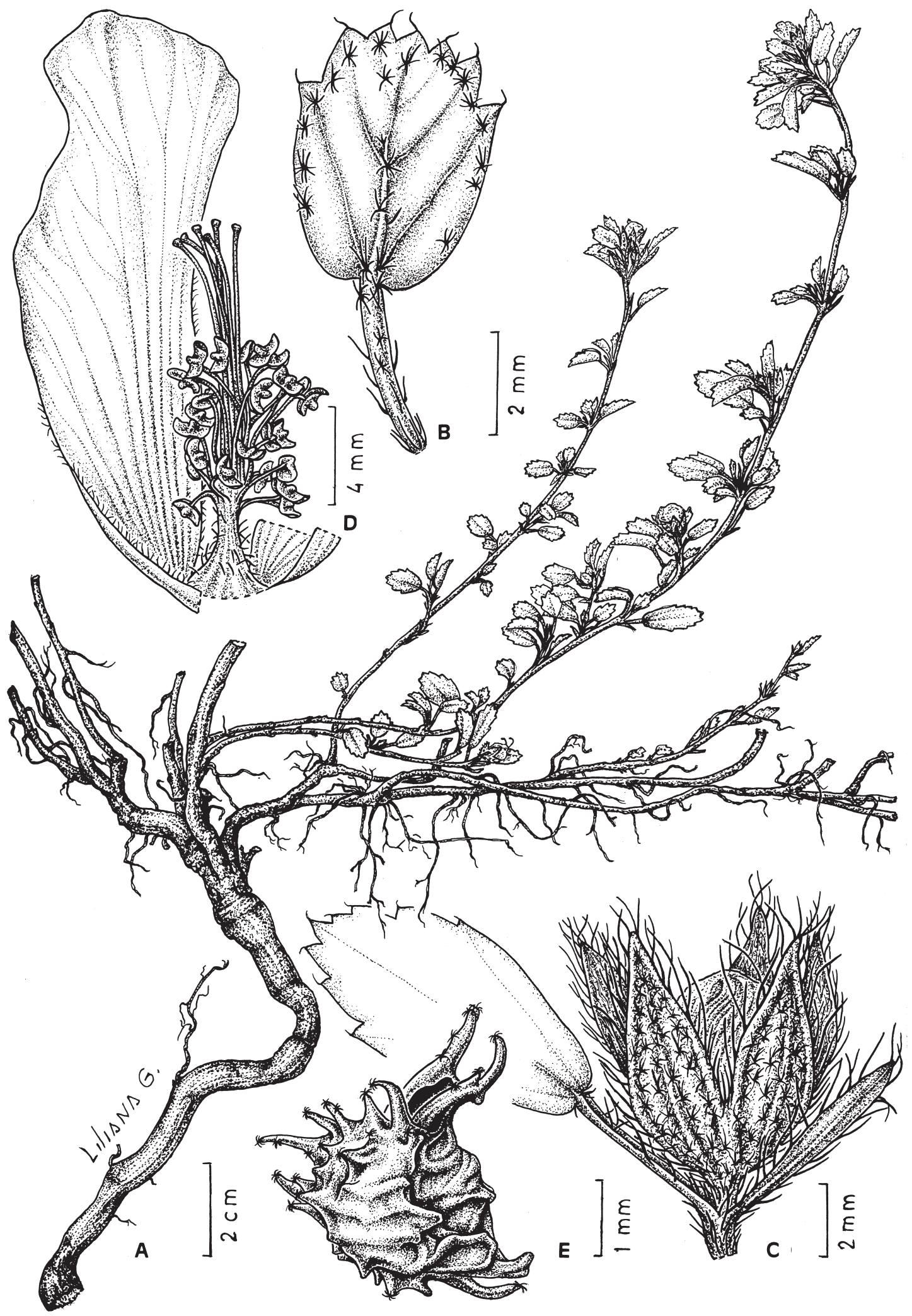

Fig. 10. Sida caulorrhiza. A: planta. B: hoja. C: cáliz. D: pétalo y tubo estaminal. E: mericarpo. 
nada en el E de Goiás, Brasil, en un área pequeña en la cuenca del río Paraná, en los municipios colindantes Flores de Goiás, Iaciara y Alvorada do Norte, entre $14^{\circ}$ y $15^{\circ}$ de latitud S.

Paratypi: BRASIL. Goiás: Mun. Alvorada do Norte, Rod. BR-020, rio Macacos, 9-I-1977, Hatschbach 39387 (CTES, MBM); 42 km NW de Iaciara, camino a Nova Roma, GO-446, 500 m, 3II-1990, Arbo \& al. 3547 (CTES, HRCB, K).

Etimología: El nombre de la especie hace referencia a las raices adventicias presentes en las ramas postradas.

\section{Sida centuriata Clement}

Fig. 5

Clement, I. D., Contr. Gray Herb. 180: 18-20. 1957. Typus: Paraguay, Concepción. zwischen río Apa und Río Aquidaban. Centurion, Okt., 1908, Fiebrig 4051 (holotypus GH, isotypi G!, SI!, W!).

Hierba perenne, rastrera. Tallo con pelos de 4 ramas y estrellados adpresos. Estípulas lineal-lanceoladas, 5-8 mm long., margen ciliado. Pecíolo 5-8 mm long., con pelos estrellados como en el tallo. Lámina 7-23 mm long. x 4-12 mm lat. ovada a elíptica, margen dentado, ambas caras con pelos estrellados, más abundantes en la cara inferior. Flores agrupadas en cabezuelas terminales; cada flor en la axila de una hoja con el pecíolo soldado con la base de las estípulas. Cáliz 5-7 mm long. con pelos estrellados pequeños y largas cilias en el margen y ápice los lóbulos. Corola rosada, pétalos 18-22 mm long., uña pilosa, cara externa con pelos muy pequeños hialinos, esparcidos. Tubo estaminal con pelos estrellados. Carpelos 7-8. Mericarpos reticulados, dorso con eminencias con un pelo estrellado de ramas retrorsas en el ápice, superficie con pelitos estrellados multiradiados y pelos glandulares. Semilla puberulenta.

Material adicional estudiado: BRASIL. Mato Grosso do Sul: $51 \mathrm{~km}$ E de Porto Murtinho, BR34, 12-VI-1968, Krapovickas 14437 (CTES, SP); mun. Aquidauana, $25 \mathrm{~km} \mathrm{~W}$ de Miranda, 20²0’S $56^{\circ} \mathrm{W}, 12-\mathrm{XII}-1976$, Krapovickas 29863 (CTES, MBM). PARAGUAY. Caaguazú: Km 117, ruta Asunción-Puerto Strossner, 3-II-1959, Gregory \& al. 9593 (LIL). Concepción: Puerto Risso, 17-I1955, Schulz 8860 (CTES); Puerto Risso, 17-I1955, Meyer \& Schulz 18704 (LIL); Estancia San Luis de la Sierra, 21-II-1990, Palacios 1907 (MO); Ruta 5, 27 km E de Col. Memby, 8-XI2001, Schinini \& al. 35547 (CTES).

\section{Sida ciliaris $\mathrm{L}$.}

Fig. 7

Linné, C., Syst. Pl. Ed. 10: 1145. 1759. Lectotypus, designado por Clement (1957): Jamaica, Browne s.n. (holotypus LINN-866.8!).(Fryxell, 1985: 81).

Sida tridentata Cav., Icon. 4: 6, t. 312, f.2. 1797. Typus: habitat in Sto. Domingo. Exemplar communicatum a D. Dupuy (holotypus MA 476294) (Monteiro, 1974: 134; Garilleti, 1993: 139).

Sida muricata Cav., Icon. 6: 78, t. 597, f. 2. 1801. Lectotypus, designado por Monteiro (1974): México, Ex Nova-Hispania prope Chalma [estado de México], Née dedit (holotypus MA!, foto F 29779!) (Monteiro, 1974: 133; Garilleti, 1993: 133).

Sida anomala var. mexicana Moric., Plantae americanae rariores: 11, tab. 9. 1830. Moric. Pl. nouv. Amér. 36-38, tab. 24, 1837. Typus: México, "circa Tampico de Tamaulipas. Berlandier Exsic. $N^{\circ} 66 "$ (G, isotypus P!).

Sida fasciculata Torrey \& A.Gray, Fl. N. Amer. 1: 231. 1838. Typus: U.S.A., Texas, Drummond 47 (holotypus NY!) [non Willd. ex Spreng. 1826].

Sida involucrata A. Rich., Hist. Phys. Cuba, Pl. vasc. 162. 1845. Lectotypus, designado por Clement (1957): Cuba, de la Sagra s.n., Herb. Richard 24 (P!, isotypus La Sagra ex Herb. de Franqueville P!). En la descripción original Richard menciona 5 carpelos pero en el lectotipo los frutos tienen 7 mericarpos.

Malvastrum linearifolium Buckley, Proc. Acad. Nat. Sci. Philadelphia 13: 449. 1862. Typus: U.S.A., N. Texas, May 1861, Buckley s.n. (holotypus $\mathrm{PH}$ ).

Sida ciliaris var. fasciculata A. Gray, Proc. 
Amer. Acad. 22: 294. 1887. Basado en S. fasciculata Torrey \& A.Gray [non Willd. ex Spreng. 1826].

Sida longistipula Merrill, Philip. J. Sci. 13, Bot. 30-31. 1918. Typus: Filipinas, Luzón, prov. Ilocos Norte, Bangui, II-III-1917, M. Ramos, Bur.Sci. 27445 (holotypus PNH?, isotypus P!).

Sida ciliaris microsp. "S. jaliscensis" Gand., Bull. Soc. Bot. France 71: 629. 1924. "Mexico, Jalisco, Pringle 4497" (P!).

Sida ciliaris microsp. "S. bellidifolia" Gand., Bull. Soc. Bot. France 71: 629, 1924. "Antillae, S. Croix, Hansen".

Sida ciliaris microsp. "S. microtricha" Gand., Bull. Soc. Bot. France 71: 629. 1924. "St. Thomas, Eggers 194".

Sida ciliaris microsp. "S. ononidifolia" Gand., Bull. Soc. Bot. France 71: 629. 1924. "St. Thomas, Eggers 194”.

Sida ciliaris var. mexicana (Moric.) Shinners., Field \& Lab. 21: 94. 1953.

Sida ciliaris var. involucrata (A.Rich.) Clement, Contr. Gray Herb. 180: 25. 1957.

Pseudomalachra ciliaris (L.) Monteiro, Portugal. Acta Biol. B, 12: 133. 1974. comb. illeg. (basado en Pseudomalachra, nom. illeg., Art. 32.3 ICBN).

Sida bellidifolia Gand. ex Fryxell, in Howard, Fl. Lesser Antilles 5: 248. 1989. pro syn.

Sida microtricha Gand. ex Fryxell, in Howard, Fl. Lesser Antilles 5: 248. 1989. pro syn.

Sida ononidifolia Gand. ex Fryxell, in Howard, Fl. Lesser Antilles 5: 248. 1989. pro syn.

Sida jaliscensis Gand. ex Fryxell, Syst. Bot. Monographs 25: 386. 1989. pro syn.

Malva minor supina betonicae folio, flore coccineo \&c. Sloane, Cat. Pl. Jamaica: 96. 1696 \& Voy. Jamaica 1: 217, t. 137, f. 2. 1707.

Malva minima supina \&c. Browne, Civ. Nat. Hist. Jamaica: 282. 1756.

Hierba erecta o postrada. Tallo con pelos estrellados adpresos de 4-6 ramas, los de 4 ramas con 2 antrorsas y 2 retrorsas. Estípulas lineales a lanceoladas, 4-8 mm long., margen ciliado. Pecíolo 4-8 mm long., acanalado, dorso con pelos estrellados adpresos, margen ciliado. Lámina angosto-elíptica, 3-5 veces más larga que ancha, por lo común 10-20 mm long. x 3-4 mm lat., en el tipo 8-11 x 5-6 mm, margen levemente dentado en el tercio supe- rior, haz glabro, envés con pelos estrellados adpresos. Flores agrupadas en cabezuelas terminales. Pedicelos breves. Cáliz $6 \mathrm{~mm}$ long. Pétalos 5-11 mm long., con la uña glabra. Tubo estaminal con pelos simples. Mericarpos $2 \mathrm{~mm}$ long., con protuberancias con un pelo estrellado apical, con los radios reflexos, superficie con pelos glandulares punctiformes. Semilla cubierta de pelos estrellados de ramas onduladas. Cromosomas $2 n=16$.

Material adicional estudiado: USA. Florida: Long Key, 29-I-1892, Simpson 472 (SI,US); Monroe Co., Big Pine Key, 26-II-1951, Killip 40927 (LP,US). Texas: Karnes Co. 1 mi. N of Cestohown, 15-X-1953, Johnson 1377 (CAS); 6 mi. NW of Kenedy, 13-X-1953, Johnson 1063 (CAS); Lavaca Co., 6 miles SE of Hallettsville, 11VI-1988, Fryxell 4961 (CTES); 30 miles N of Victoria, 4-VIII-1976, Fryxell 2755 (CTES); Refugio Co., 1,6 mi NE of Refugio, 14-VII-1981, Hill 10476 (CTES); 8,5 mi. NE of Refugio, 20VII-1981, Hill 10575 (CTES). MÉXICO. Oaxaca: El Camarón, 710 m, 18-XII-1972, Krapovickas \& Cristóbal 23582 (CTES). Puebla: Tecomatlan, 3000 feet, 12-IX-1968, Fryxell 762 (CTES). Veracruz: Plan del Río, 250 m, 25-VII1974, Ventura 10389 (CTES,MEXU); Plan del Río, 16-VII-1975, Ventura 11674 (CTES,MEXU). Yucatán: Chichén Itzá, 15-XII-1972, Krapovickas \& Cristóbal 23547 (CTES). VIRGIN ISLANDS. St. Thomas (Ind. occ.) 1880, Eggers 194 (LIL). VENEZUELA. DF: Arboretum de la Escuela de Biología, 15-VI-1981, Castillo 1139 (CTES) Caracas, Jardín Botánico, 24-VI-1978, Liesner 5379 (CTES, MO); Catia la Mar, 5 m, 10XI-1988, Ramírez 2630 (CTES). Falcón: carretera Falcón-Zulia, entre los ríos Borojó y Matícora, 25-IV-1978, Wingfield 5681 (CTES); Coro, 2-II-1978, Wingfield 5007 (CTES). Miranda: Arboretum, 22-IX-1983, Ramírez 894 (CTES). Sucre: 20 km NW of Cariaco, V-1981, Liesner \& González 11934 (CTES, MO); Parque Nacional Península de Paria, Macuro, 11-I-1984, Flores \& al. 442 (CTES, PORT). Zulia: Jardín Botánico de Maracaibo, 27-VII-1977, Bunting 5282 (CTES). ECUADOR. Guayas: Salinas, 7IV-1939, Asplund 5619 (LIL). PERÚ. Tumbes: Algarrobal, 20-30 m, 30-V-1957, Ferreyra 12328 (LIL). BOLIVIA. Beni: 8,8 km E de Trinidad, 16- 
I-2005, Seijo \& al. 3482 (CTES); Trinidad, 9-IV1979, Krapovickas \& Schinini 34649 (CTES); preov. Ballivian, Espìritu, 200 m, 2-X-1979, Beck 2617 (CTES, LPB), San Borja, 12-IV-1979, Krapovickas \& Schinini 34862 (CTES). Chuquisaca: Serrano, 2200 m, II-1949, Cárdenas 4115 (LIL); Padilla, 2179 m, 8-III-1981, Beck 6276 (CTES, LPB); Sucre, 3000 m, 7-III-1981, Beck 6207 (CTES, LPB); 6 km NW de Zudañez, 2399 m, 3-II-2004, Solis Neffa \& al. 1410 (CTES).

Santa Cruz: Puerto Pailas, 40 km E de Santa Cruz, 11-V-1977, Krapovickas \& Schinini 32449 (CTES); 22 km E de Santa Cruz, 293 m, 21-I2004, Solis Neffa \& al. 1065 (CTES); 56 km W de San José, 403 m, 29-I-2004, Solis Neffa \& al. 1308 (CTES); 32 km NW de San Ramón, 245 m, Solis Neffa \& al. 1085 (CTES); San José, 300 m, 25-IV1980, Krapovickas \& Schinini 36512 (CTES); 2 km W de San José, 300 m, 25-IV-1980, Krapovickas \& Schinini 36533 (CTES); Estancia San Miguelito, 200 km NE de Santa Cruz, 300 m, 6-IV-1995, Fuentes 641 (CTES, USZ); 29,2 km S de San Rafael, 1-II-2005, Solis Neffa \& al. 1765 (CTES). Tarija: Tarija, 1700 m, 12-II-1929, Zelada 18 (LIL); Carapari, 13-II-1980, Coro \& Rojas 1583 (CTES); Entre Ríos, 1330 m, 21-V1971, Krapovickas \& al. 19070 (CTES);prov. Arce, Río Negro, 14-II-1960, Meyer \& al. 20721

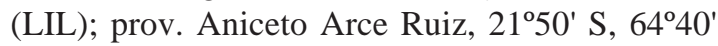
W, 2000 m, Beck \& al. 26179 (CTES, LPB). PARAGUAY. Alto Paraguay: Lagerenza, río Timane, 19-V-2003, Pérez de Molas \& Navarro 9031 (CTES, PY); Mayor Pedro Lagerenza, 5-IV1978, Schinini \& Bordas 15055 (CTES). Boquerón: 17 km NW de Fortín Teniente E. Ochoa, 12V-1994, Krapovickas \& al. 45283 (CTES); Fortín Tte. Montanía, 15-V-1981, Krapovickas \& al. 37444 (CTES, IPA); 29 km SE de Nueva Asunción, 13-V-1994, Krapovickas \& al. 45355 (CTES); Rio Verde, 4 km S de Lolita, 27-II-1991, Vanni \& al. 2417 (CTES); Mcal. Estigarribia, 20VI-1980, Schmeda 120 (CTES). FILIPINAS. Luzon: Ilocos Norte, Burgos, VII-1918, M. Ramos, Bur.Sci. 32704 (P).

Obs. 1: Según Muñoz Garmendia (1992, pág. 339) Chalma, la localidad tipo de $S$. muricata, se encuentra en el estado de México. Menciona parte del diario de viaje de Nee, donde dice: "julio 18/agosto 24, 1791", "Jalatlalco o Chalatlalco, camino de Méjico a
Chalma, a vista de Toluca" y "Real de Ocuila, puente de Ocuila (camino a Chalma)".

Obs. 2: Borssum Waalkes (1966: 179) señaló como tipo de S. longistipula Merrill el ejemplar Bur.Sc. 32704, sin embargo el mismo Merrill (1918) señaló como tipo al Bur.Sc.27445.

Obs. 3: En el lectotipo de Sida ciliaris, las hojas bien desarrolladas miden $8 \times 6,10 \times 6$, 11 x 5, 11 x 6 mm, son obtusas, sólo dentadas en el ápice. En todo el material estudiado aquí las hojas tienen 3-4 mm lat., y corresponderían con el tipo de Sida muricata Cav.

Obs. 4: Fawcett \& Rendle (1926: 115) observaron que el material de Jamaica y del Caribe tenían hojas con el epifilo glabro mientras que en ejemplares sudamericanos encontraron que la cara superior tienen pelos simples.

\section{Sida Cristobaliana Krapov., sp. nov.}

Fig. 5, 11

Herba prostrata, caulibus ad apicem adscendentibus, radiscibus simplicibus ad basis praesertim. Folia elliptica usque ad $28 \mathrm{~mm}$ longa et $14 \mathrm{~mm}$ lata, supra medium serrata, basi integerrima, supra stellato pilosa vel glabra, infra dense stellato pilosa. Inflorescencia capitata, multiflora. Petala 7-13 mm longa. Tubus stamineum $2 \mathrm{~mm}$ metiens. Ovario 7 carpidiato. Carpidia $4 \mathrm{~mm}$ longa, muricata, aristae $1 \mathrm{~mm}$ longae.

Holotypus: Paraguay. Presidente Hayes. Isla Poí, 22²8'S, 5940’W, 16-IV-1994, A. Krapovickas, C.L. Cristóbal \& A. Schinini 45489 (CTES, isotypi FCQ, G, MO, NY, SI).

Hierba postrada, con pequeñas raíces adventicias en la base de las ramas. Tallos con pelos estrellados de 4 a 6 ramas, más o menos adpresos. Estípulas en el tallo dimorfas, una lanceolada, ca. $6 \mathrm{~mm}$ long. x 1-1,5 mm lat. y la otra lineal, en las cabezuelas son todas lineales, hasta $12 \mathrm{~mm}$ long., con el margen ciliado. Pecíolo 5-7 mm long., dorso cubierto de pelos estrellados, cara superior glabra, 


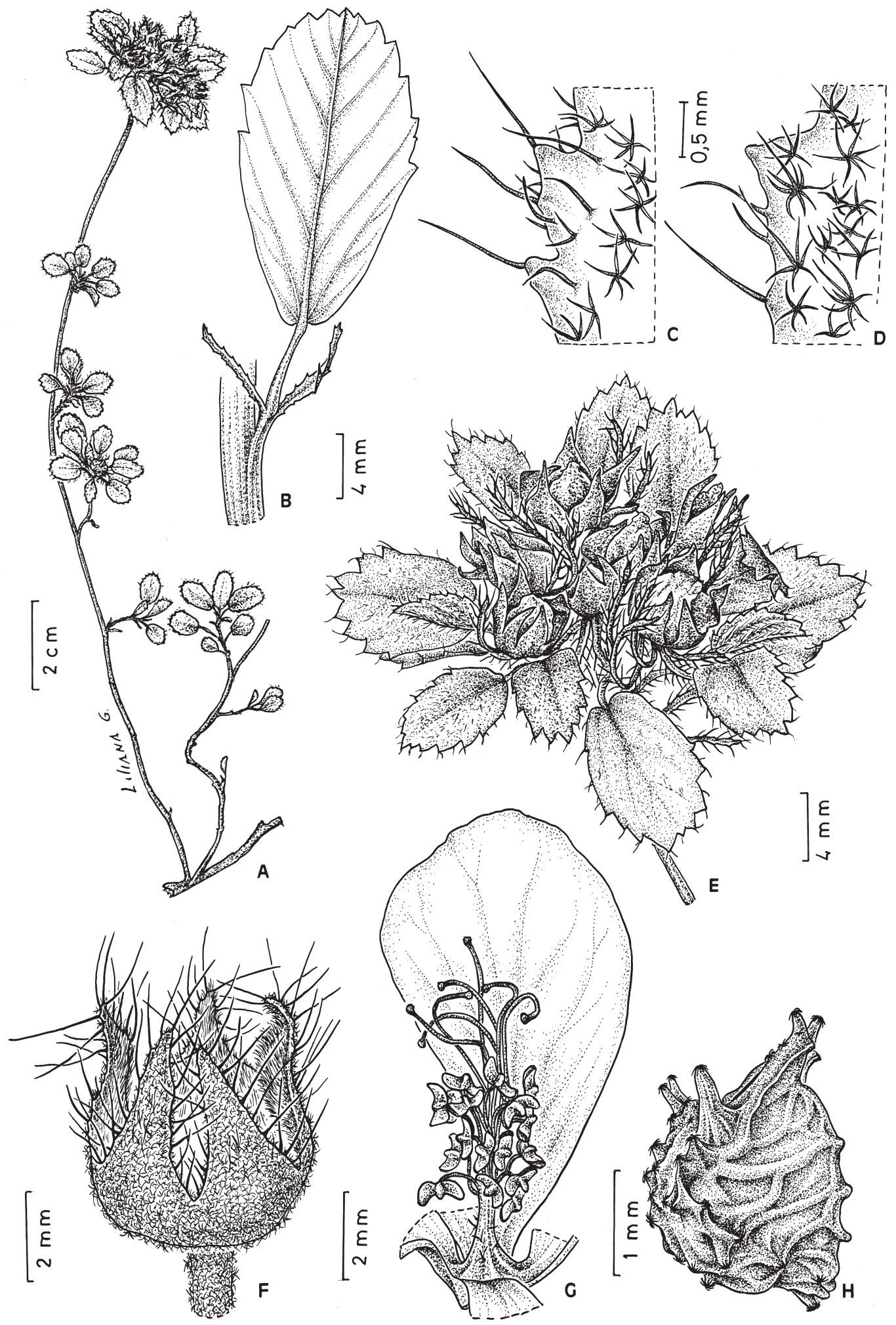

Fig. 11. Sida Cristobaliana. A: rama. B: hoja. C: epifilo. D: hipofilo. E: cabezuela apical. F: cáliz. G: pétalo y tubo estaminal. H: mericarpo (Krapovickas 45489). 
margen ciliado. Lámina elíptica, hasta $28 \mathrm{~mm}$ long. x 14 mm lat., por lo común 15-20 mm x 8-10 mm, margen con $1 / 2$ a 2/3 dentado, epifilo cubierto de pelos estrellados y con frecuencia pelos simples, largos, entremezclados, a veces glabro; hipofilo con pelos estrellados, adpresos, densos. Flores solitarias, subsésiles en la unión de pecíolo y estípulas, agrupadas en cabezuelas multifloras apicales, pecíolo y estípulas con setas de base cónica persistente; pedúnculo 1-4 mm long. Cáliz $5 \mathrm{~mm}$ long., totalmente cubierto de pelos estrellados pequeños y con largos pelos simples más abundantes en los lóbulos, cara interna de los lóbulos pilosa. Pétalos 7-8 mm long. (hasta $13 \mathrm{~mm}$, Peredo s.n.). Tubo estaminal $2 \mathrm{~mm}$ long., con pelos simples. Carpelos 7, Mericarpos $5 \mathrm{~mm}$ long., incluidas las aristas apicales, $1 \mathrm{~mm}$ long., caras reticuladas, cara dorsal con prominencias agudas, mayores hacia el margen, con un pelo estrellado de ramas retrorsas, superficie con pelos glandulares punctiformes. Semilla solitaria, péndula, pilosa. Cromosomas $2 \mathrm{n}=32$.

Distribución geográfica: Especie encontrada solamente en el NW del Chaco paraguayo y en el este de Bolivia, donde vive en campos abiertos con suelo arenoso, suelto y en médanos consolidados.

Paratypi: BOLIVIA. Santa Cruz: Prov. Chiquitos, Roboré, 6-II-1958, Krapovickas 9138 (LIL); Tapera, 15-II-1958, Krapovickas 9454 (LIL); Santiago, 600 m, 23-IV-1980, Krapovickas \& Schinini 36480 (CTES); San José de Chiquitos, 27-I-2004, Solís Neffa \& al. 1287 (CTES); 56 km W de San José, 403 m, 29-I-2004, Solís Neffa \& al. 1306 (CTES); 89 km S de Roboré, camino a Fortín Ravelo, 290 m, 6-II-2005, Solís Neffa \& al. 1897 (CTES); Prov. Cordillera, La Cuesta, 380 m, 20-II1946, Peredo s.n. (CTES, LIL); Cabezas, 420 m, 21-I-1945, Peredo 20 (LIL); Prov. Guarayos, 37 km S de Ascención de Guarayos, camino a San Ramón, 245 m, 17-I-2005, Seijo \& al. 3510 (CTES); Prov. Ñuflo de Chávez, RF 0, km 180, río San Julián, 26-V-1998, Rua \& Lavia 393 (CTES); San Ramón, 274 m, 21-I-2004, Solis Neffa \& al. 1081 (CTES); 20 km N de San Javier, 31-III-2006, Dematteis \& al. 2010 (CTES); Prov.del Sara, Rio
Perdiz, 450 m, 28-VIII-1916, Steinbach 2694 (LIL); Prov. Sandoval, San Matías, 170 m, 18-IV1980, Krapovickas \& Schinini 36215 (CTES, $\mathrm{MICH}$ ); Prov. Velasco, $12 \mathrm{~km}$ S de San Rafael, 336 m, 26-I-2004, Solís Neffa \& al. 1258 (CTES); $31 \mathrm{~km}$ S de San Rafael, 302 m, 26-I-2004, Solis Neffa \& al. 1264 (CTES); 63 km S de San Rafael, 327 m, 4-IV-2006, Dematteis \& al. 2224 (CTES). PARAGUAY. Alto Paraguay: Madrejón, Parque Nacional Defensores del Chaco. Tyto a Palmar de Las Islas, 20-VII-1997, Mereles 6659 (CTES, FCQ); Estancia San Miguel (Palmar de las Islas), 220 m, 5-III-1989, Ramella y Mereles 2486 (CTES, FCQ, G); Médanos, 20³3'S 62º' $\mathrm{W}, 23-$ V-2003, Pérez de Molas \& Navarro 9327 (CTES, PY). Boquerón: Nueva Asunción 3-IV-1978, Schinini 14825 (CTES); Nueva Asunción, 13-V1004, Krapovickas \& al. 45397 (CTES); 7 km NW de Nueva Asunción, 12-XII-1987, Schinini y Palacios 25687 (CTES); 8 km NW de Nueva Asunción, 14-V-1994, Krapovickas \& al. 45401 (CTES, FCQ, G, LIL, MO, NY); 25 km SE de Nueva Asunción, 13.V-1994, Krapovickas \& al. 45364 (CTES): Parque Médanos del Chaco, 300 m, 12-XII-1998, Zardini \& al. 49607 (CTES, MO).

Etimología: El nombre de la especie está dedicado a la Dra. Carmen Lelia Cristóbal, compañera de viajes de colección botánica.

\section{Sida cuneifolia Roxb.}

Roxburgh, W., Fl. Ind, ed. Carey 3: 170-1. 1832 [non Sida cuneifolia A.Gray, 1850].

Melochia truncata Willd., Sp. pl. 3: 601-2. 1801. Typus: "India Orientalis" (holotypus B-W 12342, microficha!).

Riedleia truncata (Willd.) DC., Prodr. 1:491. 1824.

Hermania alnifolia Wall. 1829, Numer. List. 1196, K., nomen nudum [non Sida ulmifolia L., 1753].

Dictyocarpus truncatus (Willd.) Wight, Madras J. Lit. Sci. 5: 310, tab. 19. 1837.

Sida truncata (Willd.) Masters ex Chiov., Fl. somala 2:21. 1932 [non Sida truncata Cav., 1785].

Material estudiado: SRI LANKA. Wilpattu National Park, Near Eerige Ara confluence with Modegagama Aris. 30 m, 29-XII-1968, Fosberg \& 
al. 50781 (CTES, US); Anuradhapura District, 5-6 mi. n.e. Anuradhapura, 9-XII-1970, Fosberg \& Balakrishnan 53435 (CTES, US).

\section{Sida Dureana Krapov., sp. nov.}

Fig. 12, 13

Herba prostrata caulibus ad basim lignescens radicibus tenuibus praesentibus. Folia oblonga 12 $\mathrm{mm}$ longa et 6-7 mm lata, usque ad $20 \mathrm{~mm} \times 10$ $\mathrm{mm}$, dimidio superiore serrata, supra pilis longiusculis inspersa, subtus pilis satellatis tomentosa. Flores ad apicem ramulorum congestae. Petala rosea, $15 \mathrm{~mm}$ longa. Tubus stamineus pilosus. Ovario 6-7 carpidiato. Carpidia $2 \mathrm{~mm}$ longa et $2 \mathrm{~mm}$ lata, muricata.

Holotypus: Paraguay. Amambay. Col. San An-

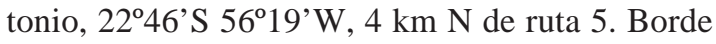
de bosque secundario, suelo alterado, arenoso. Decumbente. Flores rosadas. Abundante en el suelo quemado, 8-XI-2001, A. Schinini, J. Molero, R.Duré \& M. Quintana 35556 (PY, isotypus CTES).

Hierba rastrera o decumbente, con raíces adventicias en la base de las ramas. Tallo con pelos de 4 ramas adpresos. Hojas de las ramas con estípulas libres, las de las inflorescencias apicales con las estípulas soldadas a la base del pecíolo. Estípulas subespatuladas, $5 \mathrm{~mm}$ long. x $1 \mathrm{~mm}$ lat., margen con cilias $2 \mathrm{~mm}$ long., haz con pocos pelos simples y envés con pelos estrellados adpresos. Pecíolo 5-7 mm long., margen ciliado. Lámina oblonga, $12 \mathrm{~mm}$ long $x$ 6-7 mm lat. y hasta $20 \mathrm{~mm}$ long. x $10 \mathrm{~mm}$ lat., margen dentado en la mitad superior, haz con pelos simples $1 \mathrm{~mm}$ long., envés con pelos estrellados adpresos. Flores agrupadas en cabezuelas apicales, con pedúnculo 1-2 mm long. en la parte libre de las estípulas. Cáliz $6 \mathrm{~mm}$ long., lóbulos triangulares, $4 \mathrm{~mm}$ long. $\mathrm{x} 2 \mathrm{~mm}$ lat., cara externa con pelos estrellados adpresos y con cilias $1 \mathrm{~mm}$ long. en el extremo de los lóbulos, cara interna de los lóbulos con pelos simples adpresos. Corola rosada. Pétalos 10-15 mm long., uña pilosa. Tubo estaminal 2,5 mm long, con pelos simples, hialinos. Estilos mucho más lar- gos que los estambres. Mericarpos 6-7, reticulados, $2 \mathrm{~mm}$ long. $\mathrm{x} 2 \mathrm{~mm}$ lat. y 2 aristas apicales breves; caras laterales translúcidas, dorso con protuberancias terminadas con un gloquidio y pelos glandulares con pedicelo breve. Semilla cubierta de pelos sedosos pardos.

Paratypi: BOLIVIA. Santa Cruz: Chiquitos, 9 km W de Las Taperas, 426 m, 28-I-2004, Solis Neffa \& al. 1297 (CTES, G, MO). BRASIL. Mato Grosso do Sul: Mun. Anastacio, Palmeira, 17XII-1970, Hatschbach 23727 (CTES,MBM). Mun. Bonito, Rodovia Bonito ao trevo com a Rod. BR-267, 11-III-2003, Hatschbach \& al 74512 (CTES,MBM). Mun. Miranda, Faz. Esmeralda, 45 km S de Guaicurus, 11-XII-1978, Krapovickas 29853 (CTES). PARAgUAY. Alto Paraguay: Base aérea Adrian Jara, 15-V-2003, Pérez de Molas \& Navarro 8716 (CTES, PY). Amambay: 9 km SE de Bella Vista, ayo. Apa Mi, 20-X-1981, Schinini 21396 (CTES); 10 km S de Bella Vista, ayo. Apa-mi, 24-II-1994, Krapovickas \& Cristóbal 45002 (CTES, FCQ); 3 km S de Bella Vista, 25-II-1994, Krapovickas \& Cristóbal 45026 (CTES); 19 km SW de Bella Vista, camino a San Carlos, 11-I-2003, Schinini \& al. 36394 (CTES); 5 $\mathrm{km} \mathrm{N}$ de ruta 5, camino a Bella Vista, 26-II-1994, Krapovickas \& Cristóbal 45048 (CTES); Ruta 3, 27 km SE de Bella Vista, 16-XII-1999, Ferrucci \& al. 1562 (CTES). Concepción: Col. San Antonio, 19 km E dse Conceoción, 8-XI-2001, Schinini \& al. 35556 (CTES); Ruta 5, 3, 5 km E de Concepción, 28-II-1994, Krapovickas \& Cristóbal 45058 (CTES).

Obs.: Por la presencia de pelos simples en el haz de la hoja, Sida Dureana se aproxima a S. anomala, S. Brittonii y S. plumosa. Por los mericarpos con prominencias coronadas con un gloquidio se asemeja a $S$. anomala, de la que se diferencia por su porte más rastrero, por sus hojas que pueden llegar hasta $10 \mathrm{~mm}$ de latitud y por los pelos glandulares pedicelados de los mericarpos. Sida Brittonii tiene mericarpos cubiertos de pelos glandulares de 4 células y carece de gloquidios. Sida plumosa tiene mericarpos menores, glabros y con protuberancias apenas marcadas, sin gloquidios.

Etimología: El nombre de la especie está 


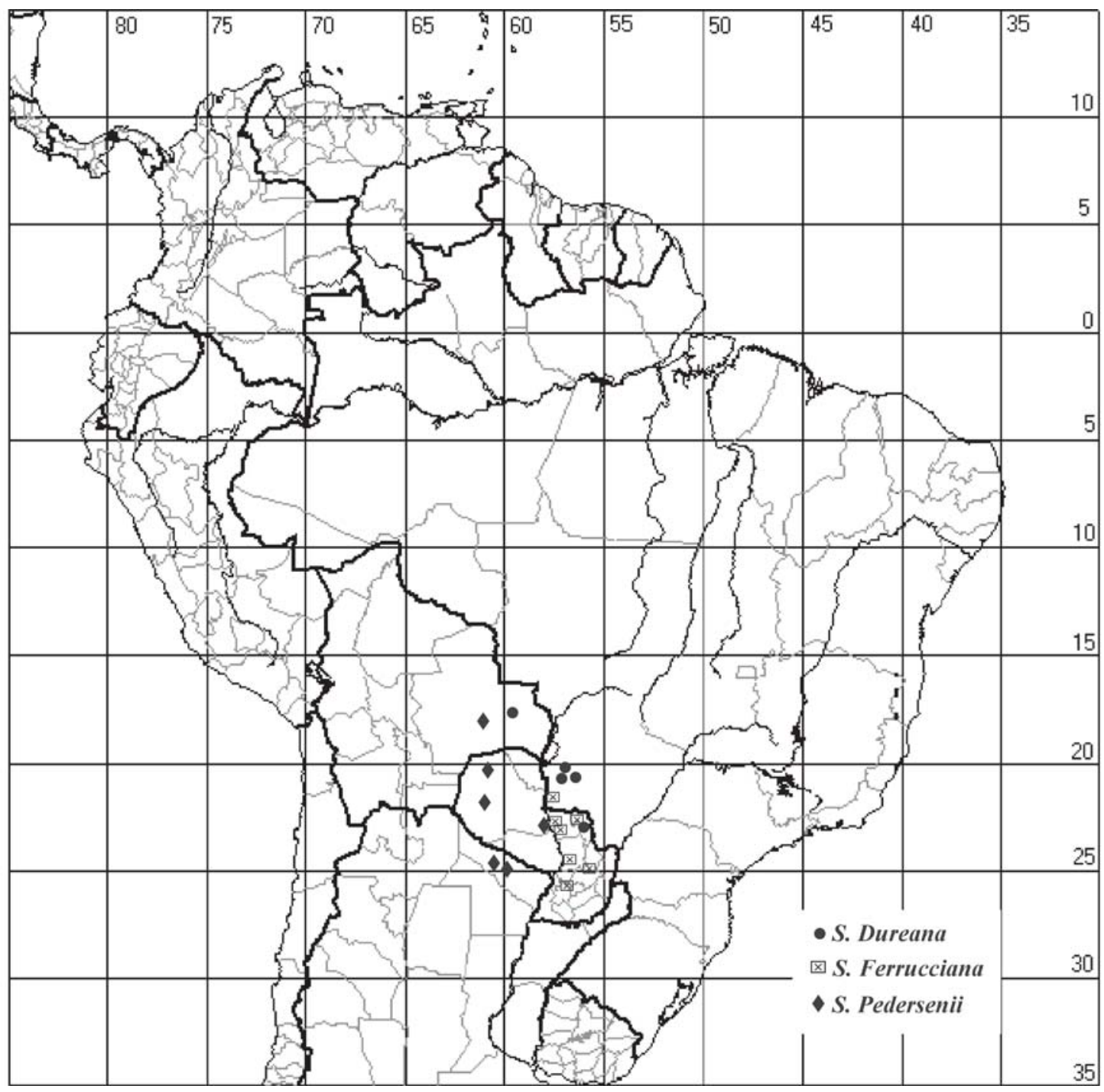

Fig. 12. Distribución geográfica de especies de Sida secc.

Malacroideae.

dedicado a Reinilda Duré, botánica del herbario PY de Asunción, Paraguay.

\section{Sida Ferrucciana Krapov., sp. nov.}

Fig. 12, 14 A-F

Herba prostrata. Folia anguste elliptica, 10-13 $\mathrm{mm}$ longa et 2-2,5 $\mathrm{mm}$ lata, margine supra 1/3 serrata, supra et infra stellato tomentosa. Flores ad apicem ramulorum congestae. Petala $13 \mathrm{~mm}$ longa. Tubus stamineus pilosus. Ovario 7 carpidiato. Carpidia muricata, biaristata, lateraliter grosse reticulata.

Holotypus: Paraguay. Amambay, $15 \mathrm{~km}$ W de Bella Vista, camino a San Carlos, 15-XII-1999, M. S. Ferrucci, A. Schinini \& M. Dematteis 1534 (CTES, isotypi FCQ, G, NY, SI).

Hierba decumbente 10-20 cm alt. Tallo con pelos estrellados de 4-6 ramas, adpresos. Estípulas lanceoladas a lineales, 2-6 mm long., glabras o con pelos estrellados adpresos y margen ciliado, en las cabezuelas soldadas a la base del pecíolo. Pecíolo 3-5 mm long., subglabro o con pocos pelos estrellados 


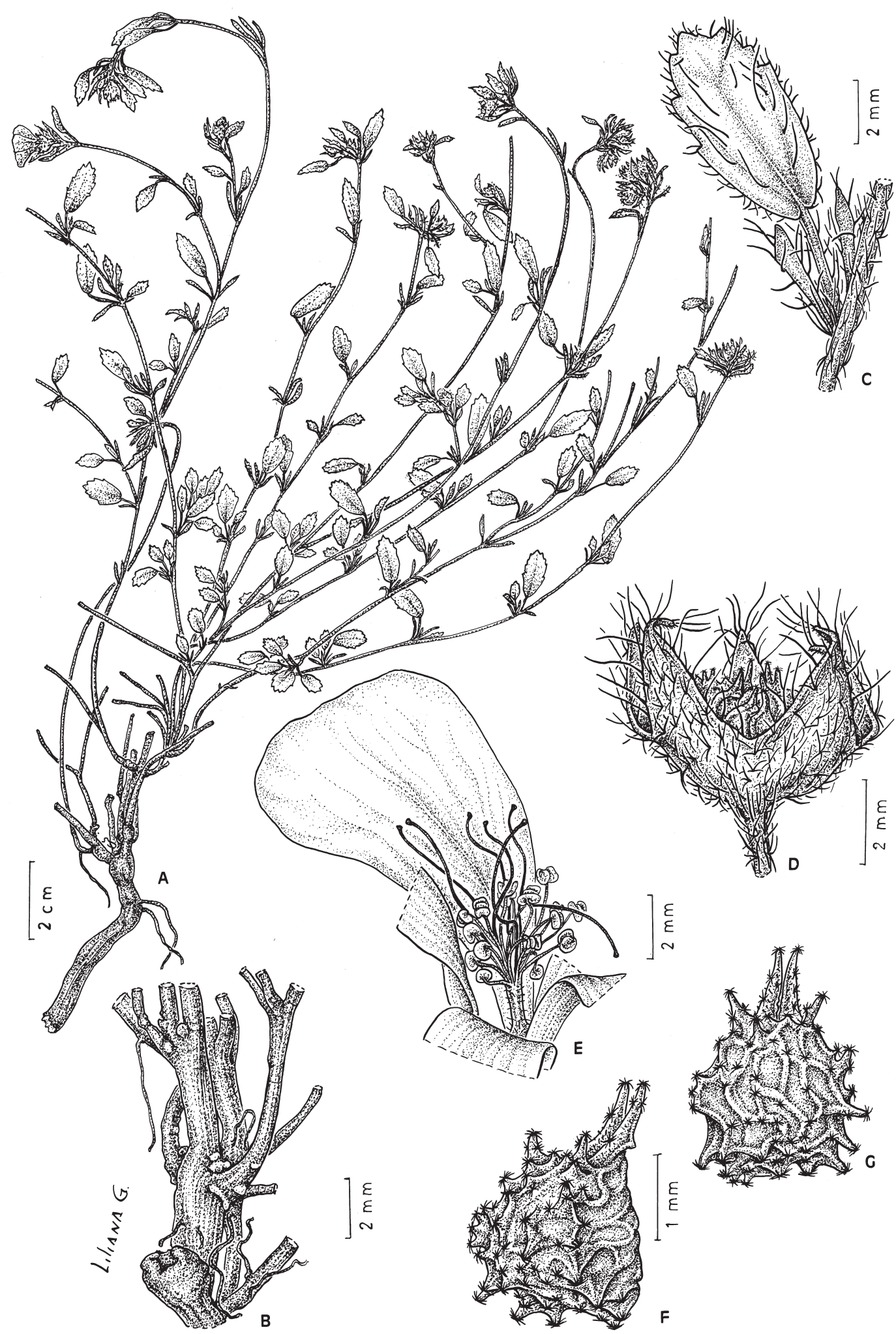

Fig. 13. Sida Dureana. A: planta. B: raíces adventicias. C: hoja. D: cáliz. E: pétalo y tubo estaminal. F: mericarpo, vista lateral. G: mericarpo, vista dorsal (Schinini 35556). 

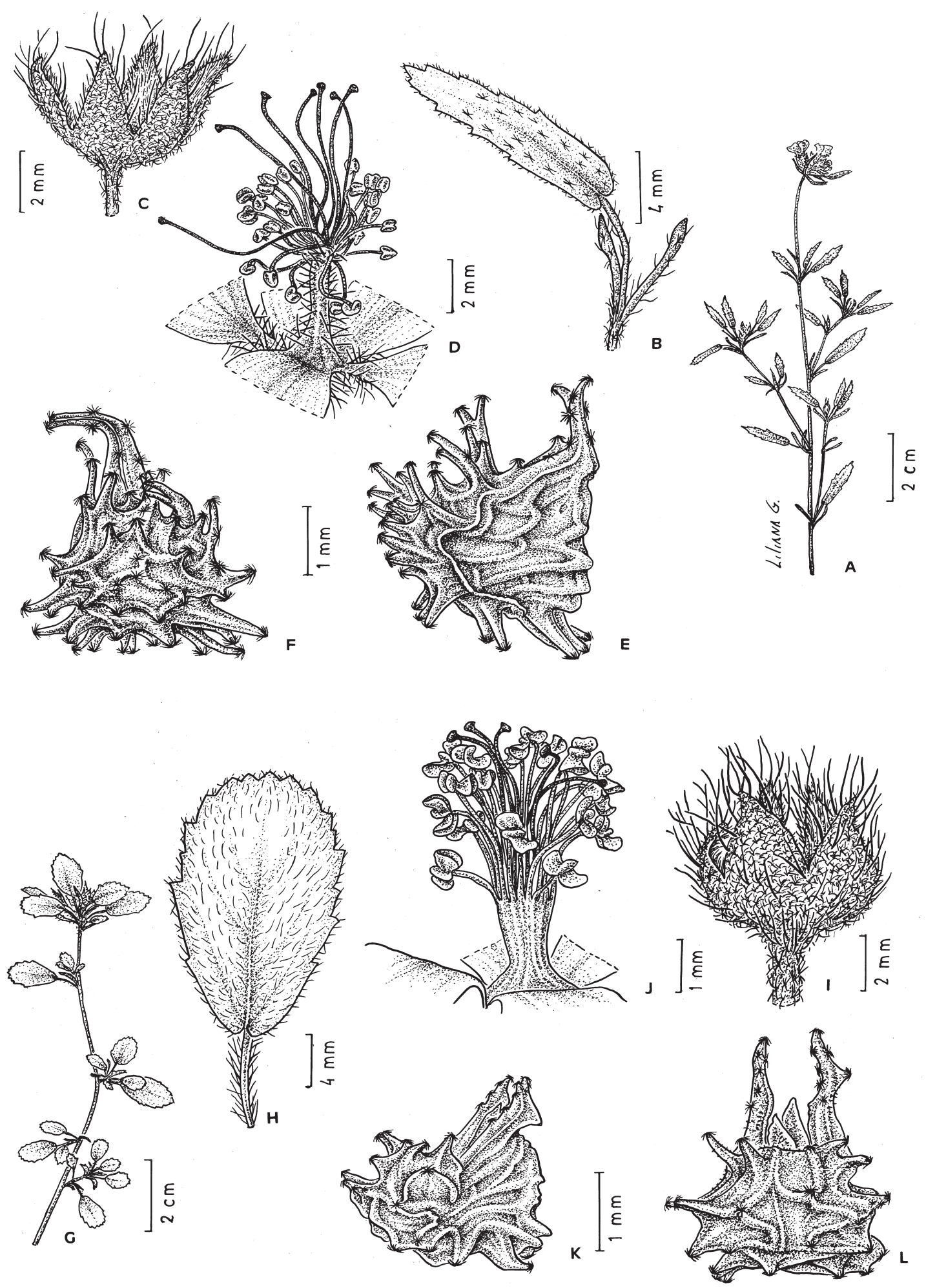

Fig. 14. Sida Ferrucciana (A-F) y Sida Harleyi (G-L). A: rama. B: hoja. C: cáliz. D: tubo estaminal. E: mericarpo, vista lateral. F: mericarpo, vista dorsal (A-F, Eliceche 107). G: rama. H. hoja. I: cáliz. J: tubo estaminal. K: mericarpo, vista lateral. L: mericarpo, vista dorsal (G-L, Hatschbach \& al. 65071). 
adpresos y margen con pocas cilias. Lámina angosto-elíptica, 10-13 mm long. x 2-3 mm lat., margen dentado en el tercio superior, ambas caras con pelos estrellados adpresos, más densos en el envés. Flores agrupadas en cabezuelas terminales. Pedicelo 1-2 mm long. Cáliz 4-5 mm long., lóbulos triangulares $3 \mathrm{~mm}$ long. x $2 \mathrm{~mm}$ lat., cubierto uniformemente de pelos estrellados muy pequeños, margen de los lóbulos ciliados, cara interna de los lóbulos con pelos simples o de dos ramas, largos, hacia los márgenes. Corola rosada o salmón, más oscura en la base. Pétalos 13 mm long., uña pilosa y margen de la porción oscura con pelos simples. Tubo estaminal $3 \mathrm{~mm}$ long., con pelos simples o de 2 ramas. Carpelos 7 . Mericarpos $3 \mathrm{~mm}$ long. y aristas apicales 1 mm long., reticulados, dorso con prominencias hasta $1 \mathrm{~mm}$ long., terminadas con un pelo estrellado antrorso, y con pelos glandulares pedicelados esparcidos. Semilla con pelos estrellados de ramas onduladas.

Paratypi: BRASIL. Mato Grosso do Sul: mun. Porto Murtinho, Faz. Florida, 2048'S, 57¹4'W, 90 m, 5-III-1994, Pott 6828 (CPAP, CTES). PARAGUAY. Amambay: declivibus Sierra de Amambay, I-1908, Hassler 10751 (LIL); Bella Vista Norte, 12-I-2000, Zardini \& al. 53508 (CTES, MO). Caaguazú: Ruta 2, km 117, 3-II1959, Gregory \& al. 9593 (CTES, LIL); Cecilio Báez, 8-I-2003, Schinini \& Quintana 36321 (CTES); 14 km W de Coronel Oviedo, 18-X-1994, Krapovickas \& al. 45716 (CTES, FCQ, G, K, MO). Concepción: entre Paso Horqueta y Concepción, 26-II-1968, Krapovickas \& al. 14236 (BAA, CTES, SI); Ruta 5, 3,5 km E de Concepción, 26-II-1994, Krapovickas \& Cristóbal 45056 (CTES); 19 km N de Concepción, camino a Loreto, 140 m, 17-II-1983, Vanni \& al. 364 (CTES); Loreto, 18-XI-1993, Zardini \& al. 37338 (CTES, MO); Estancia San Rafael, 140 km E de Concepción, 20-III-1991, Eliceche 107 (CTES, FCQ). Guayrá: Villa Rica, Jörgensen 4287 (LIL). Paraguarí: Paraguarí, 3-II-1966, Krapovickas \& al. 12364 (CTES). San Pedro: distr. Lima, Estancia Carumbé, 23-XI-1069, Pedersen 9367 (C, CTES).

Etimología: El nombre de esta especie está dedicado a María Silvia Ferrucci, botánica del
IBONE, Corrientes, Argentina.

\section{Sida Harleyi Krapov., sp. nov.}

Fig. 6, 14 G-L

Herba prostrata. Folia anguste obovata, usque ad $20 \mathrm{~mm}$ longa et $10 \mathrm{~mm}$ lata, margine 2/3 superiore serrata, supra pilis longiusculis inspersa, infra pilis stellatis tomentosa. Flores ad apicem ramulorum congestae. Petala ca. $10 \mathrm{~mm}$ longa. Tubus stamineus glaber. Ovario 6-8 carpidiato. Carpidia $2 \mathrm{~mm}$ longa, submutica, muricata, reticulata.

Holotypus: Brasil. Bahia. Mun. Pico das Almas, Pico das Almas, 1120 m, 6-XI-1988, R.M. Harley \& al. 25938 (SPF, isotypi CTES, K).

Hierba postrada, ramas tendidas hasta 80 cm long., los extremos ca. $20 \mathrm{~cm}$ ascendentes. Tallo con pelos estrellados de 4 o más ramas, no adpresos. Estípulas dimorfas, una lineal y la otra espatulada, 5-9 mm long., envés con pelos estrellados y margen ciliado. Pecíolo 5$9 \mathrm{~mm}$ long., con indumento similar al del tallo. Lámina angosto-obovada, hasta $20 \mathrm{~mm}$ long. x $10 \mathrm{~mm}$ lat., margen dentado en los 2/3 superiores, haz con pelos simples 1-2 mm long. y a veces también pelos estrellados, envés con pelos estrellados adpresos. Flores agrupadas en cabezuelas apicales. Pedicelo 2 $\mathrm{mm}$ long. Cáliz $6 \mathrm{~mm}$ long., lóbulos triangulares $3 \mathrm{~mm}$ long. $\mathrm{x} 2 \mathrm{~mm}$ lat. con pelos estrellados pequeños y cilias 1-2 mm long. en el ápice y en el margen de los lóbulos; en la base del cáliz hay un mechón de pelos simples, largos; cara interna de los lóbulos con pelos simples largos, adpresos. Corola rosado-amarillenta. Pétalos ca. 10 mm long., uña con pocos pelos. Tubo estaminal glabro. Carpelos 6-8. Mericarpos reticulados, $2 \mathrm{~mm}$ long., submúticos, dorso con prominencias terminadas en un pelo estrellado de ramas reflexas muy pequeño y con pelos glandulares breves. Semilla con pelos estrellados ferrugíneos de ramas onduladas.

Paratypi: BRASIL. Bahia: $65 \mathrm{~km} \mathrm{~S}$ de N. Senhora dos Milagres, BR-116, 30-I-1963, 
Krapovickas 10093 (CTES); Mun. Boquira, BR122, km 54, trevo para Santa Rita, Hatschbach \& al. 65071 (CTES, MBM); Mun. Jacobina, 12 km NW de Jacobina, 600 m, 17-I-1997, Arbo \& al. 7339 (CTES, CEPEC); Mun. Morro do Chapeu, Morro do Chapeu, 1050 m, 28-XI-1992, Arbo \& al. 5411 (CTES, SPF); Mun. Mucugê, Barriguda, 9-IV-1992, Hatschbach \& al. 56897 (CTES, MBM); Mun. Rio de Contas,;3 kn N of Rio de Contas, 980 m, 21-I-1974, Harley 15367 (CTES, K); Feira de Santana , Noblick 2674 (CTES, HUEFS); Mun. Caetite, 6 km S de Caetite, 1090 m, 20-XI-1992, Arbo \& al. 5638 (CTES, SPF); Itaberaba, 18-VI-1981, Ferreira 160 (CTES).

Minas Gerais: rio Pandeiros, $52 \mathrm{~km} \mathrm{~W}$ of Januaria, 520 m, 21-IV-1973, Anderson 9265 (LIL); Mun. Mato Verde, São João do Bonito, 17-IV-1996, Hatschbach \& al. 64948 (CTES, MBM); Mun. Pirapora, Pirapora, 11-I-1989, Krapovickas \& Cristóbal 42862 (BAA, CTES, FCQ, HUEFS, MEXU, SP, SPF, U, US); Conceição de Ibitipoca, 1100-1200 m, 16-IX1970, D. Sucre 7098 (RB).

Obs.: La floración del ejemplar Anderson \& al. 9265 fue observada por Fryxell (1975: 3) (sub $S$. ciliaris), quién señaló que sus flores se abrían al amanecer y permanecían abiertas hasta el mediodía. En cambio, S. meridiana, que vive junto a este ejemplar, abría sus flores poco después del mediodía y se cerraban 2 o 3 horas después.

Etimología: El nombre de esta especie está dedicado a Raymond Harley, bo tánico del herbario HUEFS, Feira de Santana, Bahia, Brasil.

\section{Sida meridiana Fryxell}

Figs. 1 C, 3 C-D, 7

Fryxell, P., Sida 6(1): 1-4, fig. 1. 1975. Typus: Brasil, Minas Gerais, Rio Pandeiros ca. 52 km W of Januaria, 520 m, 21-IV-1973, Anderson \& al. 9271 (holotypus UB!, isotypi AAU!, NY).

Hierba rastrera, con raíces adventicias en la base de las ramas. Tallo con pelos estrellados 0,5-2 mm long., no adpresos. Estípulas solda- das a la base del pecíolo, 4-8 mm long., espatuladas a lineales; en las ramas son dimorfas, una espatulada, a veces con un diente en el margen, y la otra lineal, en las cabezuelas terminales, todas son lineales, ambas caras con pelos estrellados y margen ciliado. Pecíolo 4-6 mm long., margenes ciliados. Lámina elíptica, hasta 15-18 mm long. x 10-13 mm lat., margen dentado en la mitad superior. ambas caras con pelos estrellados, algo mayores en el haz, con ramas hasta $2 \mathrm{~mm}$ long. Flores axilares hacia el ápice de las ramas y en cabezuelas paucifloras apicales. pedicelos 2-3 mm long. Cáliz 5-6 mm long., lóbulos triangulares, 3-4 mm long., cara externa con pelos estrellados pequeños, margen de los lóbulos ciliado y cara interna con pelos simples, $2 \mathrm{~mm}$ long. abundantes. Pétalos blancos, amarillentos en la base, ca. $10 \mathrm{~mm}$ long., cara externa con pelitos glandulares dispersos, uña glabra. Tubo estaminal glabro, ca. $3 \mathrm{~mm}$ long. Mericarpos 5-6, $3 \mathrm{~mm}$ long. +2 aristas $1 \mathrm{~mm}$ long., reticulados, pocas prominencias con gloquidios y el dorso con pelos glandulares de 4 células, esparcidas. Semilla péndula, con pelos estrellados de ramas onduladas, esparcidos.

Distribución geográfica: Vive en la cuenca del río São Francisco en Bahia y el norte de Minas Geraes, en Brasil.

Material adicional estudiado: BRASIL. Bahia: 10 km NW de Caetité, 20-I-1963, Krapovickas 10081 (CTES, NY, SP); Ibotirama, 19-III-1982, Krapovickas \& al. 37933 (CEN, CTES).

\section{Sida Monteiroi Krapov.}

Fig. 1 B, 2 C-D, 7

Krapovickas, A., in Burkart \& Bacigalupo (ed.), Flora Ilustrada de Entre Ríos, IV: 314, fig. 152. 2005. Typus: Argentina, Chaco, dep. San Fernando, ruta 11, acceso a Colonia Benítez, 26-IV-1970, Krapovickas 15785 (holotypus CTES, isotypi: G, K, LIL, NY, SI, SP).

Sida ciliaris L. f. flava Kuntze, Rev. gen. pl.3(2): 22. 1898. Typus: Concepcion de Paraguay, IX-92 (holotypus NY!). 
Iconografía: Rodrigo, 1944: 95-97, figs. 4 y 3(2) (sub. S. ciliaris).

Hemicriptófita, decumbente o erecta, 10-25 cm de altura. Tallos con pelos estrellados de 4 ramas, adpresos. En el tallo, estípulas lineales, 2-3 mm long., glabras o con una cilia apical; pecíolo 1-2 mm long., con cilias inconspicuas, 0,5 mm long., en el margen, o sin ellas. Lámina 5-11 mm long. x 2-4 mm lat., elíptica, con pocos dientes en la mitad superior, hojas de las inflorescencias apicales, algo mayores. Epifilo con pelos estrellados adpresos en las hojas jóvenes, en hojas adultas glabro, hipofilo con pelos estrellados adpresos. Flores solitarias, subsésiles, agrupadas en el ápice de las ramas. Cáliz $3 \mathrm{~mm}$ long., totalmente cubierto por pelos pequeños y con un mechón de pelos más largos en el ápice de los lóbulos Pétalos 4-7 mm x 1-3 mm, por lo común amarillos o anaranjados, también anaranjado-rosados. Tubo estaminal 2-4 mm long., con pocos pelos simples. Carpelos 5. Mericarpos 3 $\mathrm{mm}$ long. $\mathrm{y}$ aristas $0,5-1 \mathrm{~mm}$, pilosos, pelitos estrellados y pelos glandulares pedicelados, prominencias poco notables. Semilla péndula, $2 \mathrm{~mm}$ long. x $1 \mathrm{~mm}$ lat. con pelos punctiformes esparcidos. Cromosomas $2 n=16$.

Distribución geográfica: Especie chaqueña que vive en suelos arcillosos, pesados. Su área se extiende desde los $20^{\circ} \mathrm{S}$, en el norte del chaco paraguayo, hasta los $30^{\circ}$ en el extremo noroeste de la provincia de Entre Ríos y con una pequeña intrusión en Mato Grosso do Sul, en Porto Murtinho.

Material seleccionado estudiado: ARGENTINA. Chaco: Dep. Gral Donovan, Legua 40, XI1970, Insfran 587 (CTES); Dep. San Fernando, Resistencia, 21-VII-1947, Krapovickas 3500 (LIL); Cote-lai, 29-XII-1976, Schinini 13868 (CTES); 5 km W de Resistencia, 19-IV-1964, Krapovickas \& Cristóbal 11365 (CTES, SI); Basail, 12-III-1986, Pedersen 14540 (BAB, C, CTES, LIL); ruta nac. 11, km 1013, 21-X-1994, Lavia \& López 33 (CTES); María Sara, 23 km SW de Resistencia, 7-III-1980, Schinini 20039 (BAB, CTES); Dep. $1^{\circ}$ de Mayo, Colonia Benítez, X1931, Schulz 557 (CTES, LP); Colonia Benítez,
Palos Altos, V-1935, Schulz 2099 (CTES); Margarita Belén, río Iné, 2-XII-1946, Aguilar 971 (LIL); Colonia Benítez, 16-XII-2002, Schinini \& al. 36278 (CTES). Corrientes: Dep. Capital, Nueva Valencia, 4-X-1957, Pedersen 4647 (C, CTES). Dep. Empedrado, 6 km S de cruce rutas 5 y 6, 12II-1980, Carnevali 4199 (CTES). Dep. Esquina, 47 km W de Sauce, ruta 126, 23-X-1977, Ahumada \& al. 1407 (CTES); Colonia Libertador, ayo. Barrancas, 15-III-1975, Krapovickas \& al. 27838 (CTES); 26 km SE de Colonia Libertador, 12-III1975, Krapovickas \& al. 27429 (CTES, SI). Dep. Mburucuyá, El Descabezado, 11-XII-1967, Pedersen 8726 (C, CORD, CTES). Dep. San Cosme, Paso de la Patria, 20-II-1969, Krapovickas \& Cristóbal 14933 (CTES, NY); ídem 3-III-1972, Carnevali 2895 (CTES, MBM). Entre Ríos: Dep. La Paz, La Paz, 15-I-1960, Burkart \& Bacigalupo 21283 (LIL, SI). Formosa: dep. Formosa, Formosa, III-1918, Jorgensen 2312 (BA ,LIL, LP, RBR, SI); Mojón de Fierro, 25-III-1947, Reales 432 (LIL);ruta 81, 35 km W de Formosa, 20-II1996, Krapovickas \& Cristóbal 46536 (BAB, CTES) 59 km S de Clorinda, ruta 11, 13-III-1992, Fortunato \& al. 2668 (BAB, CTES). Dep. Matacos. G.N. , Ing Juarez, 27-II-1983, Arenas 2361 (CTES). Dep. Patiño, Comandante Fontana, 9-V-1969, Schulz 17018 (CTES); Estanislao del Campo, V-1970, Martínez Crovetto PM 80 (CTES); 16 km NW de Estanislao del Campo, 9IV-2004, Krapovickas \& al. 47907 (CTES); 21 km N de Pozo del Tigre, 21-II-1006, Krapovickas \& Cristóbal 46546 (BAB, CTES); 45 km N de Pozo del Tigre, 21-II-1996, Krapovickas \& Cristóbal 46548 (BAB, CORD, CTES, SI). Dep. Pilcomayo, Clorinda, 13-XII-1992, Krapovickas \& Cristóbal 44407 (CTES, BAB, NY); Est. Abatte, Pto. Ramos, 16-I-1949, Morel 6914 (CTES, LIL, MBM): Loma Porá, 20-XII-1946, Morel 1889 (LIL). Salta: Dep. Anta, Salar de San Francisco, 16-V-1959, Morello \& Cuezzo 1138 (LIL); Salta Forestal Sector II, 300m, 17-II-1988, Saravia Toledo 1597 (CTES). Dep. Rivadavia, 8 km E de Los Blancos, 8-IV-2004, Krapovickas \& al. 47905 (CTES); 8 km E de Los Blancos, ruta nac. 81, 8-V-1999, Krapovickas \& Seijo 47766 (CTES, G, LIL, NY, SI). Dep. San Martín, 12 km E de Hickmann, 2-IV1977, Krapovickas \& Schinini 30851 (CTES). Santa Fé: Dep. Gral Obligado, Reconquista, 3-XI1986, Blanchoud 2173 (CTES). BRASIL. Mato Grosso do Sul: Porto Murtinho, 11-VI-1968, 
Krapovickas 14430 (CTES). PARAGUAY. Alto Paraguay: Bahia Negra, 9-XI-1946, Rojas 13713 (CORD, CTES, FCQ, LIL, MO); Puerto Casado, XII-1916, Rojas 1934 (AS, CTES, RBR, SI); Pal-

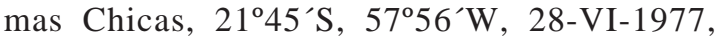
Krapovickas \& Schinini 32758 (CTES); Frente a Valle Mi, riacho Mosquito, 100 m, 17-X-2000, Kiesling \& al. 9710 (CTES, FCQ, G, SI); Estancia La Americana, ca. $280 \mathrm{~km}$ de Filadelfia, 16-IX1986, Molas y Vera 1040 (CTES, MO, PY); Cerro León, 9-II-2002, Zardini \& al. 58384 (CTES, MO). Concepción. Concepción, 18-V-1961, Krapovickas 10599 (LIL); ídem, 25-II-1968, Krapovickas \& al. 14199 (BAA, CTES, FCQ, G, $\mathrm{K}, \mathrm{LIL}, \mathrm{MO}, \mathrm{NY}$ ); entre Paso Horqueta y Concepción, 25-II-1968, Krapovickas \& al. 14232 (BAA, CTES); Concepción, aeropuerto, 28-II-1994, Krapovickas \& Cristóbal 45121 (CTES, G); San Lázaro, río Apa, 4-XI-2001, Zardini \& al. 57439 (CTES, MO); Tres Cerros, 200 m, 5-XI-2001, Zardini \& al. 57462 (CTES, MO). Paraguarí: Caañavé, Carapeguá, 25-III-1919, Rojas 3370 (AS, CTES). Presidente Hayes: Gran Chaco, Loma Clavel, 23 20' S, XI-1903, Hassler 2485 (LIL);

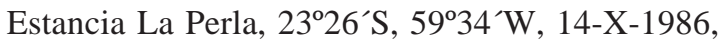
Pedersen 14626 (C, CTES); 5 km NW de Chaco-i, Ruta 12, 10-V-1974, Schinini 9217 (CTES); Puer-

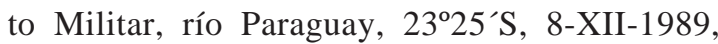
Vanni \& al. 1733 (CTES); Pto. Militar, XII-1989, Mereles 3508 (FCQ); estero Pirahu, 20 km SE de Pozo Colorado, ruta Transchaco, 10-V.1994, Krapovickas \& al. 45255 (CTES, FCQ, G, K, MBM, MO, SI); 9 km E de Pozo Colorado, 9-XI2001, Schinini \& al. 35614 (CTES).

Obs.: Esta especie figura como S. ciliaris L. en los herbarios y en la literatura (Rodrigo, 1944), pero la especie lineana, descripta para Jamaica, tiene hojas obovadas de 5-6 mm lat. con la cara superior glabra y frutos con 6-7 mericarpos, con pelos glandulares punctiformes. Sida Monteiroi se diferencia por sus hojas elípticas, 5-7 mm long. y $2 \mathrm{~mm}$ lat., con la cara superior con pelos estrellados adpresos en hojas jóvenes y luego glabra y frutos con 5 mericarpos con el dorso tomentoso, con pelos estrellados.

Etimología: El nombre de esta especie fue dedicado a Honorio da Costa Monteiro Filho (1900-1978), especialista en Malváceas, quién identificó algunos ejemplares (Rojas 1934 y Jorgensen 2312) como especie nueva.

\section{Sida paradoxa Rodrigo}

Fig. 5

Rodrigo, A. P., Notas Mus. La Plata Bot. 14: 105-109, fig. 1 y 2. 1937. Typus: Argentina Corrientes, Mercedes, arroyo Las Garzas, XI-1936, Rodrigo 605 (holotypus LP!).

Hierba perenne, subleñosa, 20 a $40 \mathrm{~cm}$ altura, con raíces leñosas, profundas. Hojas 5-8 reunidas en braquiblastos, con estípulas lanceoladas 5-7 mm long., lámina angosta, 4$11 \mathrm{~mm}$ long. x 1,5-3,5 mm lat., de base obtusa, con el ápice trunco, con tres dientes apicales, cara superior glabra y la inferior con pelos estrellados espaciados. Flores 4-5 agrupadas en el ápice de las ramas. Pedúnculos breves, 2-4 mm long. Cáliz $8 \mathrm{~mm}$ long., cubierto de pelitos estrellados blanquecinos y margen de los sépalos con cilias muy pequeñas. Pétalos rosado-amarillentos, $17 \mathrm{~mm}$ long. y $11 \mathrm{~mm}$ lat. Tubo estaminal glabro. Ovario 5-carpelar. Mericarpos biaristados, uniseminados, las aristas verticales cubiertas de pelitos blanquecinos y pelos glandulares pedicelados, el dorso y los costados rugosos y con prominencias poco notables en el dorso. Semilla con pelos muy pequeños. Cromosomas $2 n=32$ (Fernández, 1974, fig. 19).

Distribución geográfica: Vive en Corrientes y en Rio Grande do Sul (Brasil) en el Parque do Espinilho, en la Barra do Quaraí. Habita en lugares bajos, de suelo arcilloso en quebrachales o en bosques de Prosopis.

Material adicional estudiado: ARGENTINA. Corrientes: Dep. Bella Vista, Bella Vista, 19-XI2003, A. Cocucci \& al. 3061 (CORD,CTES); Dep. Berón de Astrada, Puerto Yahapé, 16-XII-1945, Ibarrola 3948 (CTES,LIL); Campo Yaguá Cuá, 22-IV-1060, Pedersen 5551 (CTES); Valencia, 46 km W de Itá Ibaté, 15-I-1977, Schinini 14020 (CTES); Dep. Concepción, Paso Pucú, 19-III1969, Pedersen 9075 (CTES); Dep. Curuzú Cuatiá, 45 km S de Curuzú Cuatyá, 7-X-1971, 
Carnevali 2659 (CTES); Dep. General Paz, Ruta 13, 5 km S de Ruta 5, 16-II-1995, Solís Neffa \& al. 217 (CTES); Lomas de Vallejos, 8-X-1945, Ibarrola 3446 (CTES,LIL); Lomas de Vallejos, 2I-1966, Krapovickas y Cristóbal 11858 (CTES, G, MEXU, P, SI, US); Dep. Itatí, Arrocera Rzepecki, 60 km E de Itatí, 28-II-1977, Ahumada \& al. 900 (CTES); Toro Jhú, 16-II-1983, Schinini y Carnevali 23255 (CTES); Scorza Cué, 16-II-1983, Carnevali 6069 (CTES); Dep. Mburucuyá, estancia Santa María, 13-III-1948, Pedersen 121 (C, CTES, US); íd.,1-XII-1983, Cowan 4079 (CORD, CTES); Dep. Mercedes, Yofre, 2-III-1945, Ibarrola 2720 (LIL); Mercedes, Estación Experimental INTA, 28-V-1968, Carnevali 1161 (CTES); Mercedes, 13-XI-1963, Royo Pallarés 1 (CTES); ea. Itá Caabó, 18-X-1961, Pedersen 6185 (CTES); co. Pajarito, 11 km S de Mercedes, 23-II1984, Tressens \& al. 2422 (CTES); Ruta 23, 20 km E de Mercedes, 20-X-1973, Schinini 7547 (CTES); Ruta 23 y rio Miriñay, 17-IX-1070, Schinini 18651 (CTES); Yofré, 4-IV-1994, Lavia \& al. 14 (CTES); Dep. Monte Caseros, arroyo Mocoretá, XI-1940, A. Castellanos s. n. (BA, LP); Dep. Paso de los Libres, Cabred, 26-I-1945, Ibarrola 2262 (LIL); ruta 127 y río Miriñay, 16-II1979, Schinini 17310 (CTES); ruta 127 y ayo. Ayuí, 17-II-1979, Schinini \& al. 17222 (CTES); Parada Pucheta, ruta 127, 17-II-1979, Ahumada 2522 (CTES), Dep. San Martín, estancia La Elisa, $12 \mathrm{~km}$ SE de C. Pellegrini, 22-II-1979, Krapovickas \& al. 29545 (CTES, G, MBM, MO, SI); Dep. San Miguel, Timbó Paso, 17-VII-1982, Carnevali 5722 (CTES). BRASIL. Rio Grande do Sul: Uruguaiana, Parque do Espinilho, 16-XI1984, Sobral \& al. 3418 (CTES,ICN); Barra do Quaraí, Parque do Espinilho, 10-XII-1986, Bueno 4889 (CTES,HAS).

\section{Sida Pedersenii Krapov., sp. nov.}

Figs. 1 D-F, 3 A-B, 4 C-D, 12, 15

Herba erecta, 20-30 cm alta. Folia anguste elliptica, usque ad $20 \mathrm{~mm}$ longa et 3-4 $\mathrm{mm}$ lata, tertia pars parce serrata vel integra, supra et infra pilis stellatis multiradiatis inspersa. Flores ad apicem ramiflorum congestae, capitulum pauciflorum formantes. Petala 7-8 mm longa et 3 $\mathrm{mm}$ lata. Tubus stamineus glaber. Ovario 5 carpidiato. Carpidia $4 \mathrm{~mm}$ longa, reticulata, pilosa, pilis stellatis, aristae $1 \mathrm{~mm}$ longae.

Holotypus: Paraguay. Alto Paraguay, Puerto Casado, Estancia "María Casilda", on almost bare ground between little thickets, soil whitish grey clay, 20-X-1956, T. M. Pedersen 4109 (CTES, isotypus $\mathrm{C}$ ).

Hierba erecta, 20-30 cm de altura. Toda la planta con pelos estrellados multiradiados, pequeños, amarillentos, no adpresos. Tallos con entrenudos 10-20 mm long., glabrescentes hacia la base. Estípulas lineales, $2 \mathrm{~mm}$ long. y hasta $5 \mathrm{~mm}$ en las cabezuelas, con pelos estrellados muy pequeños, por lo común sin cilias, salvo algunas pocas en las cabezuelas; pecíolo 2-5 mm long. estrellado tomentoso, cilias a veces presentes en las cabezuelas. Lámina angosto-elíptica, hasta $20 \mathrm{~mm}$ long, x 3-4 mm lat., margen liso o apenas dentado en el tercio superior, ápice agudo, ambas caras tomentosas con pelos multiradiados pequeños. Flor solitaria, sésil o con pedúnculo 1-3 $\mathrm{mm}$, asentado en la unión de pecíolo y estípulas. Este conjunto agrupado en cabezuelas terminales paucifloras, a veces también flores axilares solitarias. Cáliz 5 mm long, totalmente cubierto de pelos estrellados, lóbulos con los márgenes y el nervio medio engrosados, cara interna de los lóbulos pilosa. Pétalos 7-8 mm long. x $3 \mathrm{~mm}$ lat. Tubo estaminal glabro o con pelos simples. Carpelos 5. Mericarpos $5 \mathrm{~mm}$ long, incluida las aristas $1 \mathrm{~mm}$ long., dorso reticulado, piloso, pelitos estrellados y pelos glandulares pedicelados, y márgenes con crestas breves con pelo apical retrorso inconspicuo, caras laterales reticuladas. Semilla solitaria, péndula, con pelos diminutos esparcidos.

Distribución geográfica: Especie chaqueña que vive en el Chaco paraguayo y en el centro oeste de la provincia de Formosa en Argentina. También fue coleccionada en el Sur del departamento de Santa Cruz, en Bolivia. Prefiere suelos bajos, claros, pelados, arcillosos y algo salobres.

Paratypi: ARGENTINA. Formosa: dep. Patiño, Las Lomitas, predio de la Estación de Fe- 


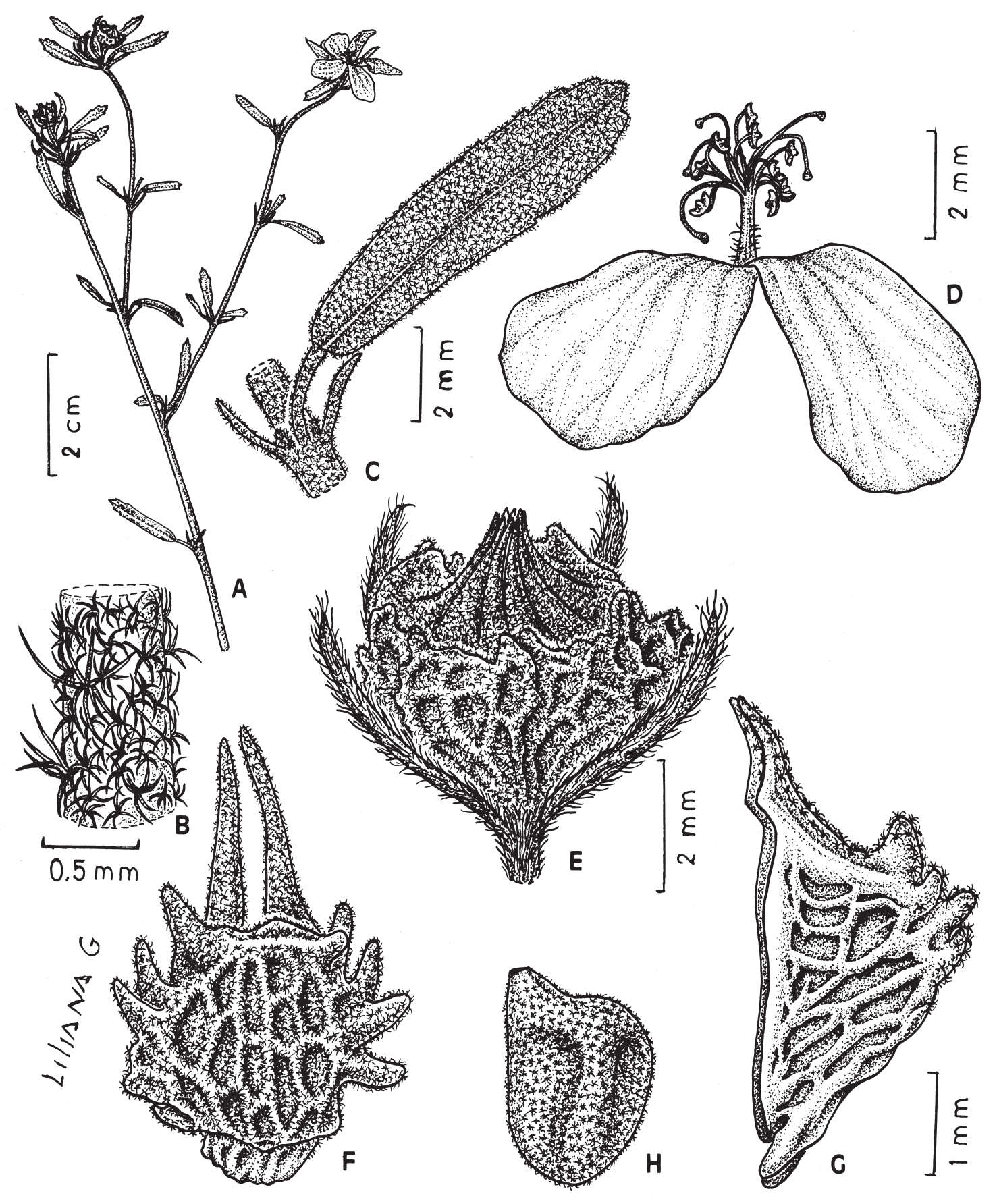

Fig. 15. Sida Pedersenii. A: rama. B: tallo. C: hoja. D: pétalos y tubo estaminal. E: fruto. F: mericarpo, vista dorsal. G: mericarpo, vista lateral. H: semilla (Pedersen 4109). 
rrocarril, frente a la calle Moreno, bajo salobre, 6V-1998, Krapovickas, Schinini \& Seijo 47234 (BAB, CTES, G, MO, NY);. Las Lomitas, 5-III2001, Schinini \& al. 35277 (CTES); 3-5 km SW de Las Lomitas, ruta 81, 13/14-XI-1984, Schinini y Bernardello 23113 (CTES).Dep. Matacos, Ing. Juárez, 13-VII-1947, Castellanos s.n. (LIL 328915); Ing. G. Juarez, 7-III-2001, Schinini \& al. 35345 (BAB, CTES, G). BOLIVIA. Santa Cruz: Prov. Cordillera, entre Tucavaca y San José, 4-II2005, Solís Neffa \& al. 1839 (CTES). PARAGUAY. Alto Paraguay: Parque Nac. Defensores del Chaco, 1 km E de Madrejón, 135 m, 6-V-2003, Pérez de MolaS \& Navarro 7854 (CTES, PY); Parque Nacional Defensores del Chaco, Madrejón Area, 20³3'S 59²8'W, 15-II-1999, Zardini \& al. 50397 CTES, MO); Boquerón, Tte. Montañía (km 220), 15-V-1981, Krapovickas \& al. 37479 (CTES); Filadelfia, 3-XII-1992, August 171 (CTES).

Obs.: Sida Pedersenii se diferencia por carecer de pelos de 4 ramas adpresos en los tallos, muy comunes en el resto de la sección, excepto $S$. meridiana. En estas dos especies, los pelos son multiradiados, grandes en S. meridiana y diminutos en $S$. Pedersenii.

Etimología: Dedico esta especie a Troels Myndel Pedersen (1916-2000), quién coleccionó el ejemplar tipo.

\section{Sida plumosa Cav.}

Fig. 7

Cavanilles, A. J., Diss. 1: 7, t. 12, f. 4. 1785. Typus: "Brasilia: observata a D. Commerson.V.S.communicatam à D. Thouin". Bresil Com[merson]. T [houin] (holotypus MA, foto F 29778!, Isotipo P-Ju 12265!) (Monteiro, 1974: 133-134; Garilleti, 1993: 135).

Malachra plumosa (Cav.) Desr., Lam. Encycl. 3: 363. 1791.

Sida fulva A.St.-Hil., Fl. Bras. Mer. 1: 176-177. 1827. Typus: "in arenosis maritimis prope Manguinhos, ad limites provinciarum Rio de Janeiro et Spiritus Sancti. Septembri florebat". (holotypus St. Hilaire B2/240 P!).

Malva ononidifolia Mart. ex Colla, Herb. pedem. 1: 386. 1833. Typus: Campus, Brasilia. Martius, 1827 (holotypus TO!).

Sida ciliaris L. var. fulva (A. St.-Hil.) K. Schum. Mart., Fl. Bras. 12 (3): 284. 1891.

Pseudomalachra plumosa (Cav.) Monteiro, Portugal. Acta Biol. B, 12: 133. 1974. comb. illeg. (basado en Pseudomalachra nom. illeg., Art. 32.3 ICBN).

Hierba postrada, con raíces adventicias. Tallo con pelos de 4 ramas, adpresos. Estípulas 5 mm long., margen ciliado; en las ramas estípulas desiguales, una lanceolada $0,5 \mathrm{~mm}$ lat. y la otra oblonga, $2 \mathrm{~mm}$ lat.; en las cabezuelas todas las estípulas son lanceoladas y están soldadas a la base del pecíolo. Pecíolo 3-6 mm long. Lámina oblonga hasta $18 \mathrm{~mm}$ long. x $7 \mathrm{~mm}$ lat., margen dentado sólo en eltercio superior; haz glabro o con algunos pelos simples $1 \mathrm{~mm}$ long., envés con pelos estrellados adpresos. Flores sésiles, agrupadas en cabezuelas terminales multifloras. Cáliz 5 mm long., lóbulos triangulares $3 \mathrm{~mm}$ long. $\mathrm{x}$ 1,5 mm lat., glabro en la base y con pelos simples 1-2 mm long. en los lóbulos. Corola amarilla o rosada. Pétalos 7-8 mm long. Tubo estaminal $3 \mathrm{~mm}$ long., glabro o con pocos pelos simples. Mericarpos 5-7, reticulados, glabros, 1,5 mm long. x 1,5 mm lat., márgenes del dorso con prominencias poco marcadas, sin gloquidios. Semilla pilosa. Cromosomas $2 n=32$.

Distribución geográfica: Vive tanto en la restinga de la costa Atlántica como en campos rupestres de Minas Gerais y de Bahía y principalmente en la caatinga, hasta los 1300 m de altura

Material adicional estudiado: BRASIL. Bahía: 10 km NW de Caetité, 20-I-1963, Krapovickas 10075 (CTES, LIL, MBM, MEXU); Porto Seguro, 20-VIII-1961, Duarte 5972 (CTES); Gov. Mangabeira, V-1972, Pinto s.n. (CTES); BR-430, trevo para Tanque Novo (Mun. Igaporã), 5-IV1992, Hatschbach 56630 (CTES, MBM); Bom Jesus da Lapa, 5-IV-1992, Hatschbach 56605 (CTES, MBM); 20 km SE de Feira de Santana, 2IV'1967, Krapovickas 12793 (CTES, HUEFS); Feira de Santana, 25-V-1983, Noblick 2675 (CTES, HUEFS); 20 km de Brumado para Vitora 
da Conquista (mun. Aracatu), 29-XII-1989, Carvalho \& al. 2703 (CEPEC, CTES); 11 km E de Vitoria da Conquista, 21-I-1963, Krapovickas 10080 (AAU, CTES, GH, MBM); 8 km S de Barra da Estiva, 23-XI-1992, Arbo \& al. 5729 (CTES, SPF); Cruz das Almas, 29-VII-1961, Santos 1981 (CTES); Miguel Calmon, 4-IV-1967, Krapovickas 12834 (CTES); 3 km E de Barreiras, 18-III-1982, Krapovickas \& al. 37871 (CEN, CTES); Tucano (Mun. Caetité), 15-III-1995, Hatschbach 61932 (CTES, MBM); Cascalheira (Mun. Itabello), 13VIII-1995, Hatschbach 63282 (CTES, MBM); 15 $\mathrm{km}$ na rodovia Brumado-Caetite, 27-XII-1989, Carvalho 2629 (CEPEC, CTES); Rodovia Maracás-Contendas do Sincorá, km 2, 14-II-1979, Mattos Silva \& al. 219 (CEPEC, CTEC); Guaibim (Mun. Valença), 14-Í-1997, Arbo \& al. 7174 (CEPEC, CTES); Tres Braços (Mun. Cravolandia), ilhas do rio Piabanha, 29-V-1994, Melo \& França 1039 (CTES, HUEFS); Salvador, Parque Metropolitano de Pituaçu, 14-II-1998, Conceição \& Costa 175 (CTES, HRB); Estrada Livramento/Rio de Contas, Balneario Dr. Edilson Pontes, 2-II-2005, Paula-Souza 5281 (CTES, ESA). Espiritu Santo: São Mateus, VIII-1972, Pinto s.n. (CTES); Rod. BR-262, Rio Jucu (Mun. Viana), 8-VI-2003, Hatschbach \& al. 75004 (CTES, MBM). Minas Gerais: Ouro Branco, 1330 m, 8-I-1982, Hensold \& al. 2737 (CTES, SPF); Poços de Caldas, 15-I-1980, Krapovickas \& Cristóbal 35346 (CTES); Paraopeba, 18-XI-1958, Heringer 6481 (CTES); Rancharia, 15 km S de Ouro Preto, 1260 m, 13-V-1990, Arbo \& al. 4013 (CTES, SPF); Fazenda California (mun. Capitão Enéas), 9-III-1998, Hatschbach \& al. 67563 (CTES, MBM); Divisopolis (mun. Pedra Azul), 13-IX-1984, Hatschbach 48164 (CTES, NBN). Rio de Janeiro: Rio de Janeiro, Gardner 12 (P); íd., Weddell 196 (P); Sebastianopolis, Martius s.n. (M, foto F 19684); rio Jurumirim, $17 \mathrm{~km} \mathrm{~W}$ de Angra dos Reis, 8-II-1978, Krapovickas \& Cristóbal 33556 (CTES); entre Campos e Morro do Côco, 8-XII-1964, Trinta 1031 (CTES); mun. Macaé, Lagoa Paulista, 10-XI-1981, Araujo 4673 (CTES, FEEMA). São Paulo: São Paulo, Jardim Botânico, 29-I-1974, Silva 212 (CTES, SP); Campos de Butantã, 3-XII-1946, Joly 17330 (CTES, SPF); Via Anhanguera, km 30, 11-IV-1949, W. Hoehne 12249 (CTES, SPF); Campinas, Jardim Guanabara, 4-I-1939, Zagatto 3809 (CTES, IAC, LIL).
Obs. 1: El holotipo sólo indica "Brasil", pero se puede precisar la localidad pues la Expedición de Bouganville, en la que participó Commerson, sólo hizo escala en Rio de Janeiro, a su paso frente de las costas de Brasil, durante su viaje alrededor del mundo (Bouganville, 1946).

Obs. 2: Cavanilles (1786:48 y 99) en su segunda disertación concluyó que Sida plumosa pertenece en realidad al género Malachra, pero no efectuó ninguna combinación.

Obs. 3: Por la presencia de pelos simples en el haz de la hoja, $S$. plumosa se aproxima a $S$. anomala, S. Brittonii y S. Dureana. De todas ellas se separa por sus cabezuelas multifloras y por sus mericarpos más pequeños, glabros y con prominencias sin gloquidios.

\section{Sida Simpsonii Krapov., sp. nov.}

Fig. 6, 16

Herba, caulibus prostratis, radiscibus simplicibus ad basim praesertim. Folia oblongolanceolata, usque $17 \mathrm{~mm}$ longa et 2-4 $\mathrm{mm}$ lata, ad apicem serrata, supra et infra pilis stellatis 4-6radiatis inspersa. Flores ad apicem ramulorum congestae. Petala $15 \mathrm{~mm}$ longa. Tubus stamineus pilosus. Ovario 6-7 carpidiato. Carpidia $2 \mathrm{~mm}$ longa et $2 \mathrm{~mm}$ lata, breviaristata, glochidiata.

Holotypus: Brasil, Mato Grosso, Mun. S.Antonio do Levenger, S. Antonio do Levenger, 12-II-1975, G. Hatschbach 36090 (MBM, isotypi CTES, NY).

Hierba postrada con raíces adventicias. Tallo con pelos estrellados de 4-5 ramas, adpresos. Estípulas algo soldadas al pecíolo sólo en las cabezuelas. Estípulas dimorfas, una lanceolada y la otra espatulada, algo mayor, 3-8 mm long., las de las cabezuelas todas lanceoladas, margen ciliado, haz glabro o con pocos pelos estrellados adpresos, envés con pelos estrellados. Pecíolo 3-5 mm long. Lámina oblongo-lanceolada, hasta $17 \mathrm{~mm}$ long. $\mathrm{x}$ 2-4 mm lat., margen dentado hacia el ápice, 

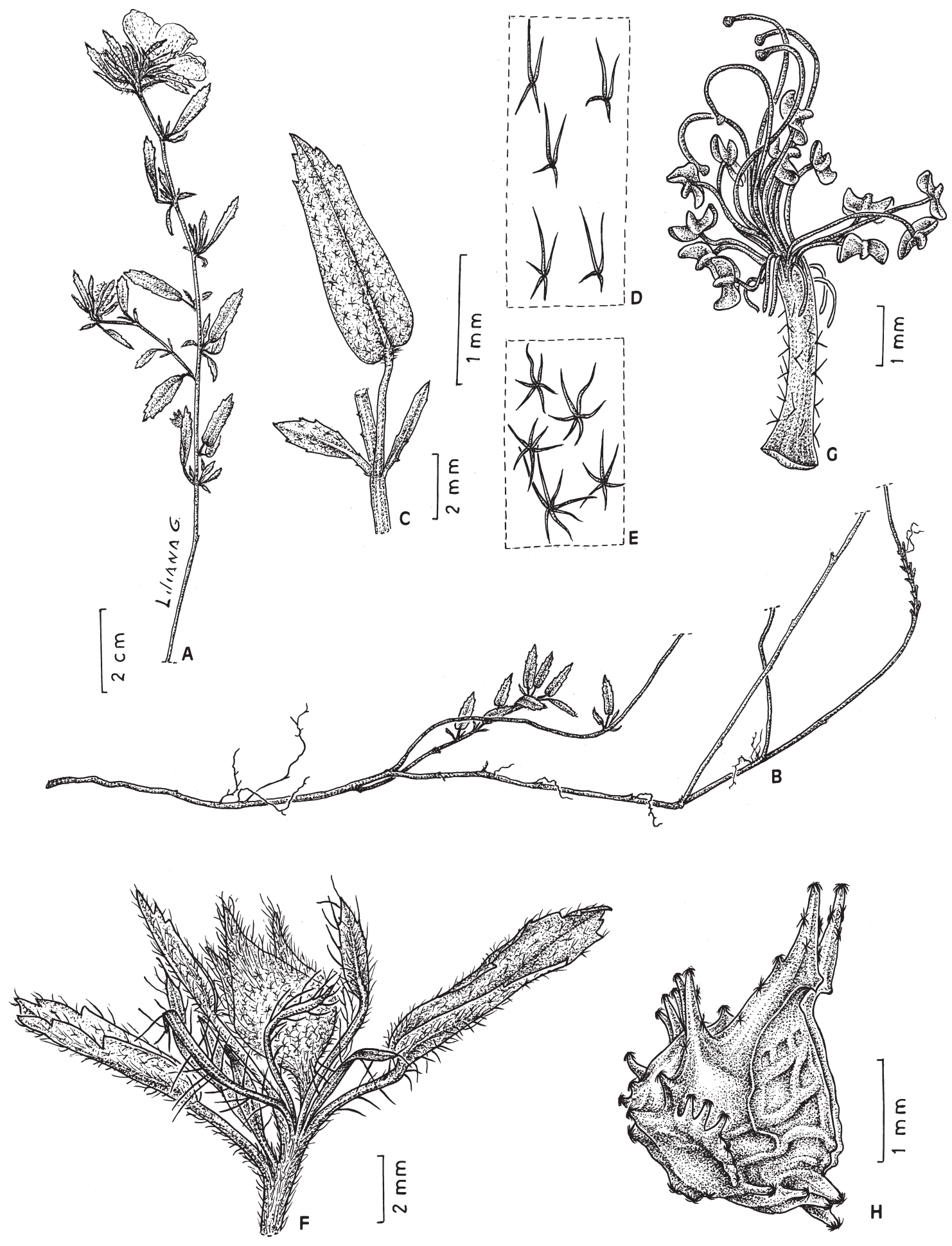

Fig. 16. Sida Simpsonii. A: rama. B: tallo con raíces adventicias. C: hoja. D: pelos del epifilo. E: pelos del hipofilo. F: cáliz. G: tubo estaminal. H: mericarpo (Krapovickas 40106). 
haz con pelos estrellados de 4-5 ramas, adpresos, envés con pelos estrellados de 5-6 ramas, también adpresos. Flores subsésiles, solitarias, agrupadas en cabezuelas terminales. Cáliz $5 \mathrm{~mm}$ long., lóbulos triangulares 3 $\mathrm{mm}$ long. $\mathrm{x} 2 \mathrm{~mm}$ lat. cubiertos de pelos estrellados pequeños y pelos simples $1 \mathrm{~mm}$ long. hacia el ápice de los lóbulos, margen de los lóbulos ciliados. Corola rosada. Pétalos 15 mm long. Tubo estaminal 3-4 mm long., con pelos simples o de 2 ramas. Mericarpos 6-7, reticulados, $2 \mathrm{~mm}$ long. x $2 \mathrm{~mm}$ lat., con 2 aristas breves apicales, caras laterales translúcidas, dorso con protuberancias largas terminadas en un gloquidio Semilla cubierta de pelos suaves, ondulados, pardos.

Paratypi: BRASIL. Mato Grosso: Sources du Paraguay (Envir. de Diamantino), XII-1844, Weddell 3073 (P, SI); Mun. Cáceres, 75 km E de Cáceres. BR-070, $\mathrm{km}$ 652, 30-V-1985, Krapovickas \& al. 40262 (CEN, CTES); Mun. Poconé, 104 km E de Cáceres, BR-070, km 623, 200 m, 17-V-1985, Krapovickas \& al. 40106 (CEN, CTES, NY).

Etimología: Nombre dedicado a Charles E. Simpson (Stephenville, Texas, USA), compañero de viajes botánicos que participara en la colección de uno de los paratipos.

\section{Sida surumuensis Ulbr.}

Fig. 6

Ulbrich, O. E., Notizbl. Köningl. Bot. Gart. Berlin-Dahlem 6: 320-321. 1915. Typus: Brasil, Rio Branco [Roraima], Surumu bei der Serra do Mel, VIII-1909, Ule 8221 (holotypus B, foto F 9397, isotypi K!, MG!, NY!, UC!, US!).

Hierba perenne, ramas procumbentes, con raíces adventicias en la base. Tallo cubierto de pelos estrellados adpresos muy pequeños, menores de 0,5 mm de diámetro. Estípulas lineales, 3-5 mm long. Pecíolo 2-3 mm long. Lámina lineal, angosta 15-20 mm long. y 1,5-3,5 $\mathrm{mm}$ lat., ápice agudo, margen entero, ambas caras cubiertas de pelos estrellados adpresos muy pequeños. Flores solitarias, agrupadas en el ápice de las ramas. Pedúnculo 1-2,5 mm long. Cáliz 5-6 mm long., lóbulos triangulares, $3 \mathrm{~mm}$ long. x 2,5 mm lat. cara externa cubierta de pelos estrellados diminutos, cara interna de los lóbulos con pelos simples. Corola anaranjada o blanca. Pétalos $16 \mathrm{~mm}$ long. Tubo estaminal 6-8 mm long., cubierto de pelos estrellados Estigmas 6. Mericarpos muricados, $2 \mathrm{~mm}$ long. y 2 aristas apicales ca. $1 \mathrm{~mm}$ long., cada prominencia terminada con un pelo estrellado de radios retrorsos. Semilla castaña, con pelos ferrugíneos.

Distribución geográfica: Conocida solamente del norte de Brasil y de Guyana.

Material adicional estudiado: GUYANA. Basin of Rupununi River, Charwair Creek, 1-XI-1937, A.C. Smith 2340 (P).

\section{Agradecimientos}

Expreso mi agradecimiento a Liliana Gómez, del IBONE, por los dibujos y a Cristina Salgado por su colaboración con el manejo del Microscopio electrónico de barrido de la Universidad Nacional del Nordeste

\section{Bibliografía}

ARECES B., F \& P.A. FRYXELL. 2007. Malvaceae. Flora de la República de Cuba, fasc. 13: 1-228.

BORSSUM WAALKES, J. van. 1966. Malesian Malvaceae revised. Blumea 14(1): 1-215.

BOUGANVILLE, L.A. de. 1946. Viaje alrededor del mundo. Buenos Aires, Espasa-Calpe.

CABRERA, A. L.1976. Regiones fitogeográficas argentinas. In L.R.Parodi, Enciclopedia argentina de Agricultura y jardinería, 2a. edición, 2(1): 1-85. Editorial ACME, Buenos Aires.

— \& A. WILLINK. 1973. Biogeografía de América Latina. OEA, Washington DC.

de CANDOLLE, A. P. 1824. Prodromus systematis naturalis regni vegetabilis. Vol. 1. Paris.

CAVANILLES, A. J. 1785. Dissertatio botanica de Sida. Paris

. 1786. Secunda dissertatio de Sida. Paris. 
1797. Icones et descriptiones plantarum 4(1). Madrid.

—. 1801. Icones et descriptiones plantarum 6(2). Madrid.

CLEMENT, I. D. 1957. Studies in Sida (Malvaceae). Contr. Gray Herb. 180: 3-191.

DON, G. 1831. A general history of dichlamideous plants I.

FAWCETT, W. \& A.B. RENDLE. 1926. Malvaceae en Flora of Jamaica 5: 92-149. British Museum, London.

FERNÁNDEZ, A. 1974. Recuentos cromosómicos en Malváceas. Bol. Soc. Argent. Bot. 15(4): 403-410. . 1981. Recuentos cromosómicos en Malvales. Bonplandia 5(10):63-71.

FRYXELL, P.A. 1975. Sidus Sidarum. Sida 6(1): 6.

—. 1985. Sidus sidarum V. The North and Central American species of Sida. Sida 11(1):62-91.

FUERTES AGUILAR, F.J. 1995. Sida L. Malvaceae. In Diaz Piedrahita \& al. (eds.), Flora de Colombia, 17: 1-142.

GANDOGER, M. 1924. Le genre Sida (Malvacées). Bull. Soc. Bot. France. 71: 627-633.

GARILLETI, R. 1993. Herbarium Cavanillesianum. Fonquera 38(1-5): 5-249:

GREUTER, W. \& al. 2000. International Code of Botanical Nomenclature (Saint Louis Code). Koeltz Scientific Books, Königstein.

KEARNEY, T. H. 1954. A tentative key to the North American species of Sida L. Leafl. W. Bot. 7(6): 138-150.

—. 1958. A tentative key to the South American species of Sida L. Leafl. W. Bot. 8(10): 249-270.

KRAPOVICKAS, A. 2005. Malvaceae. In A. Burkart \& N. Bacigalupo (Eds.), Flora ilustrada de Entre Ríos IV: 265-333.

LAVIA, G. I., A. FERNÁNDEZ \& A. KRAPOVICKAS. 2007. Cromosomas de especies de Sida americanas (Malvaceae). Bonplandia 16(3-4): 00-00.

LINNEO, C. 1759. Systema naturae, ed. 10, 2. Holmiae. MARTÍNEZ-CROVETTO, R. 1980. El SelaginelloAyenietum odonellii en el noroeste de la provincia de Corrientes (República Argentina). Phytocoenologia 7: 467-474.

MERRILL, E.D. 1918. New or noteworthy Philippine plants. XIII. Philip. J. Sci. 13, Bot.: 27-31.

MONTEIRO, H. da C. 1974. Comentários sobre algumas especies de Cavanilles. Portugaliae Acta Biol. Sér. B 12 (1-4): 132-141.

MUÑOZ GARMENDIA, F. 1992. Diarios y trabajos botánicos de Luis Nee, en La Expedición Malaspina
1789-1794. tomo III. Ministerio de Defensa - Museo Naval. Lunwerg Editores, Barcelona.

RICHARD, A. 1845. Plantes vasculaires en R. de la Sagra, Histoire physique, politique et naturelle de l’Ile de Cuba. Paris, Arthur Bertrand.

— . 1847. Tentamen florae abyssinicae, Paris, Arthur Bertrand.

RODRIGO, A. del P 1937. Una nueva Malvácea argentina. Notas Mus. La Plata 2: 105-109.

—. 1944. Las especies argentinas y uruguayas del género Sida (Malvaceae). Revista Mus. La Plata, Secc. Bot. 6: 81-212.

ROXBURGH, W. 1832. Flora indica. 1-3. Serampore.

SAINT HILAIRE, A. 1827. Malvaceae: 169-200. Florae Brasiliae meridionalis. 1(5). Paris.

SCHUMANN, K. 1890. in Engler \& Prantl, Nat. Pflanzenfam. 3(6): 30-53.

—. 1891. Malvaceae, in Mart., Fl. bras. 12 (3): 253456.

STAFLEU,F.A. \& R.S.COWAN,1976. Taxonomic literature, 2nd edition, 1:A-G. Bohn, Scheltema \& Holkena, Utrecht.

VOLLESEN, K.1986. The Sida cuneifolia-complex (Malvaceae). Kew Bull. 41(1): 91-98.

WIGHT, R. 1837. Madras journal of literature and science, 5: 310, t. 19.

WILLDENOW, C.L. 1801, Species Plantarum, ed. 4, 3. G.C. Nauk, Berolini.

\section{Indice de nombres científicos*}

Amaranthus 210

Amarantus 210

Dictyocarpus 210, 216

D. truncatus 210, 216, 234

Hermania alnifolia 234

Malachra 209

Malachra plumosa 245

Malva ononidifolia 245

Malvastrum linearifolium 230

Malvinda 210

Melochia truncata 210, 216, 234

Nostoc 216

Nototriche 209

Prospis 242

Pseudomalachra 211, 216

* Las especies tratadas en este artículo se indican en negrita. 
P. ciliaris 231

P. plumosa 245

Riedleia truncata 210, 234

Selaginella 216

Selaginella sellowii 216

Sida 209, 216

sect. Ciliares 216

sect. Malacroideae 209, 210, 216

sect. Malachroideae 210, 217

sect. Pseudomalachra 210

Sida albiflora 211, 213, 214216, 217, 218

S. anomala 210, 211, 213, 214, 216, 218, 220 , 235, 246

S. anomala f. albiflora 218

S. anomala f. albiflora subf. hirsuta 218

S. anomala var. mexicana 230

S. bellidifolia 231

S. Bordasiana 209, 211, 213, 214, 216, 218, 223

S. brachystemon 210, 211, 213, 214, 217, 223

S. Brittonii 210, 211, 213, 214, 216, 218, 224, 235, 246

S. castanocarpa 211, 213, 216, 218, 226

S. caulorrhiza 211, 213, 214, 216, 217, 228

S. centuriata 210, 211, 213, 214, 216, 218, 230

S. ciliaris 209, 210, 211, 213, 214, 216, 218, 226, 230, 242

S. ciliaris f. flava 240

S. ciliaris var. anomala 210, 211, 220

S. ciliaris var. fasciculata 230

S. ciliaris var. fulva 210, 245

S. ciliaris var. guianensis 210, 224, 226

S. ciliaris var. involucrata 231

S. ciliaris var. mexicana 231

S. ciliaris var. typica 210

S. ciliaris microsp. S. avicularioides 210

S. ciliaris microsp. S. bellidifolia 210, 231

S. ciliaris microsp. S. jaliscensis 210, 231

S. ciliaris microsp. S. microtricha 210, 231

S. ciliaria microsp. S. minutifolia 210

S. ciliaris microsp. S. ononidifolia 210, 231

S. Cristobaliana 211, 213, 214, 216, 217, 232

S. cuneifolia 210, 211, 213, 216, 218, 223, 234

S. Dureana 211, 213, 214, 216, 217, 235, 246

S. fasciculata 230

S. Ferrucciana 211, 213, 214, 216, 218, 236

S. fulva 210, 245

S. Harleyi 211, 213, 214, 216, 218, 239

S. involucrata 210, 230

S. jaliscensis 231

S. longistipula 231, 232

S. massaica 211
S. meridiana 211, 213, 214, 216, 217, 240, 245

S. microtricha 231

S. Monteiroi 211, 213, 214, 216, 218, 240

S. muricata 210, 213, 230, 232

S. ononidifolia 231

S. paradoxa 210, 211, 213, 214, 216, 218, 242

S. Pedersenii 213, 214, 216, 218, 243

S. plumosa 210, 211, 213, 214, 216, 217, 235, 245

S. Schimperiana 210, 211, 223

S. shinyangensis 211,223

S. Simpsonii 211, 213, 214, 216, 217, 246

S. surumuensis 211, 213, 214, 216, 217, 248

S. tanaensis 211

S. tenuicarpa 211

S. tridentata 210, 211, 230

S. truncata 234

S. ulmifolia 234

S. wendtii 223

Malva minima supina 231

Malva minor supina betonicae folio 231

\section{Indice de coleccionistas}

Aguilar, V. 480 (2), 971 (16)

Ahumada, O. 900 (17), 1407 (16), 1408 (2), 2522 (17), 2552 pp (2)

Aymard, G. \& B. Stergios 3164 (5)

Anderson, W.R. \& al. 9265 (14), 9471 (15)

Araujo, D. 4673 (19)

Arbo, M.M. \& al. 1713 (1), 1766 (1), 3547 (7), 4013 (19), 5411 (14), 5638 (14), 5729 (19), 7174 (19), 7339 (14), 8176 (2)

Arenas, P. 2361 (16)

Aristeguieta y Vera 83068 (5)

Asplund, E. 5619 (9)

August, L. 171 (18)

Balegno, B. 1066 (2)

Bastian, E. 66 (2)

Beck, S.G. 2617 (9), 6207 (9), 6276 (9)

Beck, S.G. \& al. 26179 (9)

Beck, S.G. \& M. Liberman, 16307 (2)

Berlandier, J.L. 66 (9)

Biraben, M. 115 (2), 5001 (2), 5028 (2)

Blanchet, J.S. 995 (5)

Blanchoud, G. 2173 (16)

Boelcke, O. 1377 (2)

Bona Nascimento, M.S. 122 (6), 208 (6), 461 (6), 534 (6)

Browne, P. (LINN-866.8) (9) 
Buckley, S.B. s.n. (9)

Bueno, O. 4883 (2), 4889 (17)

Bunting, G.S. 5282 (9)

Burkart, A. 4236 (2), 6917 (2), 21282 (2), 23404 (2)

Burkart, A. \& N. Bacigalupo 21283 (16)

Cárdenas, M. 4115 (9)

Carnevali, R. 1161 (17), 2231 (2), 2659 (17), 2895 (16), 4199 (16), 5722 (17), 6069 (17)

Carvalho, A.M. de \& al. 2629 (19), 2703 (19)

Carvalho, A.M. de \& D.J.N. Hind 3870 (6)

Castillo, A. 1139 (9)

Cocucci, A. 3061 (17)

Coelho de Moraes J. 2005 (5)

Commerson, P. F-29778 (19)

Conceição, A.S. \& J. Costa 175 (19)

Coradin, L. \& al. 3212 (5), 6283 (6)

Coro y Rojas 1583(9)

Cristóbal, C.L. \& al. 105 (2)

Dematteis, M. 2010 (10), 2224 (10)

Drummond 47 (9)

Duarte, A.P. 5972 (19)

Dupuy, D. (MA 476294) (9)

Eggers, H.F.A. 194 (9)

Ekman, E.L. 10710 (5)

Eliceche, A. 107 (13)

Fernandes, A. 2678 (5)

Fernández, A. 2796 (5), 2854 (5)

Ferreira , M.do S.G. 160 (14)

Ferreyra, R.L. 12328 (9)

Ferrucci, M.S. \& al. 1562 (12)

Ferrucci, M.S., A. Schinini \& M. Dematteis 1534 (13)

Fiebrig, K. 910 (2),2551 (2), 4051 (8)

Flores, J. \& al. 442 (9)

Fonseca, M.L. \& al. 2624 (6)

Fortunato, R. \& al. 2668 (16),

Fosberg, F.R. \& al. 50781 (11)

Fosberg, F.R. \& N. Balakrishnan 53435 (11)

Fryxell, P.A. 762 (9), 2755 (9), 4961 (9)

Fuentes, A. 641 (9)

Gardner, G. 12 (19), 2052 (5)

Gregory, W.C. \& al. 9593 (13)

Harley, R.M. 15367 (14)

Harley, R.M. \& al. 25938 (14)

Hassler, E. 1876 (1), 2485 (16), 6615 (1), 10751 (13)

Hatschbach, G. 21897 (2), 21966 (2), 23727 (12), 36090 (20) 39387 (7), 48164 (19), 56605 (19), 56630 (19), 61932 (19), 63181 (19),

Hatschbach, G. \& al. 56897 (14), 64948 (14),
65071 (14), 67563 (19), 67761 (6), 75004

(19), 74512 (12)

Hensold, N. \& al. 2737 (19)

Heringer, E.P. 5874 (6), 6481 (19)

Hill, S.R. 10476 (9), 10575 (9)

Hoehne, H. 12249 (19)

Huidobro, A.M.R. 3357 (2),

Ibarrola, T. 5 (2), 856 (2), 2551 (2), 2262 (17), 2720 (17), 3235 (2), 3357 (2), 3446 (17), 3751 (2), 3948 (17)

Insfrán, P. 587 (16)

Irwin, H.S. \& al. 31352 (6)

Joaquín, J.N. y L. Martínez 11301 (2)

Johnson, J.C. 1063 (9), 1377 (9)

Joly, A.B. 17330 (19)

Jörgensen, P. 2312 (16), 2315 (2), 4287 (13)

Kiesling, R. 3687 (2), 9710 (16)

Killip, E.P. 40927 (9)

Koch, S.D., P.A. Fryxell \& T. Wendt 79424(4)

Krapovickas, A. 3500 (16), 7957 (2), 7962 (2), 7968 (2), 8861 (2), 8891 (2), 9138 (10), 9454 (10), 10075 (19), 10080 (19), 10081 (15), 10093 (14), 10599 (16), 12793 (19), 12834 (19), 12874 (5), 12904 (5), 12930 (6), 12944 (5), 13038 (2), 14236 (13), 14428 (2), 14430 (16), 14437 (8), 15785 (16), 29853 (12), 29863 (8),

Krapovickas, A. \& al. 12364 (13), 12385 (2), 12585 (1), 12597 (2), 14199 (16), 14232 (16), 19070 (9), 22745 (2), 27429 (16), 27838 (16), 29187 (2), 29545 (17), 37444 (9), 37479 (18), 37854 (6), 37871 (19), 37896 (6), 37933 (15), 38741 (6), 38749 (6), 38759 (6), 40262 (20), 45255 (16), 45283 (9), 45355 (9), 45364 (10), 45397 (10), 45401 (10), 45657 (1), 45716 (13), 47907 (16)

Krapovickas, A. \& C.L. Cristóbal 11365 (16), 11366 (2), 11858 (17), 14933 (16), 23547 (9), 23582 (9), 33556 (19), 35346 (19), 37208 (6), 42862 (14), 43081 (2), 44406 (2), 44177 (2), 44407 (16), 45002 (12), 45048 (12), 45056 (13), 45058 (12), 45121 (16), 46536 (16), 46546 (16), 46548 (16), 47905 (16),

Krapovickas, A., C.L. Cristóbal \& A. Schinini 45489 (10)

Krapovickas, A. \& A. Schinini 30851 (16), 32449 (9), 34649 (9), 34682 (9), 32758 (16), 36215

(10), 36480 (10), 36512 (9), 36533 (9)

Krapovickas, A. \& G. Seijo 47766 (16)

Krapovickas, A., A. Schinini \& G. Seijo 47234 (18) 
Krapovickas, A., J.F.M. Valls \& G.P. Silva 37845 (6) Krapovickas, A., J.F.M. Valls, C.E. Simpson \& G. Silva 40106 (20)

Kurtz, F. 227a (2)

Lavia, G 7(2)

Lavia, G. \& A. López 33 (16)

León, J. \& Roca 7466 (5)

Liesner, R. 5379 (9)

Liesner, R. \& A. González 11934 (9)

Lorentz, P.G. 1202 (2), 1250 (2), 1762 (2)

Magalhaes, H. 226 (5)

Marchesi, E. \& al. 20787 (2)

Martínez Crovetto, R.N. PM80 (16)

Martins P. \& H.L. Cesar 10259 (6)

Martius, C.F.P. von 1827 (19)

Mattos Silva, L.A. \& al. 219 (19)

Melo, L. de M.R. 99 (5)

Melo, E. \& F. França 1039 (19)

Mereles, F. 6659 (10)

Mereles, F. \& al. 3508 (16), 8203 (2)

Meyer, T. 663 (2), 16204 (2)

Meyer, T. \& al. 20721 (9)

Meyer, T. \& A.G. Schulz 18704 (8)

Molas, L. \& V. Vera 1040 (16)

Moraes, M. 2384 (2)

Morel, I. 1579 (2), 1889 (16), 6914 (16), 7181 (2)

Morello, J. \& A.R.Cuezzo 1138 (16)

Muñoz, J. de D. 1782 (2)

Müsch, P. 83 (2)

Nee, M. (F 29779) (9)

Nicora, E. 3218 (2)

Noblick, L.R. 2674 (14), 2675 (19)

Nunes, E. 11495 (6), 12398 (6)

Palacios, R. 1907 (8)

Palacios, M.A. \& A.R. Cuezzo, 218 (2)

Paula-Souza, J. \& al. 5281 (19)

Pedersen, T.M. 121 (17), 1869 (2), 4109 (18), 4647 (16), 5551 (17), 6185 (17), 6273 (2), 8726 (16), 9044 (2), 9075 (17), 9296 (1), 9367 (13) 14540 (16), 14626 (16),15103 (2)

Peredo, I. s.n. (10), 20 (10)

Pérez de Molas, L. \& G. Navarro, 7854 (18), 8716 (13), 9031 (9), 9327 (10)

Pinto, G.C.P. 37/83 (6)

Pott, A. $6828\left(1^{\circ} 3\right)$

Pott, A. \& V.J. Pott, 4447 (2), 7899 (2)

Pott, V.J. \& al. 759 (2)

Pringle, C.G. 4497 (9)

Puyssegur, E. 5 (2)

Quarin, C. 1376 (2)

Ragonese, A. 2586 (2)
Ramalho Campêlo C. 990 (5)

Ramella, L. \& F. Mereles 2486 (10)

Ramírez, N. 894 (9), 2630 (9)

Reales, A. 160 (2), 314 (2), 432 (16)

Ramos, M. 27445 (9), 32704 (9)

Ribas, O,S. \& L.B.S. Pereira 2385 (2)

Rodrigo, A.del P. 605 (17), 649 (2)

Rojas, T. 1791 (2) 1929 (2), 1934 (16), 3370 (!6), 10088 (2), 13713 (16)

Rosales, J. y E. Briceño 435 (5)

Royo Pallarés, O.M. 1 (17)

Rua, G.H. \& G.I. Lavia 393 (10)

Sagra, R. de la (Richard 24) (9)

Santos, E. 1981 (19)

Saravia Toledo, C. 1597 (16), 12379 (2)

Sayago, M. 1833 (2)

Schinini, A. 5221 (2), 7547 (17), 7812 (2), 9217 (16), 9219 (2), 14020 (17), 14825 (10), 17310 (17), 18651 (17), 20039 (16), 21396 (12)

Schinini, A. \& al. 13868 (16), 17222 (17), 35277 (18), 35345 (18), 35547 (8), 35556 (12), 35614 (16), 36278 (16), 36394 (12)

Schinini, A. \& L. Bernardello 23113 (18)

Schinini, A. \& E. Bordas 14882 (3), 15055 (9)

Schinini, A. \& R. Carnevali 23255 (17)

Schinini, A. \& C.L. Cristóbal 9950 (2)

Schinini, A \& R. Palacios 25687 (10), 25809 (2)

Schinini, A., J. Molero, R. Duré \& M. Quintana 35556 (12)

Schinini, A. \& M. Quintana 36321 (13)

Schmeda, G. 120 (9)

Schomburgk 405 (5)

Schulz, A.G. 552 (2), 557 (16), 2099 (16), 8734 (2), 8860 (8), 17018 (16),

Seijo, G. \& al. 3482 (9), 3510 (10)

Serrano, M. 633 (2)

Sigle, M. 181 (2)

Silva 212 (19), 517 (6)

Simpson, J.H. 472 (9)

Smith, A.C. 2340 (4)

Sobral \& al. 3418 (17)

Solis Neffa, V. \& al. 217 (17), 1065 (9), 1081 (10), 1085 (9), 1258 (10), 1264 (10), 1287 (10), 1297 (12), 1306 (10), 1308 (9), 1336 (2), 1410 (9), 1765 (9), 1893 (18), 1897 (10)

Soria, N. 3706 (2)

Souza, Lorenzi \& Fernandes 28760 (5)

Souza V.C. \& J.P. Souza 26582 (5)

Sparre, C.S.B.U. \& F.B. Vervoorst 561 (2)

Spegazzini, C.L. 1293 (2),

Spichiger, R. \& al. 2511 (3) 
St. Hilaire, A. B2/240 (19), C2/2470 (2)

Steinbach, R.F. 747

Steinbach, J. 2694 (10), 6042 (2)

Sucre, D. 7098 (14)

Tressens, S.G. \& al. 2422 (17)

Trinta, Z.A. 1031 (19)

Ule, E. 8221 (21)

Vanni, R.O. \& al. 364 (13), 1733 (16), 2417 (9)

Ventura, F. 11674 (9)

Weddell, M.A. 196 (19), 3073 (21)
Werneck, W.L., C.L. Cristóbal \& A. Krapovickas 930 (7)

Wingfield, R. 5007 (9), 5681 (9)

Wirth, 60 (2)

Wood, J.L.R. 9435 (2)

Xavier, L. 358 (6)

Zagatto, O. 3809 (19)

Zardini, E.M. \& al. $37338(13), 49607$ (10), 50397 (18), 53508 (13), 57439 (16), 57462 (16), 58384 (16)

Zelada, F. 18 (9)

Original recibido el 15 de septiembre de 2007; aceptado el 10 de noviembre de 2007. 